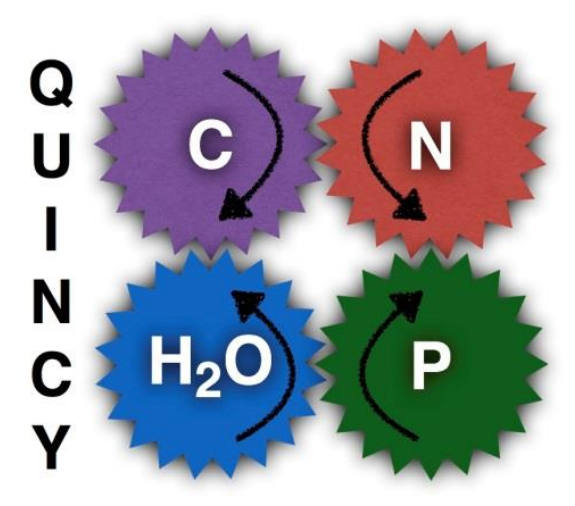

\title{
A comprehensive quantification of global nitrous oxide sources and sinks
}

\author{
Accepted version
}

(Post-prints are subject to Springer Nature re-use terms)

Tian, H., Xu, R., Canadell, J. G., Thompson, R. L., Winiwarter, W., Suntharalingam, P., et al.

\section{Published in: Nature}

Reference: Tian, H., Xu, R., Canadell, J. G., Thompson, R. L., Winiwarter, W., Suntharalingam, P., et al. (2020). A comprehensive quantification of global nitrous oxide sources and sinks. Nature, 586, 248-256. doi:10.1038/s41586-020-2780-0 
A comprehensive quantification of global nitrous oxide sources and sinks

Hanqin Tian ${ }^{1}$, Rongting Xu ${ }^{1}$, Josep G. Canadell ${ }^{2}$, Rona L. Thompson ${ }^{3}$, Wilfried Winiwarter ${ }^{4,5}$, Parvadha Suntharalingam $^{6}$, Eric A. Davidson ${ }^{7}$, Philippe Ciais ${ }^{8}$, Robert B. Jackson ${ }^{9,10,11}$, Greet Janssens-Maenhout ${ }^{12,13}$, Michael J. Prather ${ }^{14}$, Pierre Regnier ${ }^{15}$, Naiqing Pan ${ }^{1,16}$, Shufen Pan $^{1}$, Glen P. Peters ${ }^{17}$, Hao Shi ${ }^{1}$, Francesco N. Tubiello ${ }^{18}$, Sönke Zaehle ${ }^{19}$, Feng Zhou ${ }^{20}$, Almut Arneth $^{21}$, Gianna Battaglia ${ }^{22}$, Sarah Berthet ${ }^{23}$, Laurent Bopp ${ }^{24}$, Alexander F. Bouwman ${ }^{25,26,27}$, Erik T. Buitenhuis ${ }^{6,28}$, Jinfeng Chang ${ }^{8,29}$, Martyn P. Chipperfield ${ }^{30,31}$, Shree R. S. Dangal ${ }^{32}$, Edward Dlugokencky ${ }^{33}$, James W. Elkins ${ }^{33}$, Bradley D. Eyre ${ }^{34}$, Bojie Fu ${ }^{16,35}$, Bradley Hall ${ }^{33}$, Akihiko Ito $^{36}$, Fortunat Joos ${ }^{22}$, Paul B. Krummel ${ }^{37}$, Angela Landolfi ${ }^{38,39}$, Goulven G. Laruelle ${ }^{15}$, Ronny Lauerwald ${ }^{8,15,40}$, Wei Li ${ }^{8,41}$, Sebastian Lienert ${ }^{22}$, Taylor Maavara ${ }^{42}$, Michael MacLeod ${ }^{43}$, Dylan B. Millet ${ }^{44}$, Stefan Olin ${ }^{45}$, Prabir K. Patra ${ }^{46,47}$, Ronald G. Prinn ${ }^{48}$, Peter A. Raymond ${ }^{42}$, Daniel J. Ruiz ${ }^{14}$, Guido R. van der Werf ${ }^{49}$, Nicolas Vuichard ${ }^{8}$, Junjie Wang ${ }^{27}$, Ray F. Weiss ${ }^{50}$, Kelley C. Wells ${ }^{44}$, Chris Wilson ${ }^{30,31}$, Jia Yang ${ }^{51} \&$ Yuanzhi Yao ${ }^{1}$

${ }^{1}$ International Center for Climate and Global Change Research, School of Forestry and Wildlife Sciences, Auburn University, Auburn, AL, USA

${ }^{2}$ Global Carbon Project, CSIRO Oceans and Atmosphere, Canberra, Australian Capital Territory, Australia

${ }^{3}$ Norsk Institutt for Luftforskning, NILU, Kjeller, Norway

${ }^{4}$ International Institute for Applied Systems Analysis, Laxenburg, Austria

${ }^{5}$ Institute of Environmental Engineering, University of Zielona Góra, Zielona Góra, Poland.

${ }^{6}$ School of Environmental Sciences, University of East Anglia, Norwich, UK

${ }^{7}$ Appalachian Laboratory, University of Maryland Center for Environmental Science, Frostburg, MD, USA

${ }^{8}$ Laboratoire des Sciences du Climat et de l'Environnement, LSCE, CEA CNRS, UVSQ

UPSACLAY, Gif sur Yvette, France

${ }^{9}$ Department of Earth System Science, Stanford University, Stanford, CA, USA

${ }^{10}$ Woods Institute for the Environment, Stanford University, Stanford, CA, USA

${ }^{11}$ Precourt Institute for Energy, Stanford University, Stanford, CA, USA

${ }^{12}$ European Commission, Joint Research Centre (JRC), Ispra, Italy

${ }^{13}$ Ghent University, Faculty of Engineering and Architecture, Ghent, Belgium

${ }^{14}$ Department of Earth System Science, University of California Irvine, Irvine, CA, USA

${ }^{15}$ Department Geoscience, Environment \& Society, Université Libre de Bruxelles, Brussels, Belgium

${ }^{16}$ State Key Laboratory of Urban and Regional Ecology, Research Center for Eco-Environmental Sciences, Chinese Academy of Sciences, Beijing, China

${ }^{17}$ CICERO Center for International Climate Research, Oslo, Norway

${ }^{18}$ Statistics Division, Food and Agriculture Organization of the United Nations, Via Terme di

Caracalla, Rome, Italy

${ }^{19}$ Max Planck Institute for Biogeochemistry, Jena, Germany

${ }^{20}$ Sino-France Institute of Earth Systems Science, Laboratory for Earth Surface Processes, College of Urban and Environmental Sciences, Peking University, Beijing, China

${ }^{21}$ Karlsruhe Institute of Technology, Institute of Meteorology and Climate Research/Atmospheric Environmental Research, Garmisch-Partenkirchen, Germany 
${ }^{22}$ Climate and Environmental Physics, Physics Institute and Oeschger Centre for Climate Change Research, University of Bern, Bern, Switzerland

${ }^{23}$ Centre National de Recherches Météorologiques (CNRM), Université de Toulouse, Météo-

France, CNRS, Toulouse, France

${ }^{24}$ LMD-IPSL, Ecole Normale Supérieure / PSL Université, CNRS; Ecole Polytechnique,

Sorbonne Université, Paris, France

${ }^{25}$ PBL Netherlands Environmental Assessment Agency, The Hague, The Netherlands

${ }^{26}$ Department of Earth Sciences - Geochemistry, Faculty of Geosciences, Utrecht University, Utrecht, The Netherlands

${ }^{27}$ Key Laboratory of Marine Chemistry Theory and Technology, Ministry of Education, Ocean University of China, Qingdao, China

${ }^{28}$ Tyndall Centre for Climate Change Research, School of Environmental Sciences, University of East Anglia, Norwich, UK

${ }^{29}$ College of Environmental and Resource Sciences, Zhejiang University, Hangzhou, China.

${ }^{30}$ National Centre for Earth Observation, University of Leeds, Leeds, UK

${ }^{31}$ Institute for Climate and Atmospheric Science, School of Earth and Environment, University of Leeds, Leeds, UK

${ }^{32}$ Woods Hole Research Center, Falmouth, MA, USA

${ }^{33}$ NOAA Global Monitoring Laboratory, Boulder, CO, USA

${ }^{34}$ Centre for Coastal Biogeochemistry, School of Environment Science and Engineering, Southern Cross University, Lismore, New South Wales, Australia

${ }^{35}$ Faculty of Geographical Science, Beijing Normal University, Beijing, China

${ }^{36}$ Center for Global Environmental Research, National Institute for Environmental Studies, Tsukuba, Japan

${ }^{37}$ Climate Science Centre, CSIRO Oceans and Atmosphere, Aspendale, Victoria, Australia

${ }^{38}$ GEOMAR Helmholtz Centre for Ocean Research Kiel, Kiel, Germany

${ }^{39}$ Istituto di Scienze Marine, Consiglio Nazionale delle Ricerche (CNR), Rome, Italy

${ }^{40}$ Université Paris-Saclay, INRAE, AgroParisTech, UMR ECOSYS, Thiverval-Grignon, France

${ }^{41}$ Ministry of Education Key Laboratory for Earth System modeling, Department of Earth System Science, Tsinghua University, Beijing, China

${ }^{42}$ Yale School of Forestry and Environmental Studies, New Haven, CT, USA

${ }^{43}$ Land Economy, Environment \& Society, Scotland's Rural College (SRUC), Edinburgh, UK

${ }^{44}$ Department of Soil, Water, and Climate, University of Minnesota, St Paul, MN, USA

${ }^{45}$ Department of Physical Geography and Ecosystem Science, Lund University, Lund, Sweden

${ }^{46}$ Research Institute for Global Change, JAMSTEC, Yokohama, Japan

${ }^{47}$ Center for Environmental Remote Sensing, Chiba University, Chiba, Japan

${ }^{48}$ Center for Global Change Science, Massachusetts Institute of Technology, Cambridge, MA, USA

${ }^{49}$ Faculty of Science, Vrije Universiteit, Amsterdam, Netherlands.

${ }^{50}$ Scripps Institution of Oceanography, University of California San Diego, La Jolla, USA

${ }^{51}$ Department of Forestry, Mississippi State University, Mississippi State, MS, USA

87

88

89

90 
91 Nitrous oxide $\left(\mathbf{N}_{2} \mathbf{O}\right)$, like carbon dioxide, is a long-lived greenhouse gas that accumulates in

92 the atmosphere. The increase in atmospheric $\mathrm{N}_{2} \mathrm{O}$ concentrations over the past 150 years

93 has contributed to stratospheric ozone depletion ${ }^{1}$ and climate change ${ }^{2}$. Current national

94 inventories do not provide a full picture of $\mathbf{N}_{2} \mathbf{O}$ emissions owing to their omission of

95 natural sources and the limitations in methodology for attributing anthropogenic sources.

96 In order to understand the steadily increasing atmospheric burden (about 2 percent per

97 decade) and develop effective mitigation strategies, it is essential to improve quantification

98 and attribution of natural and anthropogenic contributions and their uncertainties. Here

99 we present a global $\mathrm{N}_{2} \mathrm{O}$ inventory that incorporates both natural and anthropogenic

100 sources and accounts for the interaction between nitrogen additions and the biochemical

101 processes that control $\mathbf{N}_{2} \mathrm{O}$ emissions. We use bottom-up (inventory; statistical

102 extrapolation of flux measurements; process-based land and ocean modelling) and top-

103 down (atmospheric inversion) approaches to provide a comprehensive quantification of

104 global $\mathrm{N}_{2} \mathrm{O}$ sources and sinks resulting from 21 natural and human sectors between 1980

105 and 2016. Global $\mathrm{N}_{2} \mathrm{O}$ emissions were 17.0 (minimum-maximum: 12.2-23.5) teragrams of

106 nitrogen per year (bottom-up) and $16.9(15.9-17.7)$ teragrams of nitrogen per year (top-

107 down) between 2007 and 2016. Global human-induced emissions, which are dominated by

108 nitrogen additions to croplands, increased by $30 \%$ over the past four decades to $7.3(4.2-$

109 11.4) teragrams of nitrogen per year. This increase was mainly responsible for the growth

110 in the atmospheric burden. Our findings point to growing $\mathrm{N}_{2} \mathrm{O}$ emissions in emerging

111 economies - particularly Brazil, China and India. Analysis of process-based model

112 estimates reveals an emerging $\mathbf{N}_{2} \mathbf{O}$-climate feedback resulting from interactions between

113 nitrogen additions and climate change. The recent growth in $\mathrm{N}_{2} \mathrm{O}$ emissions exceeds some 
114 of the highest projected emission scenarios ${ }^{3,4}$, underscoring the urgency to mitigate $\mathrm{N}_{2} \mathrm{O}$

115 emissions.

117 Nitrous oxide $\left(\mathrm{N}_{2} \mathrm{O}\right)$ is a long-lived stratospheric ozone-depleting substance and greenhouse gas

118 (GHG) with a current atmospheric lifetime of $116 \pm 9$ years (ref. ${ }^{1}$ ). The concentration of

119 atmospheric $\mathrm{N}_{2} \mathrm{O}$ has increased by over $20 \%$ from 270 parts per billion (ppb) in 1750 to $331 \mathrm{ppb}$

120 in 2018 (Extended Data Fig. 1), with the fastest growth observed in the past five decades ${ }^{5,6}$. Two

121 key biochemical processes, nitrification and denitrification, control $\mathrm{N}_{2} \mathrm{O}$ production in both

122 terrestrial and aquatic ecosystems, and are regulated by multiple environmental and biological

123 factors, such as temperature, water, oxygen, acidity, substrate availability ${ }^{7}$, particularly nitrogen

124 (N) fertilizer use and livestock manure management, and recycling ${ }^{8-10}$. In the coming decades,

$125 \mathrm{~N}_{2} \mathrm{O}$ emissions are expected to continue increasing due to the growing demand for food, feed,

126 fiber and energy, and a rising source from waste generation and industrial processes ${ }^{4,11,12}$. Since

127 1990, anthropogenic $\mathrm{N}_{2} \mathrm{O}$ emissions have been annually reported by Annex I Parties to the

128 United Nations Framework Convention on Climate Change (UNFCCC). More recently, over 190

129 national signatories to the Paris Agreement are now required to report biannually their national

130 GHG inventory with sufficient detail and transparency to track progress towards their Nationally

131 Determined Contributions. Yet, these inventories do not provide a full picture of $\mathrm{N}_{2} \mathrm{O}$ emissions

132 due to their omission of natural sources, the limitations in methodology for attributing

133 anthropogenic sources, and missing data for a number of key regions (e.g., South America,

134 Africa $)^{2,9,13}$. Moreover, we need a complete account of all human activities that accelerate the

135 global $\mathrm{N}$ cycle and that interact with the biochemical processes controlling the fluxes of $\mathrm{N}_{2} \mathrm{O}$ in

136 both terrestrial and aquatic ecosystems ${ }^{2,8}$. Here we present a comprehensive, consistent analysis 
137 and synthesis of the global $\mathrm{N}_{2} \mathrm{O}$ budget across all sectors, including natural and anthropogenic

138 sources and sinks, using both bottom-up (BU) and top-down (TD) methods and their cross-

139 constraints. Our assessment enhances understanding of the global N cycle and will inform policy

140 development for $\mathrm{N}_{2} \mathrm{O}$ mitigation, ideally helping to curb warming to levels consistent with the

141 long-term goal of the Paris Agreement.

142 A reconciling framework (described in Extended Data Fig. 2) was utilized to take full

143 advantage of BU and TD approaches in estimating and constraining sources and sinks of $\mathrm{N}_{2} \mathrm{O}$.

144 BU approaches include emission inventories, spatial extrapolation of field flux measurements,

145 nutrient budget modeling, and process-based modeling for land and ocean fluxes. The TD

146 approaches combine measurements of $\mathrm{N}_{2} \mathrm{O}$ mole fractions with atmospheric transport models in

147 statistical optimization frameworks (inversions) to constrain the sources. Here we constructed a

148 total of 43 flux estimates including 30 with BU approaches, five with TD approaches, and eight

149 other estimates with observation and modeling approaches (see Methods; Extended Data Fig. 2).

150 With this extensive data and BU/TD framework, we establish the most comprehensive global

151 and regional $\mathrm{N}_{2} \mathrm{O}$ budgets that include 18 sources and different versions of its chemical sink,

152 which are further grouped into six categories (Fig. 1 and Table 1): 1) Natural sources (no

153 anthropogenic effects) including a very small biogenic surface sink, 2) Perturbed fluxes from

154 ecosystems induced by changes in climate, carbon dioxide $\left(\mathrm{CO}_{2}\right)$ and land cover, 3) Direct

155 emissions of $\mathrm{N}$ additions in the agricultural sector (Agriculture), 4) Other direct anthropogenic

156 sources, which include fossil fuel and industry, waste and waste water, and biomass burning, 5)

157 Indirect emissions from ecosystems that are either downwind or downstream from the initial

158 release of reactive $\mathrm{N}$ into the environment, which include $\mathrm{N}_{2} \mathrm{O}$ release following transport and

159 deposition of anthropogenic $\mathrm{N}$ via the atmosphere or water bodies as defined by the 
160 Intergovernmental Panel on Climate Change (IPCC) ${ }^{14}$, and 6) The atmospheric chemical sink

161 with one value derived from observations and the other (TD) from the inversion models. To

162 quantify and attribute the regional $\mathrm{N}_{2} \mathrm{O}$ budget, we further partition the Earth's ice-free land into

163 ten regions (Fig. 2 and Supplementary Fig. 1). With the construction of these budgets, we

164 explore the relative temporal and spatial importance of multiple sources and sinks driving the

165 atmospheric burden of $\mathrm{N}_{2} \mathrm{O}$, their uncertainties, and interactions between anthropogenic forcing

166 and natural fluxes of $\mathrm{N}_{2} \mathrm{O}$ as an emerging climate feedback.

\section{The Global $\mathrm{N}_{2} \mathrm{O}$ Budget (2007-2016)}

169 The BU and TD approaches give consistent estimates of global total $\mathrm{N}_{2} \mathrm{O}$ emissions in the recent 170 decade to well within their respective uncertainties, with values of 17.0 (min-max: $12.2-23.5) \mathrm{Tg}$

$171 \mathrm{~N} \mathrm{yr}^{-1}$ and $16.9(15.9-17.7) \mathrm{Tg} \mathrm{N} \mathrm{yr}^{-1}$ for BU and TD sources, respectively. The global calculated 172 atmospheric chemical sink (i.e., $\mathrm{N}_{2} \mathrm{O}$ losses via photolysis and reaction with $\mathrm{O}\left({ }^{1} \mathrm{D}\right)$ in the 173 troposphere and stratosphere) is 13.5 (12.4-14.6) $\mathrm{Tg} \mathrm{N} \mathrm{yr}^{-1}$. The imbalance of sources and sinks

174 of $\mathrm{N}_{2} \mathrm{O}$ derived from the averaged $\mathrm{BU}$ and $\mathrm{TD}$ estimates is $4.1 \mathrm{Tg} \mathrm{N} \mathrm{yr}^{-1}$. This imbalance agrees 175 well with the observed 2007-2016 increase in atmospheric abundance of 3.8-4.8 $\mathrm{Tg} \mathrm{N} \mathrm{yr}^{-1}$ (see

176 Methods). Natural sources from soils and oceans contributed 57\% of total emissions (mean: 9.7;

177 min-max: 8.0-12.0 $\mathrm{Tg} \mathrm{N} \mathrm{yr}^{-1}$ ) for the recent decade according to our BU estimate. We further

178 estimate the natural soil flux at 5.6 (4.9-6.5) $\mathrm{Tg} \mathrm{N} \mathrm{yr}^{-1}$ and the ocean flux at $3.4(2.5-4.3) \mathrm{Tg} \mathrm{N}$ $179 \mathrm{yr}^{-1}$ (see Methods).

180 Anthropogenic sources contributed on average $43 \%$ to the total $\mathrm{N}_{2} \mathrm{O}$ emission (mean: 7.3;

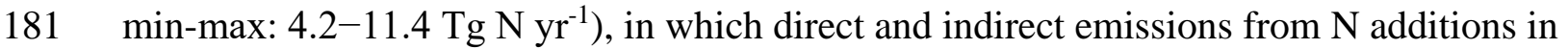
182 agriculture and other sectors contributed $\sim 52 \%$ and $\sim 18 \%$, respectively. Of the remaining 
183 anthropogenic emissions, $\sim 27 \%$ were from other direct anthropogenic sources including fossil

184 fuel and industry $(\sim 13 \%)$, with $\sim 3 \%$ from perturbed fluxes caused by climate/ $\mathrm{CO}_{2} / \mathrm{land}_{\text {cover }}$ 185 change.

\section{Four Decades of the Global $\mathbf{N}_{2} \mathrm{O}$ Budget}

188 The atmospheric $\mathrm{N}_{2} \mathrm{O}$ burden increased from $1462 \mathrm{Tg} \mathrm{N}$ in the 1980 s to $1555 \mathrm{Tg} \mathrm{N}$ in the recent 189 decade, with a possible uncertainty $\pm 20 \mathrm{Tg} \mathrm{N}$. Our results (Table 1) demonstrate that global $\mathrm{N}_{2} \mathrm{O}$

190 emissions have also significantly increased, primarily driven by anthropogenic sources, with

191 natural sources relatively steady throughout the study period. Our BU and TD global $\mathrm{N}_{2} \mathrm{O}$

192 emissions are comparable in magnitude during 1998-2016, but TD results imply a larger inter-

193 annual variability (1.0 $\mathrm{Tg} \mathrm{N} \mathrm{yr}^{-1}$; Extended Data Fig. 3a). BU and TD approaches diverge in the

194 magnitude of land versus ocean emissions, although they are consistent with respect to trends.

195 Specifically, the BU land estimate during 1998-2016 was on average $1.8 \mathrm{Tg} \mathrm{N} \mathrm{yr}^{-1}$ higher than

196 the TD estimate, but showed a slightly slower increasing rate of $0.8 \pm 0.2 \mathrm{Tg} \mathrm{N}^{-1} \mathrm{per}^{-}$decade

197 (95\% confidence interval; $\mathrm{P}<0.05)$ compared to $1.1 \pm 0.6 \mathrm{Tg} \mathrm{N} \mathrm{yr}^{-1}$ per decade $(\mathrm{P}<0.05)$ from

198 TD (Extended Data Fig. 3b). Since 2005, the difference in the magnitude of emissions between

199 the two approaches has become smaller due to a large TD-inferred emission increase,

200 particularly in South America, Africa, and East Asia (Extended Data Fig. 3d, f, i). Oceanic $\mathrm{N}_{2} \mathrm{O}$

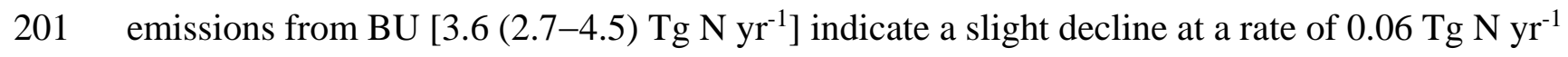

202 per decade $(\mathrm{P}<0.05)$, while the TD approach gave a higher but stable value of 5.1 (3.4-7.1) Tg

$203 \mathrm{~N} \mathrm{yr}^{-1}$ during 1998-2016 (Table 1).

204 Based on BU approaches, anthropogenic $\mathrm{N}_{2} \mathrm{O}$ emissions increased from 5.6 (3.6-8.7) $\mathrm{Tg} \mathrm{N} \mathrm{yr}^{-}$

$205{ }^{1}$ in the $1980 \mathrm{~s}$ to $7.3(4.2-11.4) \mathrm{Tg} \mathrm{N} \mathrm{yr}^{-1}$ in the recent decade at a rate of $0.6 \pm 0.2 \mathrm{Tg} \mathrm{N} \mathrm{yr}^{-1}$ per 
206 decade $(\mathrm{P}<0.05)$. Up to $87 \%$ of this increase is from direct emission from agriculture $(71 \%)$ and

207 indirect emission from anthropogenic $\mathrm{N}$ additions into soils (16\%). Direct soil emission from

208 fertilizer applications is the major source for agricultural emission increases, followed by a small

209 but significant increase in emissions from livestock manure and aquaculture. The model-based

210 estimates of direct soil emissions ${ }^{15-17}$ exhibit a faster increase than the three inventories used in

211 our study (see Methods; Extended Data Fig. 4a), which is largely attributed to the interactive

212 effects between climate change and $\mathrm{N}$ additions as well as spatio-temporal variability in

213 environmental factors such as rainfall and temperature that modulate the $\mathrm{N}_{2} \mathrm{O}$ yield from

214 nitrification and denitrification. This result is in line with the elevated emission factor (EF)

215 deduced from the TD estimates, in which the inversion-based soil emissions increased at a faster

216 rate than suggested by the IPCC Tier $1 \mathrm{EF}^{14}$ (which assumes a linear response), especially after

2172009 (ref. ${ }^{18}$ ). The remaining causes of the increase are attributed to other direct anthropogenic

218 sources $(6 \%)$ and perturbed fluxes from climate/ $\mathrm{CO}_{2} /$ land cover change $(8 \%)$. The part of fossil

219 fuel and industry emissions decreased rapidly over 1980-2000 largely due to the installation of

220 emissions abatement equipment in industrial facilities producing nitric and adipic acid. However,

221 after 2000 such emissions began to increase slowly due to rising fossil fuel combustion

222 (Extended Data Fig. 5a-b).

223 Our analysis of process-based model estimates indicates that soil $\mathrm{N}_{2} \mathrm{O}$ emissions accelerated

224 substantially due to climate change since the early 1980s, which has offset the reduction due to

225 elevated $\mathrm{CO}_{2}$ concentration (Extended Data Fig. 6a). Elevated $\mathrm{CO}_{2}$ enhances plant growth and

226 thus increases $\mathrm{N}$ uptake, which in turn decreases soil $\mathrm{N}_{2} \mathrm{O}$ emissions ${ }^{16,19}$. Land conversion from

227 tropical mature forests with higher $\mathrm{N}_{2} \mathrm{O}$ emissions to pastures and other unfertilized agricultural

228 lands has significantly reduced global natural $\mathrm{N}_{2} \mathrm{O}$ emissions ${ }^{11,20,21}$. This decrease, however, was 
229 partly offset by an increase in soil $\mathrm{N}_{2} \mathrm{O}$ emissions attributable to the temporary rise of emissions

230 following deforestation (post-deforestation pulse effect) and background emissions from

231 converted croplands or pastures ${ }^{21}$ (see Methods; Extended Data Fig. 7).

232 From the ensemble of process-based land model emissions ${ }^{15,16}$, we estimate a global

233 agricultural soil EF of $1.8 \%(1.3 \%-2.3 \%)$, which is significantly larger than the IPCC Tier-1

234 default for direct emission of $1 \%$. This higher EF, derived from process-based models, suggests a

235 strong interactive effect between $\mathrm{N}$ additions and other global environmental changes (Table 1,

236 Perturbed fluxes from climate, atmospheric $\mathrm{CO}_{2}$, and land cover change). Previous field

237 experiments reported a better fit to local observations of soil $\mathrm{N}_{2} \mathrm{O}$ emissions when assuming a

238 non-linear response to fertilizer $\mathrm{N}$ inputs under varied climate and soil conditions ${ }^{17,22}$. The non-

239 linear response is likely also associated with long-term $\mathrm{N}$ accumulation in agricultural soils from

$240 \mathrm{~N}$ fertilizer use and in aquatic systems from $\mathrm{N}$ loads (the legacy effect) ${ }^{18,23}$, which provides more

241 substrate for microbial processes ${ }^{18,24}$. The increasing $\mathrm{N}_{2} \mathrm{O}$ emissions estimated by process-based

242 models ${ }^{16}$ also suggest that recent climate change (particularly warming) may have boosted soil

243 nitrification and denitrification processes, contributing to the growing trend in $\mathrm{N}_{2} \mathrm{O}$ emissions

244 together with rising $\mathrm{N}$ additions to agricultural soils ${ }^{16,25-27}$ (Extended Data Fig. 8).

246 Regional $\mathbf{N}_{2} \mathrm{O}$ Budgets (2007-2016)

247 BU approaches give estimates of $\mathrm{N}_{2} \mathrm{O}$ emissions in the five source categories, while TD

248 approaches only provide total emissions (Fig. 2). BU and TD approaches indicate that Africa was

249 the largest $\mathrm{N}_{2} \mathrm{O}$ source in the last decade, followed by South America (Fig. 2). BU and TD

250 approaches agree well in the magnitudes and trends of $\mathrm{N}_{2} \mathrm{O}$ emissions from South Asia and

251 Oceania (Extended Data Fig. 3j, 1). For the remaining regions, BU and TD estimates are 
252 comparable in their trends but diverge in their source strengths. Clearly, much more work on

253 regional $\mathrm{N}_{2} \mathrm{O}$ budgets is needed, particularly for South America and Africa where we see larger

254 differences between BU and TD estimates and larger uncertainty in each approach. Advancing

255 the understanding and model representation of key processes responsible for $\mathrm{N}_{2} \mathrm{O}$ emissions from

256 land and ocean are priorities for reducing uncertainties in BU estimates. Atmospheric

257 observations in underrepresented regions of the world and better atmospheric transport models

258 are essential for uncertainty reduction in TD estimates, while more accurate activity data and

259 robust EFs are critical for GHG inventories (See Methods for additional discussion on

260 uncertainty).

261 Based on the Global $\mathrm{N}_{2} \mathrm{O}$ Model Intercomparison Project (NMIP) estimates ${ }^{16}$, natural soil

262 emissions (to different extents) dominated in tropical and sub-tropical regions. Soil $\mathrm{N}_{2} \mathrm{O}$

263 emissions in the tropics $\left(0.1 \pm 0.04 \mathrm{~g} \mathrm{~N} \mathrm{~m}^{-2} \mathrm{yr}^{-1}\right)$ are about $50 \%$ higher than the global average,

264 since many lowland, highly-weathered tropical soils have excess $\mathrm{N}$ relative to phosphorus ${ }^{20}$.

265 Total anthropogenic emissions in the ten terrestrial regions were highest in East Asia (1.5;

$266 \quad 0.8-2.6 \mathrm{Tg} \mathrm{N} \mathrm{yr}^{-1}$ ), followed by North America, Africa, and Europe. High direct agricultural $\mathrm{N}_{2} \mathrm{O}$

267 emissions can be attributed to large-scale synthetic $\mathrm{N}$ fertilizer applications in East Asia, Europe,

268 South Asia, and North America, which together consume over $80 \%$ of the world's synthetic N

269 fertilizers $^{28}$. In contrast, direct agricultural emissions from Africa and South America are mainly

270 induced by livestock manure that is deposited in pastures and rangelands ${ }^{28,29}$. East Asia

271 contributed $71 \%-79 \%$ of global aquaculture $\mathrm{N}_{2} \mathrm{O}$ emissions; South Asia and Southeast Asia

272 together contributed $10 \%-20 \%$ (refs. ${ }^{30,31}$ ). Indirect emissions play a moderate role in the total

$273 \mathrm{~N}_{2} \mathrm{O}$ budget, with the highest emission in East Asia $\left(0.3 ; 0.1-0.5 \mathrm{Tg} \mathrm{N} \mathrm{yr}^{-1}\right)$. Other direct 


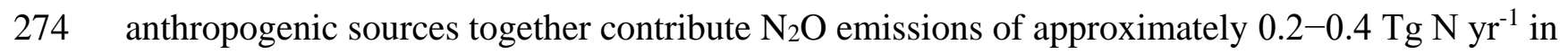

275 East Asia, Africa, North America, and Europe.

276 Both BU and TD estimates of ocean $\mathrm{N}_{2} \mathrm{O}$ emissions for northern, tropical, and southern ocean

277 regions $\left(90^{\circ}-30^{\circ} \mathrm{N}, 30^{\circ} \mathrm{N}-30^{\circ} \mathrm{S}\right.$, and $30^{\circ}-90^{\circ} \mathrm{S}$, respectively) reveal that the tropical oceans

278 contribute over $50 \%$ to the global oceanic source. In particular, the upwelling regions of the

279 equatorial Pacific, Indian and tropical Atlantic (Fig. 3) provide significant sources of $\mathrm{N}_{2} \mathrm{O}^{32-34}$.

280 BU estimates suggest the southern ocean is the second largest regional contributor with

281 emissions about twice as high as from the northern oceans (53\% tropical oceans, 31\% southern

282 oceans, $17 \%$ northern oceans), in line with their area, while the TD estimates suggest

283 approximately equal contributions from the southern and northern oceans.

\section{Four Decades of Anthropogenic $\mathbf{N}_{2} \mathrm{O}$ Emissions}

286 Trends in anthropogenic emissions varied among regions (Fig. 3). Fluxes from Europe and

287 Russia decreased by a total of $0.6(0.5-0.7) \mathrm{Tg} \mathrm{N} \mathrm{yr}^{-1}$ over the past 37 years (1980-2016). The

288 decrease in Europe is associated with successful emissions abatement in industry as well as

289 agricultural policies, while the decrease in Russia is associated with the collapse of the

290 agricultural cooperative system after 1990. In contrast, fluxes from the remaining eight regions

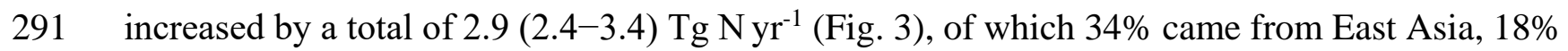

292 from Africa, 18\% from South Asia, 13\% from South America, only 6\% from North America,

293 and with remaining increases due to other regions.

294 The relative importance of each anthropogenic source to the total emission increase differs

295 among regions. East Asia, South Asia, Africa, and South America show larger increases in total

296 agricultural $\mathrm{N}_{2} \mathrm{O}$ emissions (direct and indirect) compared to the remaining six regions during 
$298 \mathrm{~N}_{2} \mathrm{O}$ emissions but to smaller extent. Rising indirect emissions in these four regions (East Asia,

299 South Asia, Africa, and South America) on average constitute $20 \%$ of total agricultural $\mathrm{N}_{2} \mathrm{O}$

300 emissions and are largely induced by the considerable increase in fertilizer $\mathrm{N}$ inputs to

301 agricultural soils ${ }^{35,36}$. The most rapid increase in emissions from other direct anthropogenic

302 sources was found in East Asia, primarily owing to the fast-growing industrial emissions. Africa

303 and South Asia show a fast emission increase due to emissions from fossil fuel and industry and

304 waste and waste water.

305 Our findings point to growing $\mathrm{N}_{2} \mathrm{O}$ emissions in emerging economies, particularly Brazil,

306 China, and India. For example, we find here that the substantial increases in livestock manure

307 left on pasture and in fertilizer use caused a $\sim 120 \%$ increase in Brazilian agricultural $\mathrm{N}_{2} \mathrm{O}$

308 emissions during 1980-2016 (Extended Data Fig. 9). In addition to fertilizer applications, global

309 livestock manure production has been growing steadily, in line with increased livestock

310 numbers ${ }^{15,28}$. Rising demand for meat and dairy products has significantly increased global $\mathrm{N}_{2} \mathrm{O}$

311 emissions from livestock manure production and management associated with the expansion of

312 pastures and grazing land ${ }^{37}$. Meanwhile, expansion of feed crop production to support the growth

313 of livestock could further enhance global $\mathrm{N}_{2} \mathrm{O}$ emissions ${ }^{37,38}$. Likewise, increasing demand for

314 fish has triggered a five-fold increase in global aquaculture production since the late $1980 \mathrm{~s}^{39}$,

315 with demand projected to increase further ${ }^{40}$, although this remains a small fraction $(<1 \%)$ of total

$316 \quad \mathrm{~N}_{2} \mathrm{O}$ emissions.

317 The acceleration of global $\mathrm{N}_{2} \mathrm{O}$ emissions resulting from anthropogenic sources is apparent in 318 both BU and TD results and currently tracks the highest Representative Concentration Pathway $319(\mathrm{RCP} 8.5)^{4}$ in the fifth assessment report (AR5) of IPCC ${ }^{2}$ and exceeds all the Shared 
320 Socioeconomic Pathways (SSPs) ${ }^{3}$ in CMIP6 for the sixth assessment report (AR6) of IPCC (Fig.

321 4). Observed atmospheric $\mathrm{N}_{2} \mathrm{O}$ concentrations are beginning to exceed predicted levels across all

322 scenarios. Emissions need to be reduced to a level that is consistent with or below that in RCP2.6

323 or SSP1-2.6 in order to limit warming well below the $2^{\circ} \mathrm{C}$ target of the Paris Agreement. Failure

324 to include $\mathrm{N}_{2} \mathrm{O}$ within climate mitigation strategies will necessitate even greater abatement of

$325 \mathrm{CO}_{2}$ and $\mathrm{CH}_{4}$. Although $\mathrm{N}_{2} \mathrm{O}$ mitigation is difficult because $\mathrm{N}$ is the key-limiting nutrient in the

326 agricultural production, this study demonstrates that effective mitigation actions have reduced

327 emissions in some regions, such as Europe, through technological improvements in industry and

328 improved $\mathrm{N}$ use efficiency in agriculture.

329 There are a number of mitigation options in the agriculture sector available for immediate

330 deployment, including increased $\mathrm{N}$ use efficiency in (i) animal production through tuning of feed

331 rations to reduce $\mathrm{N}$ excretion, and (ii) in crop production through precision delivery of $\mathrm{N}$

332 fertilizers, split applications and better timing to match $\mathrm{N}$ applications to crop demand,

333 conservation tillage, prevention of waterlogging, and the use of nitrification inhibitors ${ }^{43,44}$.

334 Success stories include the stabilization or reduction of $\mathrm{N}_{2} \mathrm{O}$ emissions through improving $\mathrm{N}$ use

335 efficiency in the United States and Europe, while maintaining or even increasing crop yields ${ }^{44,45}$.

336 There is every reason to expect that additional implementation of more sustainable practices and

337 emerging technologies will lead to further reductions in these regions. For example, $\mathrm{N}_{2} \mathrm{O}$

338 emissions from European agricultural soils decreased by $21 \%$ between 1990 and 2010, a decline

339 attributable to the implementation of the Nitrates Directive (an agricultural policy favoring

340 optimization and reduction of fertilizer use as well as water protection legislation ${ }^{46}$. For regions

341 where emissions are growing, an immediate opportunity lies in the reduction of excess fertilizer

342 use along with the implementation of more sustainable agricultural practices that together have 
343 been shown to increase crop yields, reduce $\mathrm{N}_{2} \mathrm{O}$ emissions, increase water quality, and increase

344 farm income ${ }^{47}$. In addition, $\mathrm{N}_{2} \mathrm{O}$ emissions can be efficiently abated in the chemical

345 industry $^{11,43,48,49}$, as has been achieved successfully in nitric acid plants in the European Union

346 where industrial $\mathrm{N}_{2} \mathrm{O}$ emissions dropped from $11 \%$ to $3 \%$ of total emissions between 2007 and

3472012 (ref. ${ }^{46}$ ). Additional available strategies to reduce $\mathrm{N}_{2} \mathrm{O}$ emissions include promoting lower

348 meat consumption in some parts of the world ${ }^{9}$ and reducing food waste ${ }^{11}$.

349 We present the most comprehensive global $\mathrm{N}_{2} \mathrm{O}$ budget to date, with a detailed sectorial and

350 regional attribution of sources and sinks. Each of the past four decades had higher global $\mathrm{N}_{2} \mathrm{O}$

351 emissions than the previous one, and in all, agricultural activities dominated the growth in

352 emissions. Total industrial emissions have been quite stable with increased emissions from the

353 fossil fuel sector offset to some extent by the decline in emissions in other industrial sectors as a

354 result of successful abatement policies. We also highlight a number of complex interactions

355 between $\mathrm{N}_{2} \mathrm{O}$ fluxes and human-driven changes whose impact on the global atmospheric $\mathrm{N}_{2} \mathrm{O}$

356 growth rate was previously unknown. Those interactions include the effects of climate change,

357 increasing atmospheric $\mathrm{CO}_{2}$, and deforestation. Cumulatively, these exert a relatively small

358 effect on the overall $\mathrm{N}_{2} \mathrm{O}$ growth, however, individual flux components, such as the growing

359 positive climate- $\mathrm{N}_{2} \mathrm{O}$ feedback, are significant. These fluxes are not currently included in the

360 national GHG reporting. We further find that Brazil, China, and India dominate the regional

361 contributions to the increase in global $\mathrm{N}_{2} \mathrm{O}$ emissions over the most recent decade. Our extensive

362 database and modelling capability fill current gaps in national and regional emissions

363 inventories. Future research is needed to further constrain complex biogeochemical interactions

364 between natural/anthropogenic fluxes and global environmental changes, which could lead to

365 significant feedbacks in the future. Reducing excess $\mathrm{N}$ applications to croplands and adopting 
precision fertilizer application methods provide the largest immediate opportunities for $\mathrm{N}_{2} \mathrm{O}$

emissions abatement.

\section{References}

3701 Prather, M. J. et al. Measuring and modeling the lifetime of nitrous oxide including its variability. Journal of Geophysical Research: Atmospheres 120, 5693-5705 (2015). Ciais, P. et al. in Climate Change 2013: The Physical Science Basis. Contribution of Working Group I to the Fifth Assessment Report of the Intergovernmental Panel on Climate Change 465-570 (Cambridge University Press, 2014).

3 Gidden, M. J. et al. Global emissions pathways under different socioeconomic scenarios for use in CMIP6: a dataset of harmonized emissions trajectories through the end of the century. Geoscientific Model Development 12, 1443-1475 (2019).

4 Davidson, E. A. Representative concentration pathways and mitigation scenarios for nitrous oxide. Environmental Research Letters 7, 024005 (2012). Hall, B., Dutton, G. \& Elkins, J. The NOAA nitrous oxide standard scale for atmospheric observations. Journal of Geophysical Research: Atmospheres 112, D09305 (2007). from the Advanced Global Atmospheric Gases Experiment (AGAGE). Earth System Science Data 10, 985-1018 (2018).

7 Butterbach-Bahl, K., Baggs, E. M., Dannenmann, M., Kiese, R. \& ZechmeisterBoltenstern, S. Nitrous oxide emissions from soils: how well do we understand the processes and their controls? Phil. Trans. R. Soc. B 368, 20130122 (2013).

8 Tian, H. et al. The terrestrial biosphere as a net source of greenhouse gases to the atmosphere. Nature 531, 225-228 (2016).

9 UNEP. Drawing down $\mathrm{N}_{2} \mathrm{O}$ to protect climate and the ozone layer. Report No. 9280733583, (United Nations Environment Programme (UNEP), 2013).

10 Park, S. et al. Trends and seasonal cycles in the isotopic composition of nitrous oxide since 1940. Nature Geoscience 5, 261-265 (2012).

11 Davidson, E. A. \& Kanter, D. Inventories and scenarios of nitrous oxide emissions. Environmental Research Letters 9, 105012 (2014).

12 Reay, D. S. et al. Global agriculture and nitrous oxide emissions. Nature Climate Change 2, 410-416 (2012).

13 Syakila, A. \& Kroeze, C. The global nitrous oxide budget revisited. Greenhouse Gas Measurement and Management 1, 17-26 (2011).

14 IPCC. 2006 IPCC Guidelines for National Greenhouse Gas Inventories., (Japan on behalf of the IPCC, Hayama, Japan, 2006).

15 Dangal, S. R. et al. Global nitrous oxide emissions from pasturelands and rangelands: Magnitude, spatio-temporal patterns and attribution. Global Biogeochemical Cycles 33, 200-222 (2019).

16 Tian, H. Q. et al. Global soil nitrous oxide emissions since the preindustrial era estimated by an ensemble of terrestrial biosphere models: Magnitude, attribution, and uncertainty. 
17 Wang, Q. et al. Data-driven estimates of global nitrous oxide emissions from croplands. National Science Review 7, 441-452 (2020).

41018 Thompson, R. L. et al. Acceleration of global $\mathrm{N}_{2} \mathrm{O}$ emissions seen from two decades of atmospheric inversion. Natural Climate Change 9, 993-998 (2019). Zaehle, S., Ciais, P., Friend, A. D. \& Prieur, V. Carbon benefits of anthropogenic reactive nitrogen offset by nitrous oxide emissions. Nature Geoscience 4, 601-605 (2011). Davidson, E. A. et al. Recuperation of nitrogen cycling in Amazonian forests following agricultural abandonment. Nature 447, 995-998 (2007).

21 Verchot, L. V. et al. Land use change and biogeochemical controls of nitrogen oxide emissions from soils in eastern Amazonia. Global Biogeochemical Cycles 13, 31-46 (1999).

22 Shcherbak, I., Millar, N. \& Robertson, G. P. Global metaanalysis of the nonlinear response of soil nitrous oxide $\left(\mathrm{N}_{2} \mathrm{O}\right)$ emissions to fertilizer nitrogen. Proceedings of the National Academy of Sciences 111, 9199-9204 (2014).

23 Van Meter, K. J., Basu, N. B., Veenstra, J. J. \& Burras, C. L. The nitrogen legacy: emerging evidence of nitrogen accumulation in anthropogenic landscapes. Environmental Research Letters 11, 035014 (2016).

24 Firestone, M. K. \& Davidson, E. A. Microbiological basis of $\mathrm{NO}$ and $\mathrm{N}_{2} \mathrm{O}$ production and consumption in soil. Exchange of trace gases between terrestrial ecosystems the atmosphere 47, 7-21 (1989).

25 Griffis, T. J. et al. Nitrous oxide emissions are enhanced in a warmer and wetter world. Proceedings of the National Academy of Sciences 114, 12081-12085 (2017).

26 Pärn, J. et al. Nitrogen-rich organic soils under warm well-drained conditions are global nitrous oxide emission hotspots. Nature Communications 9, 1135 (2018).

27 Smith, K. The potential for feedback effects induced by global warming on emissions of nitrous oxide by soils. Global Change Biology 3, 327-338 (1997).

28 FAOSTAT. The Food and Agriculture Organization of the United Nations Statistics: Emissions-Agriculture, Emissions Land Use Trade (Crops and livestock products), Population, Agri-Environmental Indicators (Livestock Manure) (2019).

$29 \mathrm{Xu}, \mathrm{R}$. et al. Increased nitrogen enrichment and shifted patterns in the world's grassland: 1860-2016. Earth System Science Data 11, 175-187 (2019).

30 Beusen, A. H., Bouwman, A. F., Van Beek, L. P., Mogollón, J. M. \& Middelburg, J. J. Global riverine $\mathrm{N}$ and $\mathrm{P}$ transport to ocean increased during the 20th century despite increased retention along the aquatic continuum. Biogeosciences 13, 2441-2451 (2016).

31 MacLeod, M., Hasan, M. R., Robb, D. H. F. \& Mamun-Ur-Rashid, M. Quantifying and mitigating greenhouse gas emissions from global aquaculture. FAO, Rome (2019).

32 Buitenhuis, E. T., Suntharalingam, P. \& Le Quéré, C. Constraints on global oceanic emissions of $\mathrm{N}_{2} \mathrm{O}$ from observations and models. Biogeosciences 15, 2161-2175 (2018).

33 Manizza, M., Keeling, R. F. \& Nevison, C. D. On the processes controlling the seasonal cycles of the air-sea fluxes of $\mathrm{O}_{2}$ and $\mathrm{N}_{2} \mathrm{O}$ : A modelling study. Tellus B: Chemical and Physical Meteorology 64, 18429 (2012).

34 Martinez-Rey, J., Bopp, L., Gehlen, M., Tagliabue, A. \& Gruber, N. Projections of oceanic $\mathrm{N}_{2} \mathrm{O}$ emissions in the 21 st century using the IPSL Earth system model. Biogeosciences 12, 4133-4148 (2015).

35 Maavara, T. et al. Nitrous oxide emissions from inland waters: Are IPCC estimates too high? Global Change Biology 25, 473-488 (2019). 
45436 Yao, Y. et al. Increased global nitrous oxide emissions from streams and rivers in the

$455 \quad$ Anthropocene. Natural Climate Change 10, 138-142 (2020).

45637 Gerber, P. J. et al. Tackling climate change through livestock: a global assessment of

457 emissions and mitigation opportunities. FAO (2013).

$45838 \quad$ Herrero, M. et al. Biomass use, production, feed efficiencies, and greenhouse gas emissions from global livestock systems. Proceedings of the National Academy of Sciences 110, 20888-20893 (2013).

39 Yuan, J. et al. Rapid growth in greenhouse gas emissions from the adoption of industrialscale aquaculture. Nature Climate Change 9, 318-322 (2019).

40 Froehlich, H. E., Runge, C. A., Gentry, R. R., Gaines, S. D. \& Halpern, B. S. Comparative terrestrial feed and land use of an aquaculture-dominant world. Proceedings of the National Academy of Sciences 115, 5295-5300 (2018).

41 O'Neill, B. C. et al. The Scenario Model Intercomparison Project (ScenarioMIP) for CMIP6. Geoscience Model Development 9, 3461-3482 (2016). Güstem Science Data 8, 571-603 (2016).
Syst al. The PRIMAP-hist natio

43 Winiwarter, W., Höglund-Isaksson, L., Klimont, Z., Schöpp, W. \& Amann, M. Technical opportunities to reduce global anthropogenic emissions of nitrous oxide. Environmental Research Letters 13, 014011 (2018).

44 Zhang, X. et al. Managing nitrogen for sustainable development. Nature 528, 51-59 (2015).

45 Mueller, N. D. et al. Declining spatial efficiency of global cropland nitrogen allocation. Global Biogeochemical Cycles 31, 245-257 (2017).

46 European Environment Agency. Annual European Union greenhouse gas inventory 19902017 and inventory report 2019. Submission under the United Nations Framework Convention on Climate Change and the Kyoto Protocol, Copenhagen, DK (2019).

47 Cui, Z. et al. Pursuing sustainable productivity with millions of smallholder farmers. Nature 555, 363-366 (2018).

48 Kanter, D. et al. A post-Kyoto partner: considering the stratospheric ozone regime as a tool to manage nitrous oxide. Proceedings of the National Academy of Sciences 110, 4451-4457 (2013).

49 Schneider, L., Lazarus, M. \& Kollmuss, A. J. S. M. S. E. I. Industrial $\mathrm{N}_{2} \mathrm{O}$ projects under the CDM: Adipic acid-A case of carbon leakage. Stockholm Environment Institute (2010). 
496 Table 1 The global $\mathrm{N}_{2} \mathrm{O}$ budget in the 1980s, 1990s, 2000s, and 2007-2016.

\begin{tabular}{|c|c|c|c|c|c|c|c|c|c|c|c|c|c|}
\hline \multirow{2}{*}{\multicolumn{2}{|c|}{ Anthropogenic sources }} & \multicolumn{3}{|c|}{ the 1980s } & \multicolumn{3}{|c|}{ the 1990s } & \multicolumn{3}{|c|}{ the 2000s } & \multicolumn{3}{|c|}{ 2007-2016 } \\
\hline & & mean & $\min$ & $\max$ & mean & $\min$ & $\max$ & mean & $\min$ & $\max$ & mean & $\min$ & $\max$ \\
\hline \multirow{5}{*}{$\begin{array}{c}\text { Direct emissions } \\
\text { of } \mathrm{N} \text { additions in } \\
\text { the agricultural } \\
\text { sector } \\
\text { (Agriculture) }\end{array}$} & Direct soil emissions & 1.5 & 0.9 & 2.6 & 1.7 & 1.1 & 3.1 & 2.0 & 1.3 & 3.4 & 2.3 & 1.4 & 3.8 \\
\hline & Manure left on pasture & 0.9 & 0.7 & 1.0 & 1.0 & 0.7 & 1.1 & 1.1 & 0.8 & 1.2 & 1.2 & 0.9 & 1.3 \\
\hline & Manure management & 0.3 & 0.2 & 0.4 & 0.3 & 0.2 & 0.4 & 0.3 & 0.2 & 0.5 & 0.3 & 0.2 & 0.5 \\
\hline & Aquaculture & 0.01 & 0.00 & 0.03 & 0.03 & 0.01 & 0.1 & 0.1 & 0.02 & 0.2 & 0.1 & 0.02 & 0.2 \\
\hline & sub-total & 2.6 & 1.8 & 4.1 & 3.0 & 2.1 & 4.8 & 3.4 & 2.3 & 5.2 & 3.8 & 2.5 & 5.8 \\
\hline \multirow{4}{*}{$\begin{array}{l}\text { Other direct } \\
\text { anthropogenic } \\
\text { sources }\end{array}$} & Fossil fuel and industry & 0.9 & 0.8 & 1.1 & 0.9 & 0.9 & 1.0 & 0.9 & 0.8 & 1.0 & 1.0 & 0.8 & 1.1 \\
\hline & Waste and waste water & 0.2 & 0.1 & 0.3 & 0.3 & 0.2 & 0.4 & 0.3 & 0.2 & 0.4 & 0.3 & 0.2 & 0.5 \\
\hline & Biomass burning & 0.7 & 0.7 & 0.7 & 0.7 & 0.6 & 0.8 & 0.6 & 0.6 & 0.6 & 0.6 & 0.5 & 0.8 \\
\hline & sub-total & 1.8 & 1.6 & 2.1 & 1.9 & 1.7 & 2.1 & 1.8 & 1.6 & 2.1 & 1.9 & 1.6 & 2.3 \\
\hline \multirow{4}{*}{$\begin{array}{l}\text { Indirect } \\
\text { emissions from } \\
\text { anthropogenic } \mathrm{N} \\
\text { additions }\end{array}$} & $\begin{array}{l}\text { Inland waters, } \\
\text { estuaries, coastal zones }\end{array}$ & 0.4 & 0.2 & 0.5 & 0.4 & 0.2 & 0.5 & 0.4 & 0.2 & 0.6 & 0.5 & 0.2 & 0.7 \\
\hline & $\begin{array}{l}\text { Atmospheric } \mathrm{N} \\
\text { deposition on land }\end{array}$ & 0.6 & 0.3 & 1.2 & 0.7 & 0.4 & 1.4 & 0.7 & 0.4 & 1.3 & 0.8 & 0.4 & 1.4 \\
\hline & $\begin{array}{l}\text { Atmospheric } \mathrm{N} \\
\text { deposition on ocean }\end{array}$ & 0.1 & 0.1 & 0.2 & 0.1 & 0.1 & 0.2 & 0.1 & 0.1 & 0.2 & 0.1 & 0.1 & 0.2 \\
\hline & sub-total & 1.1 & 0.6 & 1.9 & 1.2 & 0.7 & 2.1 & 1.2 & 0.6 & 2.1 & 1.3 & 0.7 & 2.2 \\
\hline \multirow{5}{*}{$\begin{array}{l}\text { Perturbed fluxes } \\
\text { from } \\
\text { climate/ } \mathrm{CO}_{2} / \text { land } \\
\text { cover change }\end{array}$} & $\mathrm{CO}_{2}$ effect & -0.2 & -0.3 & 0.0 & -0.2 & -0.4 & 0.0 & -0.3 & -0.5 & 0.1 & -0.3 & -0.6 & 0.1 \\
\hline & Climate effect & 0.4 & 0.0 & 0.8 & 0.5 & 0.1 & 0.9 & 0.7 & 0.3 & 1.2 & 0.8 & 0.3 & 1.3 \\
\hline & $\begin{array}{l}\text { Post-deforestation pulse } \\
\text { effect }\end{array}$ & 0.7 & 0.6 & 0.8 & 0.7 & 0.6 & 0.8 & 0.7 & 0.7 & 0.8 & 0.8 & 0.7 & 0.8 \\
\hline & $\begin{array}{l}\text { Long-term effect of } \\
\text { reduced mature forest } \\
\text { area }\end{array}$ & -0.8 & -0.8 & -0.9 & -0.9 & -0.8 & -1.0 & -1.0 & -0.9 & -1.1 & -1.1 & -1.0 & -1.1 \\
\hline & sub-total & 0.1 & -0.4 & 0.7 & 0.1 & -0.5 & 0.7 & 0.2 & -0.4 & 0.9 & 0.2 & -0.6 & 1.1 \\
\hline \multicolumn{2}{|c|}{ Anthropogenic total } & 5.6 & 3.6 & 8.7 & 6.2 & 3.9 & 9.7 & 6.7 & 4.1 & 10.3 & 7.3 & 4.2 & 11.4 \\
\hline \multicolumn{14}{|l|}{ Natural fluxes } \\
\hline \multirow{5}{*}{\multicolumn{2}{|c|}{$\begin{array}{l}\text { Natural soils baseline } \\
\text { Ocean baseline } \\
\text { Natural (Inland waters, estuaries, coastal } \\
\text { zones) } \\
\text { Lightning and atmospheric production } \\
\text { Surface sink }\end{array}$}} & 5.6 & 4.9 & 6.6 & 5.6 & 4.9 & 6.5 & 5.6 & 5.0 & 6.5 & 5.6 & 4.9 & 6.5 \\
\hline & & 3.6 & 3.0 & 4.4 & 3.5 & 2.8 & 4.4 & 3.5 & 2.7 & 4.3 & 3.4 & 2.5 & 4.3 \\
\hline & & 0.3 & 0.3 & 0.4 & 0.3 & 0.3 & 0.4 & 0.3 & 0.3 & 0.4 & 0.3 & 0.3 & 0.4 \\
\hline & & 0.4 & 0.2 & 1.2 & 0.4 & 0.2 & 1.2 & 0.4 & 0.2 & 1.2 & 0.4 & 0.2 & 1.2 \\
\hline & & -0.01 & 0.00 & -0.3 & -0.01 & 0.00 & -0.3 & -0.01 & 0.00 & -0.3 & -0.01 & 0.00 & -0.3 \\
\hline \multicolumn{2}{|l|}{ Natural total } & 9.9 & 8.5 & 12.2 & 9.8 & 8.3 & 12.1 & 9.8 & 8.2 & 12.0 & 9.7 & 8.0 & 12.0 \\
\hline \multicolumn{2}{|l|}{$\begin{array}{l}\text { Bottom-up total } \\
\text { source }\end{array}$} & 15.5 & 12.1 & 20.9 & 15.9 & 12.2 & 21.7 & 16.4 & 12.3 & 22.4 & 17.0 & 12.2 & 23.5 \\
\hline \multicolumn{2}{|l|}{$\begin{array}{l}\text { Top-down Ocean } \\
\text { Top-down Land }\end{array}$} & & & & & & & $\begin{array}{r}5.1 \\
10.8\end{array}$ & $\begin{array}{l}3.1 \\
9.3\end{array}$ & $\begin{array}{r}7.2 \\
12.5\end{array}$ & $\begin{array}{r}5.1 \\
11.8\end{array}$ & $\begin{array}{r}3.4 \\
10.6\end{array}$ & $\begin{array}{r}7.1 \\
13.8\end{array}$ \\
\hline \multicolumn{2}{|l|}{$\begin{array}{l}\text { Top-down total } \\
\text { source }\end{array}$} & & & & & & & 15.9 & 15.1 & 16.9 & 16.9 & 15.9 & 17.7 \\
\hline \multirow{3}{*}{\multicolumn{2}{|c|}{$\begin{array}{l}\text { Top-down Statospheric sink } \\
\text { Observed atmospheric chemical sink* } \\
\text { Change in atmospheric abundance }{ }^{* *}\end{array}$}} & & & & & & & 12.1 & 11.4 & 13.1 & 12.4 & 11.7 & 13.3 \\
\hline & & & & & & & & 13.3 & 12.2 & 14.4 & 13.5 & 12.4 & 14.6 \\
\hline & & & & & & & & 3.7 & 3.2 & 4.2 & 4.3 & 3.8 & 4.8 \\
\hline \multicolumn{2}{|c|}{$\begin{array}{l}\text { Atmospheric } \\
\text { burden }\end{array}$} & 1462 & 1442 & 1482 & 1493 & 1472 & 1514 & 1531 & 1510 & 1552 & 1555 & 1533 & 1577 \\
\hline
\end{tabular}

497 Note: BU estimates include four categories of anthropogenic sources (red for agriculture, orange for 498 other direct anthropogenic sources, maroon for indirect emissions from anthropogenic $N$ additions, and 499 brown for perturbed fluxes from climate/ $\mathrm{CO}_{2}$ /land cover change) and one category for natural sources 500 and sinks (green). The sources and sinks of $\mathrm{N}_{2} \mathrm{O}$ are given in $\mathrm{Tg} \mathrm{Nyr} r^{-1}$. The atmospheric burden is given 501 in Tg N. *calculated from satellite observations with a photolysis model (about 1\% of this sink 502 occurs in the troposphere). **Calculated from the combined NOAA and AGAGE record of surface $\mathrm{N}_{2} \mathrm{O}$, 503 and adopting the uncertainty of the IPCC AR5 (Chapter 6) ${ }^{2}$. Detailed information on calculating each 504 sub-category is shown in Supplementary Tables 1-13. 


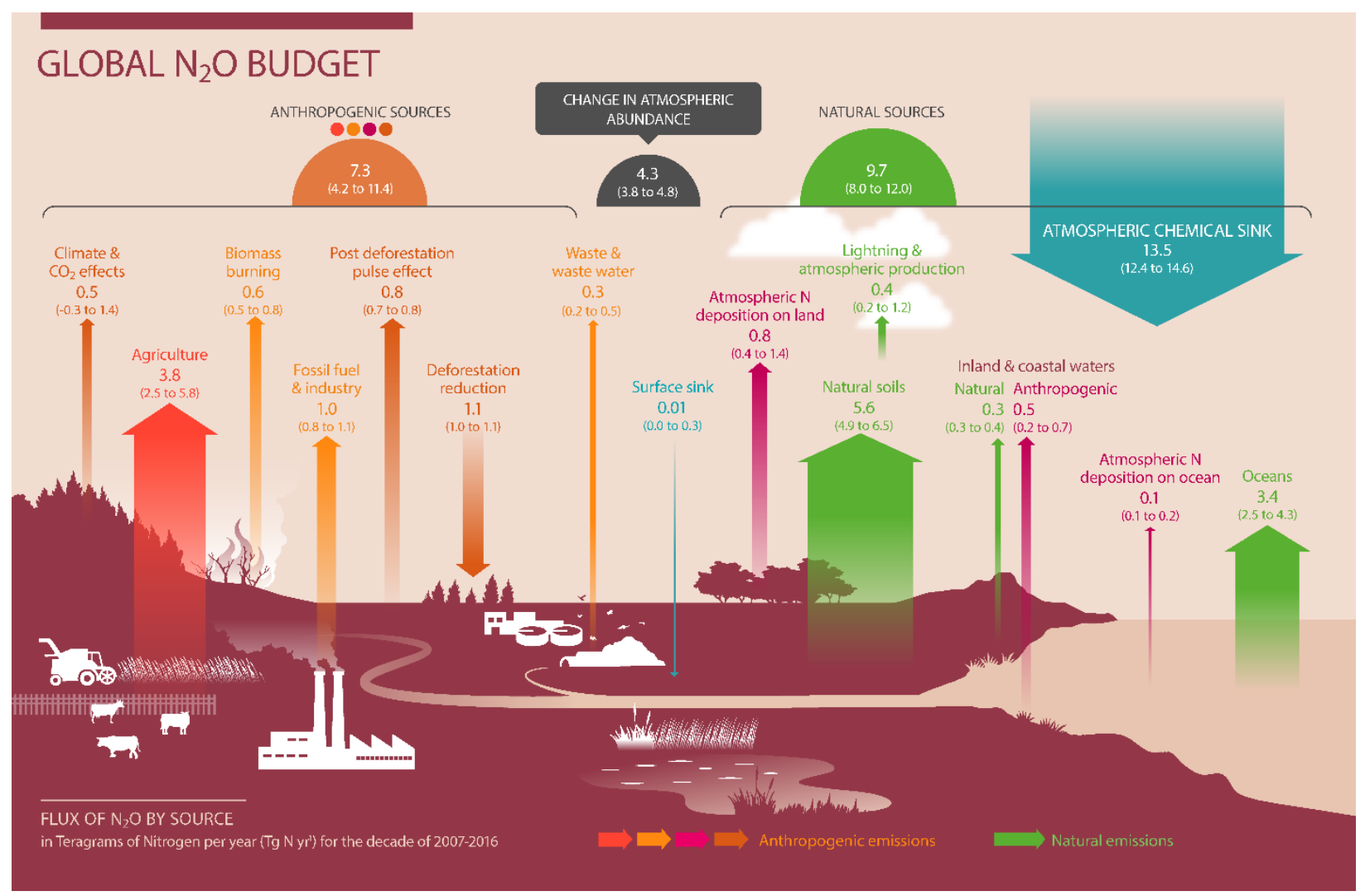

Fig. 1 Global $\mathbf{N}_{2} \mathrm{O}$ budget for the recent decade (2007-2016). The red arrow represents direct emissions of $N$ additions in the agricultural sector (Agriculture). The orange arrows represent emissions from other direct anthropogenic sources. The maroon arrows represent indirect emissions from anthropogenic $N$ additions. The brown arrows represent perturbed fluxes from climate/CO $/$ /land cover change effects. The green arrows represent natural source. The anthropogenic and natural $\mathrm{N}_{2} \mathrm{O}$ sources are derived from $B U$ estimates. The blue arrows represent surface sink and observed atmospheric chemical sink of which about $1 \%$ occurs in the troposphere. The total budget (sources + sinks) does not exactly match the observed atmospheric accumulation, because each of the terms has been derived independently and we do not force top-down agreement by rescaling the terms. This imbalance readily falls within the overall uncertainty in closing the $\mathrm{N}_{2} \mathrm{O}$ budget, as reflected in each of the terms. The $\mathrm{N}_{2} \mathrm{O}$ sources and sinks are given in $\mathrm{Tg} \mathrm{N} y r^{-1}$. 


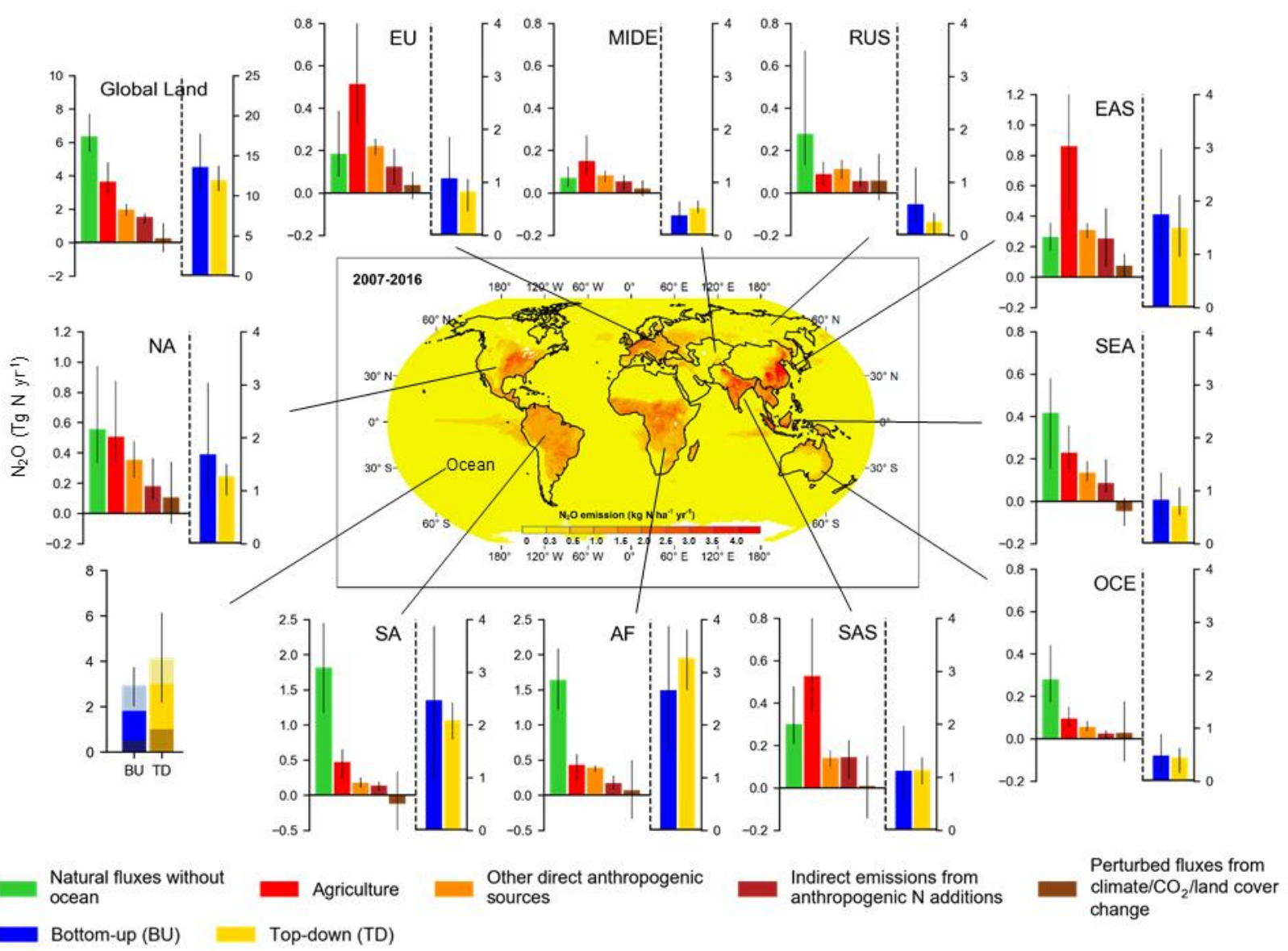

Fig. 2 Regional $\mathrm{N}_{2} \mathrm{O}$ sources in the recent decade (2007-2016) over 11 regions. The Earth's ice-free land is partitioned into ten regions: North America (NA), South America (SA), Europe (EU), Middle East (MIDE), Africa (AF), Russia (RUS), East Asia (EAS), South Asia (SAS), Southeast Asia (SEA), and Oceania (OCE). In each subplot from left to right: emissions from five sub-sectors using $B U$ approaches: natural fluxes without ocean (green), direct emissions of $N$ additions in the agricultural sector (Agriculture, red), other direct anthropogenic sources (orange), indirect emissions from anthropogenic $N$ additions (maroon), and perturbed fluxes from climate/CO $\mathrm{O}_{2} /$ land cover change (brown); the sum of these five categories by BU approaches (blue), and the estimates by TD approaches (gold). BU and TD estimates of ocean emissions are shown at the bottom left (from bottom to top: $30^{\circ}-90^{\circ} \mathrm{N}$, $30^{\circ} \mathrm{S}-30^{\circ} \mathrm{N}$, and $90^{\circ}-30^{\circ} \mathrm{S}$ ). Error bars indicate the spread between the minimum and the maximum values. The center map shows the spatial distribution of 10-year average $\mathrm{N}_{2} \mathrm{O}$ emissions from land and ocean based on the land and ocean models. Per capita $\mathrm{N}_{2} \mathrm{O}$ emission ( $\mathrm{kg} \mathrm{N}$ capita $\left.\mathrm{er}^{-1} \mathrm{yr}^{-1}\right)$ during 2007-2016 is shown in Supplementary Fig. 2. 

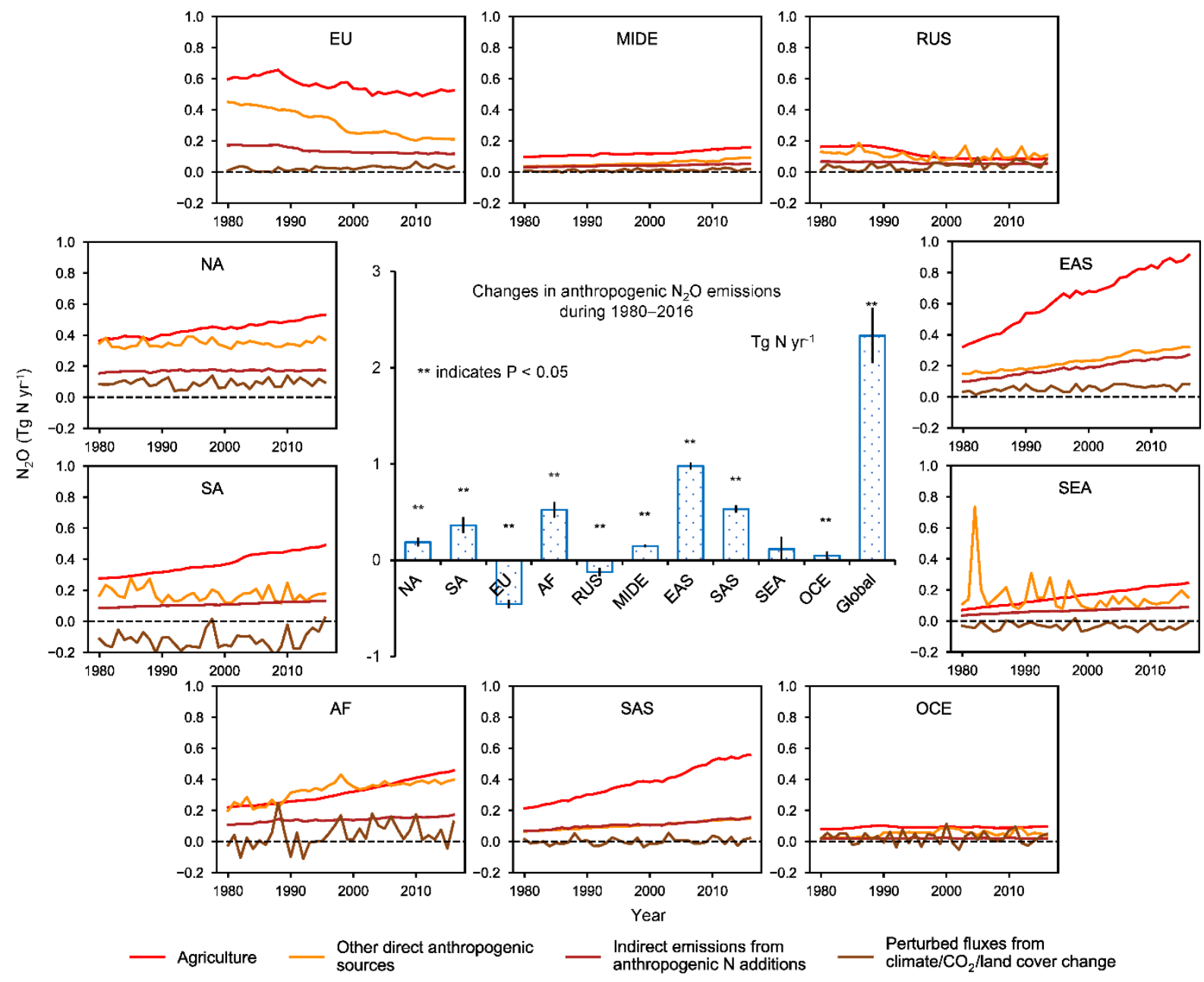

Fig. 3 Ensembles of regional anthropogenic $\mathrm{N}_{2} \mathrm{O}$ emissions over the 1980-2016 period. The bar chart in the center shows the accumulated changes in regional and global $\mathrm{N}_{2} \mathrm{O}$ emissions during the study period. Error bars indicate the 95\% confidence interval for the average of accumulated changes. The Mann-Kendall test was performed to examine a monotonic increasing or decreasing trend in the estimated ensemble $\mathrm{N}_{2} \mathrm{O}$ emissions for each region and the globe during 1980-2016. The accumulated changes were calculated from the linear regressed annual change rate ( $\left.\mathrm{Tg} N \mathrm{yr}^{-2}\right)$ multiplied by 37 years. All regions except SEA show a significant increasing or decreasing trend in the estimated ensemble $\mathrm{N}_{2} \mathrm{O}$ emissions during the study period (indicated by **for each bar). 

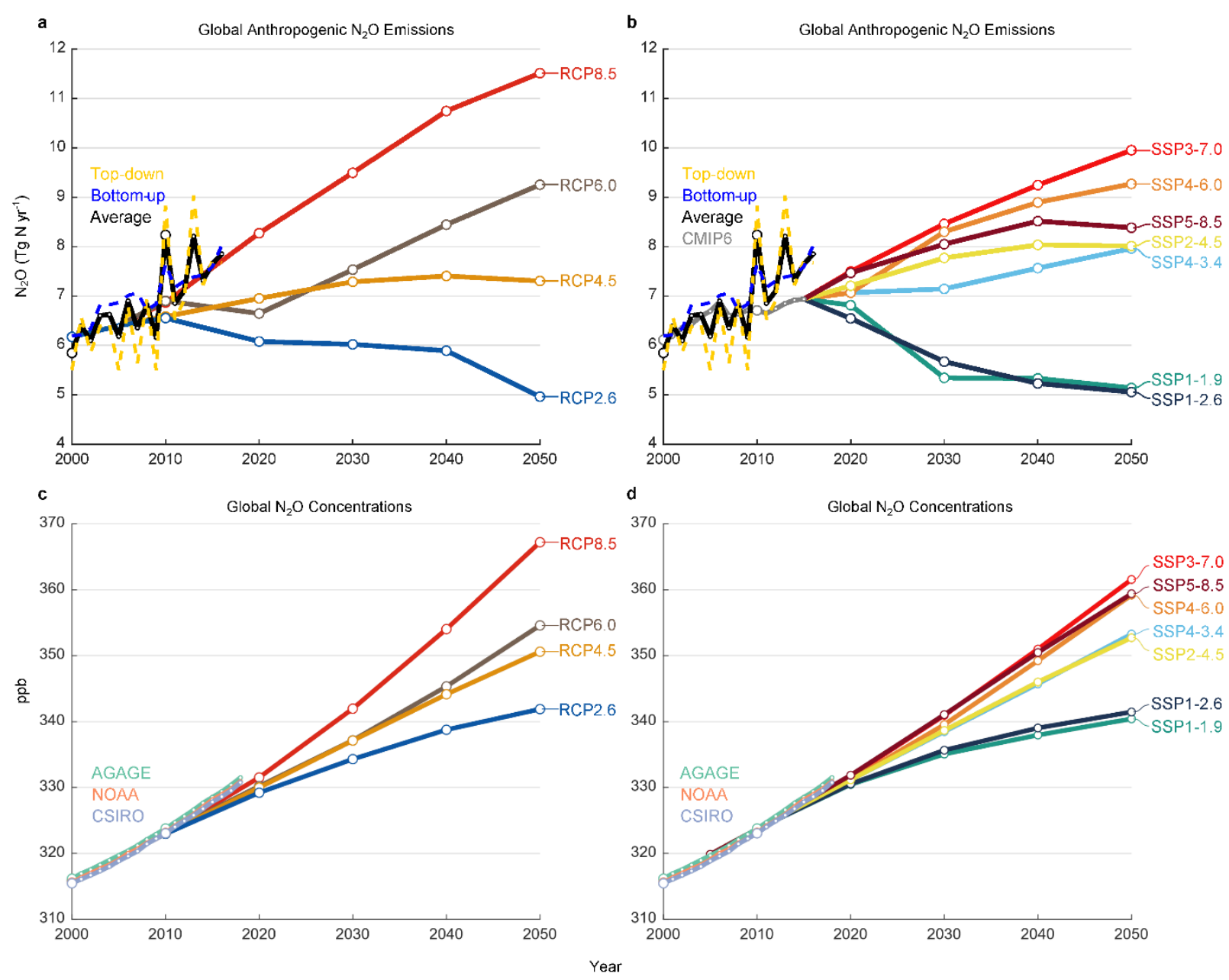

Fig. 4 Historical and projected global anthropogenic $\mathrm{N}_{2} \mathrm{O}$ emissions and concentrations. Global anthropogenic $\mathrm{N}_{2} \mathrm{O}$ emissions $(\boldsymbol{a}, \boldsymbol{b})$ and concentrations $(\boldsymbol{c}, \boldsymbol{d})$ compared to the four representative concentration pathways (RCPS) in the IPCC AR5 (a, c, ref. $\left.{ }^{2}\right)$ and the new marker scenarios based on the Shared Socioeconomic Pathways (SSPs) used in CMIP6 (b, d, ref. $\left.{ }^{41}\right)$. The historical data is represented as the mean of the $\mathrm{BU}$ and TD estimates of anthropogenic $\mathrm{N}_{2} \mathrm{O}$ emissions, while the atmospheric concentration uses the three observation networks available, AGAGE, NOAA, and CSIRO. TD anthropogenic emissions were calculated by subtracting BUderived natural fluxes. To aid the comparison, the four RCPs were shifted down so that the 2005 value is equal to the 2000-2009 average of the mean of TD and BU estimates. The SSPs are harmonized ${ }^{3}$ to match the historical emissions used in CMIP6 ${ }^{42}$ and Extended Data Fig. 10 
561 Terminology. This study provides an estimation of the global $\mathrm{N}_{2} \mathrm{O}$ budget considering all

562 possible sources and all global change processes that can perturb the budget. A total of 18

563 sources and three sinks of $\mathrm{N}_{2} \mathrm{O}$ are identified and grouped into six categories (Figure 1, Table 1):

564 1) Natural fluxes in absence of climate change and anthropogenic disturbances including Soil

565 emissions, Surface sink, Ocean emissions, Lightning and atmospheric production, and Natural

566 emission from inland waters, estuaries, coastal zones (inland and coastal waters), 2) Perturbed

567 fluxes from climate/ $\mathrm{CO}_{2} /$ land cover change including $\mathrm{CO}_{2}$ effect, Climate effect, Post-

568 deforestation pulse effect, and Long-term effect of reduced mature forest area, 3) Direct

569 emissions of $\mathrm{N}$ additions in the agricultural sector (Agriculture) including emissions from direct

570 application of synthetic $\mathrm{N}$ fertilizers and manure (henceforth Direct soil emissions), Manure left

571 on pasture, Manure management, and Aquaculture, 4) Indirect emissions from anthropogenic N

572 additions including atmospheric $\mathrm{N}$ deposition (NDEP) on land, atmospheric NDEP on ocean, and

573 effects of anthropogenic loads of reactive $\mathrm{N}$ in inland waters, estuaries, coastal zones, 5) Other

574 direct anthropogenic sources including Fossil fuel and industry, Waste and waste water, and

575 Biomass burning, and 6) Two estimates of stratospheric sinks obtained from atmospheric

576 chemistry transport models and observations, and one tropospheric sink (Table 1, Extended Data

577 Fig. 2).

578 For the purpose of compiling national GHG inventories for country reporting to the climate

579 convention, our anthropogenic $\mathrm{N}_{2} \mathrm{O}$ emission categories are aligned with those used in UNFCCC

580 reporting and IPCC 2006 methodologies (Supplementary Table 14). We also provide the detailed

581 comparison of our methodology and quantification with the IPCC AR5 (see Supplementary

582 Section 4; Supplementary Table 15). 
583 Data synthesis. We consider global $\mathrm{N}_{2} \mathrm{O}$ emission from land and ocean consisting of natural

584 fluxes and anthropogenic emissions based on BU and TD approaches, however, the TD approach 585 cannot separate natural and anthropogenic sources.

586 'Natural soil baseline' emissions were obtained from six terrestrial biosphere models

587 (NMIP ${ }^{16}$, Supplementary Tables $\left.16-17\right)$ and provided here reflect a situation without

588 consideration of land use change (e.g., deforestation) and without consideration of indirect

589 anthropogenic effects via global change (i.e., climate, elevated $\mathrm{CO}_{2}$, and atmospheric $\mathrm{N}$

590 deposition). $\mathrm{BU}$ oceanic $\mathrm{N}_{2} \mathrm{O}$ emissions were based on an inter-comparison of five global ocean

591 biogeochemistry models (Supplementary Table 18). The natural emission from 'Inland water,

592 estuaries, coastal zones' includes coastal upwelling ${ }^{50}$ and inland and coastal waters that were

593 obtained from Yao et al. ${ }^{36}$, Maavara et al. ${ }^{35}$, and Lauerwald et al. ${ }^{51}$. Since the data (rivers,

594 reservoirs, and estuaries) provided by Maavara et al. and Lauerwald et al. are for the year 2000,

595 we assume that these values are constant during 1980-2016. Yao et al. ${ }^{36}$ provided annual

596 riverine $\mathrm{N}_{2} \mathrm{O}$ emissions using DLEM during the same period. Here, we averaged estimates from

597 Yao et al. with that from Maavara et al. ${ }^{35}$. In addition, we estimated $\mathrm{N}_{2} \mathrm{O}$ emissions from global

598 and regional reservoirs in the 2000s, and averaged their estimates with that from Maavara et al. ${ }^{35}$

599 to represent emissions from reservoirs during 1980-2016. The estimate for global and regional

600 estuaries and lakes is still based on the long-term averaged values provided by Maavara et al. ${ }^{35}$

601 and Lauerwald et al. ${ }^{51}$, respectively. We considered the riverine emissions in the year 1900 as

602 equivalent to the natural emission for the DLEM estimate assuming that the $\mathrm{N}$ load from land

603 was negligible in that period ${ }^{52}$. We quantified the contribution of natural sources to total

604 emission from reservoirs, lakes, and estuaries at 44\% (36\%-52\%), with consideration of all $\mathrm{N}$

605 inputs (i.e., inorganic, organic, dissolved, particulate forms). We combined the estimate from 
606 lightning with that from atmospheric production into an integrated category 'Lightning and

607 atmospheric production'. We make the simplification of considering the category 'Lightning and

608 atmospheric production' as purely natural, however, atmospheric production is affected to some

609 extent by anthropogenic activities through enhancing the concentrations of the reactive species

$610 \mathrm{NH}_{2}$ and $\mathrm{NO}_{2}$. This category is in any case very small and the anthropogenic enhancement effect

611 is uncertain. Lightning produces $\mathrm{NO}_{x}$, the median estimate of which is $5 \mathrm{Tg} \mathrm{N} \mathrm{yr}^{-1}\left(\right.$ ref. $\left.^{53}\right)$. We

612 assumed an EF of $1 \%$ (ref. ${ }^{54}$ ) and a global estimate of $0.05(0.02-0.09) \mathrm{Tg} \mathrm{N} \mathrm{yr}^{-1}$ from lightning.

613 Atmospheric production of $\mathrm{N}_{2} \mathrm{O}$ results from the reaction of $\mathrm{NH}_{2}$ with $\mathrm{NO}_{2}$ (refs. ${ }^{55,56}$ ), $\mathrm{N}$ with

$614 \mathrm{NO}_{2}$, and oxidation of $\mathrm{N}_{2}$ by $\mathrm{O}\left({ }^{1} \mathrm{D}\right)^{57}$, all of which constitute an estimated source of $0.3(0.2-1.1)$

$615 \mathrm{Tg} \mathrm{N} \mathrm{yr}^{-1}$. The estimate of 'Surface sink' was obtained from Schlesinger ${ }^{58}$ and Syakila et al. ${ }^{59}$.

616 The anthropogenic sources include four sub-sectors:

617 (a) Agriculture. It consists of four components: 'Direct soil emissions', 'Manure left on

618 pasture', 'Manure management', and 'Aquaculture'. Data for 'Direct soil emissions' were

619 obtained as the ensemble mean of $\mathrm{N}_{2} \mathrm{O}$ emissions from an average of three inventories (EDGAR

620 v4.3.2, FAOSTAT, and GAINS), the SRNM/DLEM models, and the NMIP/DLEM models. The

621 statistical model SRNM only covers cropland $\mathrm{N}_{2} \mathrm{O}$ emissions, the same as the NMIP. Thus, we

622 add the DLEM-based estimate of pasture $\mathrm{N}_{2} \mathrm{O}$ emissions into the two estimates in cropland to

623 represent direct agricultural soil emissions (i.e., SRNM/DLEM or NMIP/DLEM). The 'Manure

624 left on pasture' and 'Manure management' emissions are the ensemble mean of EDGAR v4.3.2,

625 FAOSTAT, and GAINS databases. Global N flows (i.e., fish feed intake, fish harvest, and waste)

626 in freshwater and marine aquaculture were obtained from Beusen et al. ${ }^{30}$ and Bouwman et al. ${ }^{60,61}$

627 based on a nutrient budget model for the period 1980-2016. We then calculated global

628 aquaculture $\mathrm{N}_{2} \mathrm{O}$ emissions through considering $1.8 \%$ loss of $\mathrm{N}$ waste in aquaculture, the same 
629 EF used in Hu et al. ${ }^{62}$ and Macleod et al. ${ }^{31}$. The uncertainty range of the EF is from $0.5 \%\left(\right.$ ref. ${ }^{14}$ )

630 to $5 \%$ (ref. ${ }^{63}$ ), the same range used in the UNEP report ${ }^{9}$. The 'Aquaculture' emission for the

631 period 2007-2016 was a synthesis data from Hu et al..$^{62}$ in 2009, the FAO Report ${ }^{31}$ in 2013, and

632 our calculations. The estimate of aquaculture $\mathrm{N}_{2} \mathrm{O}$ emission prior to 2009 was from our

633 calculations only.

634 The estimated direct emissions from agriculture have increased from $2.6(1.8-4.1) \mathrm{Tg} \mathrm{N}^{-1}$

635 in the 1980 s to $3.8(2.5-5.8) \mathrm{Tg} \mathrm{N} \mathrm{yr}^{-1}$ over the recent decade (2007-2016, Table 1).

636 Specifically, direct soil emission from the application of fertilizers is the major source and

637 increased at a rate of $0.27 \pm 0.01 \mathrm{Tg} \mathrm{N} \mathrm{yr}^{-1}$ per decade $(\mathrm{P}<0.05$; Table 1). Compared with the

638 three global inventories (FAOSTAT, EDGAR v4.3.2, and GAINS), the estimates from process-

639 based models (NMIP/DLEM ${ }^{15,16}$ ) and a statistical model (SRNM)/DLEM ${ }^{15,17}$ exhibited a faster

640 increase (Extended Data Fig. 4a). Over the past four decades, we also found a small but

641 significant increase in emissions from livestock manure (i.e., manure left on pasture and manure

642 management) at a rate of $0.1 \pm 0.01 \mathrm{Tg} \mathrm{N} \mathrm{yr}^{-1}$ per decade ( $\mathrm{P}<0.05$; Extended Data Fig. 4b-c).

643 Meanwhile, global aquaculture $\mathrm{N}_{2} \mathrm{O}$ emissions increased 10-fold, however, this flux remains the

644 smallest term in the global budget (Extended Data Fig. 4d).

645 (b) Other direct anthropogenic sources. It includes 'Fossil fuel and industry', 'Waste and

646 waste water', and 'Biomass burning'. Both 'Fossil fuel and industry' and 'Waste and waste

647 water' are the ensemble means of EDGAR v4.3.2 and GAINS databases. The 'Biomass burning'

648 emission is the ensemble mean of FAOSTAT, DLEM, and GFED4s databases.

649 Emissions from a combination of fossil fuel and industry, waste and waste water, and biomass

650 burning increased from $1.8(1.6-2.1) \mathrm{Tg} \mathrm{N} \mathrm{yr}^{-1}$ in the 1980 s to $1.9(1.6-2.3) \mathrm{Tg} \mathrm{N} \mathrm{yr}^{-1}$ over the

651 period of 2007-2016 (Table 1). The waste and waste water emission showed a continuous 
652 increase at a rate of $0.04 \pm 0.01 \mathrm{Tg} \mathrm{N} \mathrm{yr}^{-1}$ per decade $(\mathrm{P}<0.05)$ (Extended Data Fig. $5 \mathrm{c}$ ).

653 Emissions from biomass burning, estimated based on three data sources (DLEM, GFED4s, and

654 FAOSTAT), slightly decreased at a rate of $-0.03 \pm 0.04 \mathrm{Tg} \mathrm{N} \mathrm{yr}^{-1}$ per decade $(\mathrm{P}=0.3)$ since

655 the1980s (Extended Data Fig. 5d). This item is largely affected by climate and land use

656 change ${ }^{64,65}$. Of the three data sources, the DLEM estimate exhibited significant inter-annual

657 variability, especially during 1980-2000 when extreme fire events were detected in 1982, 1987,

658 1991, 1994, and 1998. The occurrences of these extreme fires were associated with El Niño-

659 Southern Oscillation (ENSO) events, especially in Indonesia (e.g., 'Great Fire of Borneo' in

$6601982)^{66}$. Since 1997, $\mathrm{N}_{2} \mathrm{O}$ emissions from fires estimated by DLEM, GFED4s, and FAOSTAT

661 were consistent in the inter-annual variability. All the three estimates showed a decreasing trend,

662 agreeing well with satellite-observed decrease of global burned area ${ }^{64,65}$.

663 (c) Indirect emissions from anthropogenic $\mathbf{N}$ additions. Data were obtained from various

664 sources and considered $\mathrm{N}$ deposition on land and ocean (' $\mathrm{N}$ deposition on land' and ' $\mathrm{N}$

665 deposition on ocean'), as well as the $\mathrm{N}$ leaching and runoff from upstream ('Inland and coastal

666 waters'). The emission from 'N deposition on ocean' was provided by Suntharalingam et al. ${ }^{67}$,

667 while emission from ' $\mathrm{N}$ deposition on land' was the ensemble mean of an average of three

668 inventories: FAOSTAT/EDGAR v4.3.2, GAINS/EDGAR v4.3.2, and NMIP. FAOSTAT and

669 GAINS documented the sector 'Indirect agricultural $\mathrm{N}_{2} \mathrm{O}$ emissions' by separating estimates

670 from $\mathrm{N}$ leaching or $\mathrm{N}$ deposition, while EDGAR v4.3.2 did not. Here, we treated 'Indirect

671 agricultural $\mathrm{N}_{2} \mathrm{O}$ emissions' from EDGAR v4.3.2 as 'Inland and coastal waters' emissions for

672 data synthesis. Only EDGAR v4.3.2 provided an estimate of indirect emission from non-

673 agricultural sectors, while both FAOSTAT and GAINS, following the IPCC guidelines, provided

$674 \mathrm{NH}_{x} / \mathrm{NO}_{y}$ volatilization from agricultural sectors. Here, we sum FAOSTAT or GAINS with 
676 deposition induced soil emissions from both agricultural and non-agricultural sectors. The $\mathrm{N}_{2} \mathrm{O}$

677 emissions from 'Inland and coastal waters' consist of rivers, reservoirs, lakes, estuaries, and

678 coastal zone, which is the ensemble mean of an average of three inventories (EDGAR v4.3.2,

679 FAOSTAT, GAINS), and the mean of process-based models. The anthropogenic emission

680 estimated by Yao et al. ${ }^{36}$ considered annual $\mathrm{N}$ inputs and other environmental factors (i.e.,

681 climate, elevated $\mathrm{CO}_{2}$, and land cover change). For long-term average in rivers, reservoirs,

682 estuaries and lakes, we applied a mean of $56 \%$ (based on the ratio of anthropogenic to total $\mathrm{N}$

683 additions from land) to calculate anthropogenic emissions. Seagrass, mangrove, saltmarsh and

684 intertidal $\mathrm{N}_{2} \mathrm{O}$ emissions were undated from Murray et $\mathrm{al}^{68}$. Coastal waters with low disturbance

685 generally either have low $\mathrm{N}_{2} \mathrm{O}$ emissions or act as a sink for $\mathrm{N}_{2} \mathrm{O}^{69,70}$. Here, coastal zone

686 emissions were treated as anthropogenic emissions due to intensive human disturbances ${ }^{71}$.

$687 \quad \mathrm{~N}_{2} \mathrm{O}$ emissions following transport of anthropogenic $\mathrm{N}$ additions via atmosphere and water

688 bodies increased from $1.1(0.6-1.9) \mathrm{Tg} \mathrm{N} \mathrm{yr}^{-1}$ in the $1980 \mathrm{~s}$ to $1.3(0.7-2.2) \mathrm{Tg} \mathrm{N} \mathrm{yr}^{-1} \mathrm{during}$

689 2007-2016 (Table 1). The $\mathrm{N}_{2} \mathrm{O}$ emissions from inland and coastal waters increased at a rate of

$690 \quad 0.03 \pm 0.00 \mathrm{Tg} \mathrm{N} \mathrm{yr}^{-1}$ per decade $(\mathrm{P}<0.05)$. Such an increase was reported by all the three

691 inventories (FAOSTAT, GAINS, and EDGAR v4.3.2) with FAOSTAT giving the largest

692 estimate. In contrast, the DLEM-based estimate presented a divergent trend: first increasing from

693 1980-1998 and then slightly decreasing thereafter (Extended Data Fig. 6a). Emissions from

694 atmospheric $\mathrm{N}$ deposition on oceans were relatively constant with a value of $0.1(0.1-0.2) \mathrm{Tg} \mathrm{N}$

$695 \mathrm{yr}^{-1}$, while a large increase in emissions was found from atmospheric $\mathrm{N}$ deposition on land, with

$6960.06 \pm 0.01 \mathrm{Tg} \mathrm{N} \mathrm{yr}^{-1}$ per decade $(\mathrm{P}<0.05)$ reported in the three estimates $($ FAOSTAT/EDGAR

697 v4.3.2, GAINS/EDGAR v4.3.2, and NMIP). The FAOSTAT agricultural source, together with 
the EDGAR v4.3.2 industrial source, is consistent with NMIP estimates in the magnitude of $\mathrm{N}_{2} \mathrm{O}$

699 emissions, with the latter estimating a slightly slower increase from 2010 to 2016 (Extended

700 Data Fig. 6b).

701

702

703

704

705

706

707

708

709

710

711

712

713

714

715

716

717

718

719

720

(d) Perturbed fluxes from climate/ $\mathrm{CO}_{2} /$ land cover change. Perturbed $\mathrm{N}_{2} \mathrm{O}$ fluxes represent the sum of the effects of climate, elevated atmospheric $\mathrm{CO}_{2}$, and land cover change. The estimate of climate and $\mathrm{CO}_{2}$ effects on emissions was based on NMIP. The effect of land cover change on $\mathrm{N}_{2} \mathrm{O}$ dynamics includes the reduction due to 'Long-term effect of reduced mature forest area' and the emissions due to 'Post-deforestation pulse effect'. The two estimates were based on the book-keeping approach and the DLEM model simulation. The book-keeping method is developed by Houghton et al. ${ }^{72}$ for accounting for carbon flows due to land use. In this study, an observation dataset consisting of 18 tropical sites was collected to follow the book-keeping logic.

The dataset covers $\mathrm{N}_{2} \mathrm{O}$ emissions from a reference mature forest and their nearby converted pastures aged between one and 60 years. The average tropical forest $\mathrm{N}_{2} \mathrm{O}$ emission rate of 1.974 $\mathrm{kg} \mathrm{N}_{2} \mathrm{O}-\mathrm{N} \mathrm{ha}^{-1} \mathrm{yr}^{-1}$ was adopted as the baseline ${ }^{73}$. Two logarithmic response curves of soil $\mathrm{N}_{2} \mathrm{O}$ emissions (normalized to the baseline) after deforestation were developed: $y=-0.31 \ln (x)+$ $1.53\left(R^{2}=0.30\right)$ and $y=-0.454 \ln (x)+2.21\left(R^{2}=0.09\right)$. The first logarithmic function uses data collected by a review analysis ${ }^{74}$, based upon which the second one further considers observations from Verchot et al. ${ }^{21}$ and Keller and Reiners ${ }^{75}$. In the first function, $x$ (unit: year) indicates pasture age in years after deforestation and $y$ (unitless; $0-1$ ) indicates the ratio of pasture $\mathrm{N}_{2} \mathrm{O}$ emission over the $\mathrm{N}_{2} \mathrm{O}$ emission from the nearby reference mature forest. In the second function, $x$ (unit: year) indicates secondary forest age and $y$ (unitless; $0-1$ ) indicates the ratio of secondary forest $\mathrm{N}_{2} \mathrm{O}$ emission over that of a reference mature forest. This form of the response functions can effectively reproduce the short-lived increase in soil $\mathrm{N}_{2} \mathrm{O}$ emissions after 
721 initial forest clearing and the gradually declining emission rates of converted crops/pastures ${ }^{21,76}$.

722 Using these two curves and the baseline, we kept track of the $\mathrm{N}_{2} \mathrm{O}$ reduction of tropical forests

723 and the post-deforestation crop/pasture $\mathrm{N}_{2} \mathrm{O}$ emissions at an annual time-scale. This book-

724 keeping method was applied to the two deforestation area datasets (Supplementary Text 2.8), so

725 we could investigate not only the difference caused by the two sets of land use data but also the

726 difference between this empirical method and the process-based model. For land conversion

727 from natural vegetation to croplands or pastures, DLEM uses a similar strategy to Houghton et

728 al. ${ }^{72}$ and McGuire et al. ${ }^{77}$ to simulate its influences on carbon and $\mathrm{N}$ cycles. Moreover, through

729 using the sites of field observation from Davidson et al. ${ }^{20}$ and Keller and Reiners ${ }^{75}$, we estimated

$730 \mathrm{~N}_{2} \mathrm{O}$ emission from secondary tropical forests based on the algorithm: $y=0.0084 x+0.2401\left(R^{2}\right.$

$731=0.44) . x$ (unit: year) indicates secondary forest age and $y$ (unitless; $0-1$ ) indicates the ratio of

732 secondary forest $\mathrm{N}_{2} \mathrm{O}$ emission over that of a reference mature forest. The difference between

733 primary forests and secondary forests were subtracted from natural soil emissions simulated by

734 six terrestrial biosphere models in NMIP.

735 We calculated the ensemble of oceanic $\mathrm{N}_{2} \mathrm{O}$ emission based on the $\mathrm{BU}$ approach (five ocean

736 biogeochemical models; Supplementary Table 18) and the TD approach (five estimates from

737 four inversion models; Supplementary Table 19), respectively. The atmospheric burden and its

738 rate of change during 1980-2016 were derived from mean maritime surface mixing ratios of

$739 \mathrm{~N}_{2} \mathrm{O}$ (refs. ${ }^{78,79}$ ) with a conversion factor of $4.79 \mathrm{Tg} \mathrm{N} / \mathrm{ppb}$ (ref. ${ }^{80}$ ). Combining uncertainties in

740 measuring the mean surface mixing $\operatorname{ratios}^{78}$ and that of converting surface mixing ratios to a

741 global mean abundance ${ }^{80}$, we estimate a $\pm 1.4 \%$ uncertainty in the burden. Annual change in

742 atmospheric abundance is calculated from the combined NOAA and AGAGE record of surface

$743 \mathrm{~N}_{2} \mathrm{O}$ and uncertainty is taken from the IPCC AR5 (ref. ${ }^{2}$ ). There shows an agreement of the 
744 stratospheric loss from atmospheric chemistry transport models (TD modeled chemical sink ${ }^{18,81}$ )

745 and from satellite observations with a photolysis model (observed photochemical sink ${ }^{1}$ ), which

746 differ only by $\sim 1 \mathrm{Tg} \mathrm{N} \mathrm{yr}^{-1}$. The satellite-based lifetime, $116 \pm 9$ years, gives an overall

747 uncertainty in the annual loss of $\pm 8 \%$. The tropospheric loss of $\mathrm{N}_{2} \mathrm{O}$ from reaction with $\mathrm{O}\left({ }^{1} \mathrm{D}\right)$ is

748 included in observed atmospheric chemical sink (Table 1$)$ and is small ( $1 \%$ of the stratospheric

749 sink) with an estimated range of 0.1 to $0.2 \mathrm{Tg} \mathrm{N} \mathrm{yr}^{-1}$.

750 Comparison with the IPCC guidelines. The IPCC has provided guidance to quantify $\mathrm{N}_{2} \mathrm{O}$

751 emissions, which is widely used in emission inventories for reporting to the UNFCCC. Over time

752 the recommended approaches have changed, which is critical for estimating emissions from

753 agricultural soils, the largest emission source. Previous global $\mathrm{N}_{2} \mathrm{O}$ assessments ${ }^{52,82,83}$ based on

754 the IPCC 1996 guidelines ${ }^{84}$ attributed about $6.3{\mathrm{Tg} \mathrm{N} \mathrm{yr}^{-1}}^{-1}$ to the agricultural sector, including

755 both direct and indirect emissions. This estimate is significantly larger than our results (Fig. 1;

756 Table 1) derived from multiple methods, and is also larger than the most recent estimates from

757 global inventories (EDGAR v4.3.2, FAOSTAT, and GAINS) that are based on the IPCC 2006

758 guidelines ${ }^{14}$. The main reason is that indirect emissions from leaching and groundwater were

759 overestimated in previous studies ${ }^{85}$. Correspondingly, projections of atmospheric $\mathrm{N}_{2} \mathrm{O}$

760 concentrations based on these overestimated emissions ${ }^{82}$ led to biased estimates. For example,

761 Mosier and Kroeze ${ }^{82}$ expected atmospheric $\mathrm{N}_{2} \mathrm{O}$ concentrations to be $340-350 \mathrm{ppb}$ in the year

7622020 , instead of $333 \mathrm{ppb}^{5}$ as observed. Recently, the 2019 Refinement to the 2006 IPCC

763 Guidelines for National Greenhouse Gas Inventories has been published. It adopts the same

764 approach for $\mathrm{N}$ application on soils, but considers impacts of different climate regimes. The new

765 guidelines, based on a wealth of new scientific literature, proposed much smaller emissions from

766 grazing animals by a factor of 5-7. Preliminary calculations we have made indicate that global 
767 soil emissions based on these new guidelines may decrease by $20 \%-25 \%$. Integrating estimates 768 relying on the IPCC methodology with estimates by process-based models provides for a more

769 balanced assessment in this paper. We also added information from assessments ${ }^{86,87}$ that derived 770 agricultural emissions as the difference between atmospheric terms and other emissions like

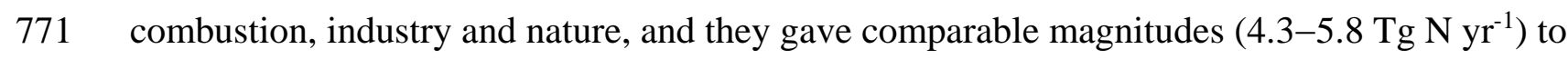
772 our bottom-up results.

773 Uncertainty. Current data analysis and synthesis of long-term $\mathrm{N}_{2} \mathrm{O}$ fluxes are based on a wide 774 variety of TD and BU methods. TD approaches, consisting of four inversion frameworks ${ }^{88-91}$, 775 provide a wide range of estimates largely due to systematic errors in the modelled atmospheric 776 transport and stratospheric loss of $\mathrm{N}_{2} \mathrm{O}$. In addition, the emissions from TD analyses are 777 dependent on the magnitude and distribution of the prior flux estimates to an extent that is 778 strongly determined by the number of atmospheric $\mathrm{N}_{2} \mathrm{O}$ measurements ${ }^{18}$. Inversions are 779 generally not well constrained (and thus rely heavily on a priori estimates) in Africa, Southeast 780 Asia, southern South America, and over the oceans, owing to the paucity of observations in these 781 regions. The improvement of atmospheric transport models, more accurate priors, and more 782 atmospheric $\mathrm{N}_{2} \mathrm{O}$ measurements would reduce uncertainty in further TD estimates, particularly 783 for ocean and regional emissions.

784 BU approaches are subject to uncertainties in various sources from land ${ }^{16}$ and oceans ${ }^{32}$. For 785 process-based models (e.g. NMIP and ocean biogeochemical models), the uncertainty is 786 associated with differences in model configuration as well as process parameterization ${ }^{16,32}$. The 787 uncertainty of estimates from NMIP could be reduced in multiple ways ${ }^{16}$. First, the six models in 788 NMIP exhibited different spatial and temporal patterns of $\mathrm{N}_{2} \mathrm{O}$ emissions even though they used 789 the same forcings. Although these models have considered essential biogeochemical processes in 
790 soils (e.g., biological $\mathrm{N}$ fixation, nitrification/denitrification, mineralization/immobilization,

791 etc. $)^{92}$, some missing processes such as freeze-thaw cycles and ecosystem disturbances should be

792 included in terrestrial biosphere models to reduce uncertainties. Second, the quality of input

793 datasets, specifically the amount and timing of $\mathrm{N}$ application, and spatial and temporal changes

794 in distribution of natural vegetation and agricultural land, is critical for accurately simulating soil

$795 \mathrm{~N}_{2} \mathrm{O}$ emissions. Third, national and global $\mathrm{N}_{2} \mathrm{O}$ flux measurement networks ${ }^{17}$ could be used to

796 validate model performance and constrain large-scale model simulations. Data assimilation

797 techniques could be utilized to improve model accuracy.

798 Current remaining uncertainty in global ocean model estimates of $\mathrm{N}_{2} \mathrm{O}$ emission includes the 799 contribution of $\mathrm{N}_{2} \mathrm{O}$ flux derived from the tropical oceanic low oxygen zones (e.g., the Eastern

800 Equatorial Pacific, the northern Indian ocean) relative to the global ocean. These low oxygen

801 zones are predominantly influenced by high yield $\mathrm{N}_{2} \mathrm{O}$ formation processes (e.g., denitrification

802 and enhanced nitrification). Regional observation-based assessments have also suggested that

803 these regions may produce more $\mathrm{N}_{2} \mathrm{O}$ than is simulated by the models ${ }^{32}$. The current generation

804 of global ocean biogeochemistry models are not sufficiently accurate to represent the high $\mathrm{N}_{2} \mathrm{O}$

805 production processes in low-oxygen zones, and their associated variability (see refs. ${ }^{34,93,94}$ for

806 more detail). Thus, precisely representing the local ocean circulation and associated

807 biogeochemical fluxes of these regions could further reduce the uncertainty in estimates of 808 global and regional oceanic $\mathrm{N}_{2} \mathrm{O}$ emissions.

809 Regardless of the tier approach used, GHG inventories for agriculture suffer from high

810 uncertainty in the underlying agriculture and rural data and statistics used as input, including

811 statistics on fertilizer use, livestock manure availability, storage and applications, and nutrient,

812 crop and soils management. For instance, animal waste management is an uncertain aspect, since 
813 much of the manure is either not used, or employed as a fuel or building material, or may be

814 discharged directly to surface water ${ }^{95,96}$, with important repercussions for the calculated

815 emissions. Furthermore, GHG inventories using default EFs show large uncertainties at local to

816 global scales, especially for agricultural $\mathrm{N}_{2} \mathrm{O}$ emissions, due to the poorly captured dependence

817 of EFs on spatial diversity in climate, management, and soil physical and biochemical

818 conditions $^{2,22}$. It is well known, for example from the IPCC guidelines, that higher-tier GHG

819 inventories may provide more reasonable estimates by using the alternative EFs that are

820 disaggregated by environmental factors and management-related factors ${ }^{97}$. A large range of EFs

821 have been used to estimate aquaculture $\mathrm{N}_{2} \mathrm{O}$ emissions ${ }^{31,39,62,86}$ and long-term estimates of $\mathrm{N}$

822 flows in freshwater and marine aquaculture are scarce ${ }^{30}$. Uncertainty also remains in several $\mathrm{N}_{2} \mathrm{O}$

823 sources that have not yet been fully understood or quantified. To date, robust estimates of $\mathrm{N}_{2} \mathrm{O}$

824 emissions from global peatland degradation are still lacking, although we have accounted for

$825 \mathrm{~N}_{2} \mathrm{O}$ emissions due to the drainage of organic soils (histosols) obtained from FAOSTAT and

826 GAINS databases ${ }^{28,43}$. Recent evidence shows that permafrost thawing ${ }^{98}$ and the freeze-thaw

827 cycle ${ }^{99}$ contribute to increasing $\mathrm{N}_{2} \mathrm{O}$ emissions, which, however, have not been well established

828 in the current estimates of the global $\mathrm{N}_{2} \mathrm{O}$ budget.

829 Statistics. Through using the Mann-Kendall test in R-3.4.4, we checked the significance of

830 trends in annual $\mathrm{N}_{2} \mathrm{O}$ emissions from each sub-sector based on the BU approach.

831

832

$83350 \quad$ Nevison, C. D., Lueker, T. J. \& Weiss, R. F. Quantifying the nitrous oxide source from $834 \quad$ coastal upwelling. Global Biogeochemical Cycles 18, GB1018 (2004).

$83551 \quad$ Lauerwald, R. et al. Natural lakes are a minor global source of $\mathrm{N}_{2} \mathrm{O}$ to the atmosphere.

$836 \quad$ Global Biogeochemical Cycles 33, 1564-1581 (2019).

$83752 \quad$ Kroeze, C., Mosier, A. \& Bouwman, L. Closing the global $\mathrm{N}_{2} \mathrm{O}$ budget: a retrospective 838 analysis 1500-1994. Global Biogeochemical Cycles 13, 1-8 (1999). 
53 Schumann, U. \& Huntrieser, H. The global lightning-induced nitrogen oxides source. Atmospheric Chemistry and Physics 7, 3823-3907 (2007).

54 De Klein, C. et al. $\mathrm{N}_{2} \mathrm{O}$ emissions from managed soils, and $\mathrm{CO}_{2}$ emissions from lime and urea application. IPCC Guidelines for National Greenhouse Gas Inventories, Prepared by the National Greenhouse Gas Inventories Programme 4, 1-54 (2006).

55 Dentener, F. J. \& Crutzen, P. J. A three-dimensional model of the global ammonia cycle. Journal of Atmospheric Chemistry 19, 331-369 (1994).

56 Röckmann, T., Kaiser, J., Crowley, J. N., Brenninkmeijer, C. A. \& Crutzen, P. J. The origin of the anomalous or "mass-independent" oxygen isotope fractionation in tropospheric $\mathrm{N}_{2} \mathrm{O}$. Geophysical Research Letters 28, 503-506 (2001).

57 Kaiser, J. \& Röckmann, T. Absence of isotope exchange in the reaction of $\mathrm{N}_{2} \mathrm{O}+\mathrm{O}\left({ }^{1} \mathrm{D}\right)$ and the global $\Delta^{17} \mathrm{O}$ budget of nitrous oxide. Geophysical Research Letters 32 (2005).

58 Schlesinger, W. H. An estimate of the global sink for nitrous oxide in soils. Global Change Biology 19, 2929-2931 (2013).

59 Syakila, A., Kroeze, C. \& Slomp, C. P. Neglecting sinks for $\mathrm{N}_{2} \mathrm{O}$ at the earth's surface: does it matter? Journal of Integrative Environmental Sciences 7, 79-87 (2010).

60 Bouwman, A. F. et al. Hindcasts and future projections of global inland and coastal nitrogen and phosphorus loads due to finfish aquaculture. Reviews in Fisheries Science 21, 112-156 (2013).

61 Bouwman, A. F. et al. Global hindcasts and future projections of coastal nitrogen and phosphorus loads due to shellfish and seaweed aquaculture. Reviews in Fisheries Science 19, 331-357 (2011).

62 Hu, Z., Lee, J. W., Chandran, K., Kim, S. \& Khanal, S. K. Nitrous oxide $\left(\mathrm{N}_{2} \mathrm{O}\right)$ emission from aquaculture: a review. Environmental science technology 46, 6470-6480 (2012).

63 Williams, J. \& Crutzen, P. J. Nitrous oxide from aquaculture. Nature Geoscience 3, 143 (2010).

64 Andela, N. et al. A human-driven decline in global burned area. Science 356, 1356-1362 (2017).

65 Yang, J. et al. Spatial and temporal patterns of global burned area in response to anthropogenic and environmental factors: Reconstructing global fire history for the 20th and early 21st centuries. Journal of Geophysical Research: Biogeosciences 119, 249-263 (2014).

66 Dennis, R. A review of fire projects in Indonesia (1982-1998). Cifor (1999).

67 Suntharalingam, P. et al. Quantifying the impact of anthropogenic nitrogen deposition on oceanic nitrous oxide. Geophysical Research Letters 39, L07605 (2012).

68 Murray, R. H., Erler, D. V. \& Eyre, B. D. Nitrous oxide fluxes in estuarine environments: response to global change. Global Change Biology 21, 3219-3245 (2015).

69 Erler, D. V. et al. Applying cavity ring - down spectroscopy for the measurement of dissolved nitrous oxide concentrations and bulk nitrogen isotopic composition in aquatic systems: Correcting for interferences and field application. Limnology and Oceanography: Methods 13, 391-401 (2015).

70 Murray, R., Erler, D., Rosentreter, J. \& Eyre, B. Seasonal and spatial $\mathrm{N}_{2} \mathrm{O}$ concentrations and emissions in three tropical estuaries. Marine Chemistry 221, 103779 (2020).

71 Vernberg, F. J. \& Vernberg, W. B. The coastal zone: past, present, and future. Univ of South Carolina Press (2001). 
72 Houghton, R. et al. Changes in the Carbon Content of Terrestrial Biota and Soils between 1860 and 1980: A Net Release of $\mathrm{CO}_{2}$ to the Atmosphere. Ecological monographs 53, 235-262 (1983).

73 Davidson, E. A. The contribution of manure and fertilizer nitrogen to atmospheric nitrous oxide since 1860. Nature Geoscience 2, 659-662 (2009).

74 van Lent, J., Hergoualc'h, K. \& Verchot, L. V. Reviews and syntheses: Soil $\mathrm{N}_{2} \mathrm{O}$ and NO emissions from land use and land-use change in the tropics and subtropics: a metaanalysis. Biogeosciences 12, 7299-7313 (2015).

75 Keller, M. \& Reiners, W. A. Soil-atmosphere exchange of nitrous oxide, nitric oxide, and methane under secondary succession of pasture to forest in the Atlantic lowlands of Costa Rica. Global Biogeochemical Cycles 8, 399-409 (1994).

76 Melillo, J. M. et al. Nitrous oxide emissions from forests and pastures of various ages in the Brazilian Amazon. Journal of Geophysical Research: Atmospheres 106, 34179-34188 (2001).

77 McGuire, A. et al. Carbon balance of the terrestrial biosphere in the twentieth century: Analyses of $\mathrm{CO}_{2}$, climate and land use effects with four process-based ecosystem models. Global Biogeochemical Cycles 15, 183-206 (2001).

78 Dlugokencky, E., Steele, L., Lang, P. \& Masarie, K. The growth rate and distribution of atmospheric methane. Journal of Geophysical Research: Atmospheres 99, 17021-17043 (1994).

79 Prather, M. et al. Annex II: Climate system scenario tables. Cambridge, United Kingdom and New York, NY, USA (2013).

80 Prather, M. J., Holmes, C. D. \& Hsu, J. Reactive greenhouse gas scenarios: Systematic exploration of uncertainties and the role of atmospheric chemistry. Geophysical Research Letters 39, L09803 (2012).

81 Prather, M. J. \& Hsu, J. Coupling of Nitrous Oxide and Methane by Global Atmospheric Chemistry. Science 330, 952-954 (2010).

82 Mosier, A. \& Kroeze, C. Potential impact on the global atmospheric $\mathrm{N}_{2} \mathrm{O}$ budget of the increased nitrogen input required to meet future global food demands. ChemosphereGlobal Change Science 2, 465-473 (2000).

83 Mosier, A. et al. Closing the global $\mathrm{N}_{2} \mathrm{O}$ budget: nitrous oxide emissions through the agricultural nitrogen cycle. Nutrient cycling in Agroecosystems 52, 225-248 (1998).

84 IPCC. Revised 1996 IPCC guidelines for national greenhouse gas inventories. Hayama, Japan (1997).

85 Nevison, C. in IPCC, Background Papers: IPCC Expert Meetings on Good Practice Guidance and Uncertainty Management in National Greenhouse Gas Inventories. IPCC National Greenhouse Gas Inventories Programme, Technical Support Unit. 381-397 (2000).

86 Crutzen, P. J., Mosier, A. R., Smith, K. A. \& Winiwarter, W. $\mathrm{N}_{2} \mathrm{O}$ release from agrobiofuel production negates global warming reduction by replacing fossil fuels. Atmospheric Chemistry and Physics 8, 389-395 (2008).

87 Smith, K. A., Mosier, A. R., Crutzen, P. J. \& Winiwarter, W. The role of $\mathrm{N}_{2} \mathrm{O}$ derived from crop-based biofuels, and from agriculture in general, in Earth's climate. Philosophical Transactions of the Royal Society of London B: Biological Sciences 367, 1169-1174 (2012). 
92988 Thompson, R. L. et al. Nitrous oxide emissions 1999 to 2009 from a global atmospheric inversion. Atmospheric Chemistry and Physics 14, 1801-1817 (2014).

89 Wells, K. C. et al. Simulation of atmospheric $\mathrm{N}_{2} \mathrm{O}$ with GEOS-Chem and its adjoint: evaluation of observational constraints. Geoscience Model Development 8, 3179-3198 (2015).

90 Wilson, C., Chipperfield, M., Gloor, M. \& Chevallier, F. Development of a variational flux inversion system (INVICAT v1.0) using the TOMCAT chemical transport model. Geoscientific Model Development 7, 2485-2500 (2014).

91 Patra, P. K. et al. Improved Chemical Tracer Simulation by MIROC4. 0-based Atmospheric Chemistry-Transport Model (MIROC4-ACTM). Sola 14, 91-96 (2018).

92 Tian, H. Q. et al. The Global $\mathrm{N}_{2} \mathrm{O}$ Model Intercomparison Project. Bulletin of the American Meteorological Society 99, 1231-1252 (2018).

93 Suntharalingam, P. et al. Anthropogenic nitrogen inputs and impacts on oceanic $\mathrm{N}_{2} \mathrm{O}$ fluxes in the northern Indian Ocean: The need for an integrated observation and modelling approach. Deep Sea Research Part II: Topical Studies in Oceanography 166, 104-113 (2019).

94 Battaglia, G. \& Joos, F. Marine $\mathrm{N}_{2} \mathrm{O}$ Emissions From Nitrification and Denitrification Constrained by Modern Observations and Projected in Multimillennial Global Warming Simulations. Global Biogeochemical Cycles 32, 92-121 (2018).

95 Galloway, J. et al. The impact of animal production systems on the nitrogen cycle. Vol. 1, Island Press (2010).

96 Steinfeld, H., Mooney, H. A., Schneider, F. \& Neville, L. E. Livestock in a changing landscape, volume 1: drivers, consequences, and responses. Vol. 1, Island Press (2013).

97 IPCC. 2019 Refinement to the 2006 IPCC Guidelines for National Greenhouse Gas Inventories. Hayama, Japan (2019).

98 Elberling, B., Christiansen, H. H. \& Hansen, B. U. High nitrous oxide production from thawing permafrost. Nature Geoscience 3, 332-335 (2010).

99 Wagner-Riddle, C. et al. Globally important nitrous oxide emissions from croplands induced by freeze-thaw cycles. Nature Geoscience 10, 279-283 (2017).

100 Suntharalingam, P. et al. Estimates of Oceanic Nitrous-oxide Emissions from Global Biogeochemistry Models. American Geophysical Union, Fall Meeting 2018 (2018).

101 Janssens-Maenhout, G. et al. EDGAR v4.3.2 Global Atlas of the three major greenhouse gas emissions for the period 1970-2012. Earth System Science Data 11, 959-1002 (2019).

102 Tubiello, F. et al. Estimating greenhouse gas emissions in agriculture: a manual to address data requirements for developing countries. FAO, Rome (2015).

103 Van Der Werf, G. R. et al. Global fire emissions estimates during 1997-2016. Earth System Science Data 9, 697-720 (2017).

104 Dentener, F. Global maps of atmospheric nitrogen deposition, 1860, 1993, and 2050. Data set. Available on-line ( http://daac. ornl. gov/) from Oak Ridge National Laboratory Distributed Active Archive Center, Oak Ridge, TN, USA (2006).

105 Riahi, K. et al. The Shared Socioeconomic Pathways and their energy, land use, and greenhouse gas emissions implications: An overview. Global Environmental Change 42, 153-168 (2017).

\section{Data availability}


The relevant datasets of this study are archived in the box site of International Center for Climate and Global Change Research at Auburn University (https://auburn.box.com/). Source data for Figs. 1-4, Table 1, Extended Figs. 1-10 and Supplementary Information are provided with the paper. Additional description on data availability for atmospheric $\mathrm{N}_{2} \mathrm{O}$ observations from NOAA, AGAGE and CSIRO networks is provided in the Supplementary Information. The data presented here are made available in the belief that their dissemination will lead to greater understanding and new scientific insights on the global and regional $\mathrm{N}_{2} \mathrm{O}$ budgets and changes to it, and helping to reduce the uncertainties. As data are the result of initial processing to fit to the purpose of this publication, typically a wealth of underlying information is with the original data providers. Researchers interested to use results made available in the repository are encouraged, as good practice, to take advantage of underlying information by contacting the original data providers. If such a contact develops into a more intensive scientific discussion, further involvement including co-authorship should be considered.

\section{Code availability}

990 The relevant codes of this study are archived in the box site of International Center for Climate and Global Change Research at Auburn University (https://auburn.box.com/).

\section{Acknowledgements}

This paper is the result of a collaborative international effort under the umbrella of the Global Carbon Project (a project of Future Earth and a research partner of the World Climate Research Programme) and International Nitrogen Initiative. This research was made possible partly by Andrew Carnegie Fellowship Award no. G-F-19-56910; NSF grant nos. 1903722,1243232 and 1922687; NASA grant nos. NNX14AO73G, NNX10AU06G, NNX11AD47G and NNX14AF93G; NOAA grant nos. NA16NOS4780207 and NA16NOS4780204; National Key R \& D Program of China (grant nos. 2017YFA0604702 and 2018YFA0606001), National Natural Science Foundation of China (Grant no. 41961124006), CAS grants (KFJ-STSZDTP-0; SKLURE2017-1-6), and OUC-AU Joint Center Program. Additional funding support includes: E.T.B, P.R., G.P.P., R.L.T., P.S. acknowledge funding support from VERIFY project (EC H2020 grant no. 776810). P.S. also acknowledges funding from the EC H2020 grant No 641816 (CRESCENDO); A.I. acknowledges funding support from JSPS KAKENHI grant (no. 17H01867). G.B., F.J, and S.L. acknowledge support by Swiss National Science Foundation (\#200020_172476) and by the EC H2020 grant no. 821003 (Project 4C) and no. 820989 (Project COMFORT). A.L. acknowledges support by DFG project SFB754/3. S.Z. acknowledges support by the EC H2020 grant no. 647204. K.C.W. and D.B.M. acknowledge support from NASA (IDS Grant \#NNX17AK18G) and NOAA (Grant \#NA13OAR4310086); P.A.R. acknowledges NASA Award NNX17AI74G, M.M. acknowledges support from the Scottish Government's Rural and Environment Science and Analytical Services Division (RESAS) Environmental Change Programme (2016-2021); B.E. acknowledges the support from ARC Linkage Grants LP150100519 and LP190100271; M.P. acknowledges US Department of Energy, DESC0012536; Lawrence Livermore National Laboratory, B628407 and NASA MAP program, NNX13AL12G; S.B. was supported by the EC H2020 with the CRESCENDO project (grant no. 641816) and by the COMFORT project (grant no. 820989). S.B. also acknowledges the support of the team in charge of the CNRM-CM climate model; F.Z. acknowledges the support from the 
National Natural Science Foundation of China (41671464). Supercomputing time was provided by the Météo-France/DSI supercomputing center. P.K.P. is partly supported by Environment Research and Technology Development Fund (\#2-1802) of the Ministry of the Environment, Japan. R.L. acknowledges support from the French state aid managed by the ANR under the "Investissements d'avenir" programme with the reference ANR-16-CONV-0003. NOAA groundbased observations of atmospheric $\mathrm{N}_{2} \mathrm{O}$ are supported by NOAA's Climate Program Office under the Atmospheric Chemistry Carbon Cycle and Climate (AC4) theme. The AGAGE stations measuring $\mathrm{N}_{2} \mathrm{O}$ are supported by NASA (USA) grants NNX16AC98G to MIT, and NNX16AC97G and NNX16AC96G to SIO, and by BEIS (UK) for Mace Head, NOAA (USA) for Barbados, and CSIRO and BoM (Australia) for Cape Grim. We also thank Dr. Steve Frolking and two anonymous reviewers for constructive comments and suggestions that have helped improve this paper. The statements made and views expressed are solely the responsibility of the authors.

\section{Author contributions}

1035

Author contributions. H.T., R.L.T., J.G.C. and R.B.J. designed and coordinated the study. H.T.,

1036

1037 R.X., J.G.C., R.L.T., W.W., P.S., E.A.D., P.C., R.B.J., G.J.M., M.J.P., N.P., S.P., P.R., H.S., F.N.T., S.Z., F.Z., B.F. and G.P. conducted data analysis, synthesis and wrote the paper. R.L.T. led atmospheric inversions teaming with M.P.C., T.M., D.B.M., P.K.P., K.C.W., and C.W.; H.T. led land biosphere modeling teaming with P.C., H.S., S.Z., A.A., F.J., J.C., S.R.S.D., A.I., W.L., S.L., S.O., N.V., E.A.D., S.D. and W. Li; P.S. led ocean biogeochemical modeling teaming with G.B., L.B., S.B., E.T.B., F.J. and A.L.; P.R. led inland water and coastal modeling and synthesis teaming with B.D.E., G.G.L., R.L., T.M., P.A.R., H.T. and Y.Y.; A.F.B., J.W., M.M. provided data of $\mathrm{N}_{2} \mathrm{O}$ flux in aquaculture. G.R.W. and J.Y. provided data of $\mathrm{N}_{2} \mathrm{O}$ emissions from biomass burning. F.Z. provided cropland $\mathrm{N}_{2} \mathrm{O}$ flux data from a statistical model and field observations. G.J.M., F.N.T. and W.W. provided $\mathrm{N}_{2} \mathrm{O}$ inventory data. M.J.P. and D.J.R. provided data of stratospheric and tropospheric sinks. G.P.P. provided RCP and SSP scenarios data and analysis. B.H., E.D. and J.E. provided a global $\mathrm{N}_{2} \mathrm{O}$ monitoring dataset of NOAA/ESRL GMD. R.P. and R.W. provided a global $\mathrm{N}_{2} \mathrm{O}$ monitoring dataset of AGAGE stations. P.K. provided a global $\mathrm{N}_{2} \mathrm{O}$ monitoring dataset of CSIRO. All coauthors reviewed and commented on the manuscript.

\section{Competing interests: The authors declare no competing interests.}

\section{Additional information}

\section{Supplementary information is available for this paper at https://}

\section{Correspondence and requests for materials should be addressed to H.T.}

tianhan@auburn.edu 


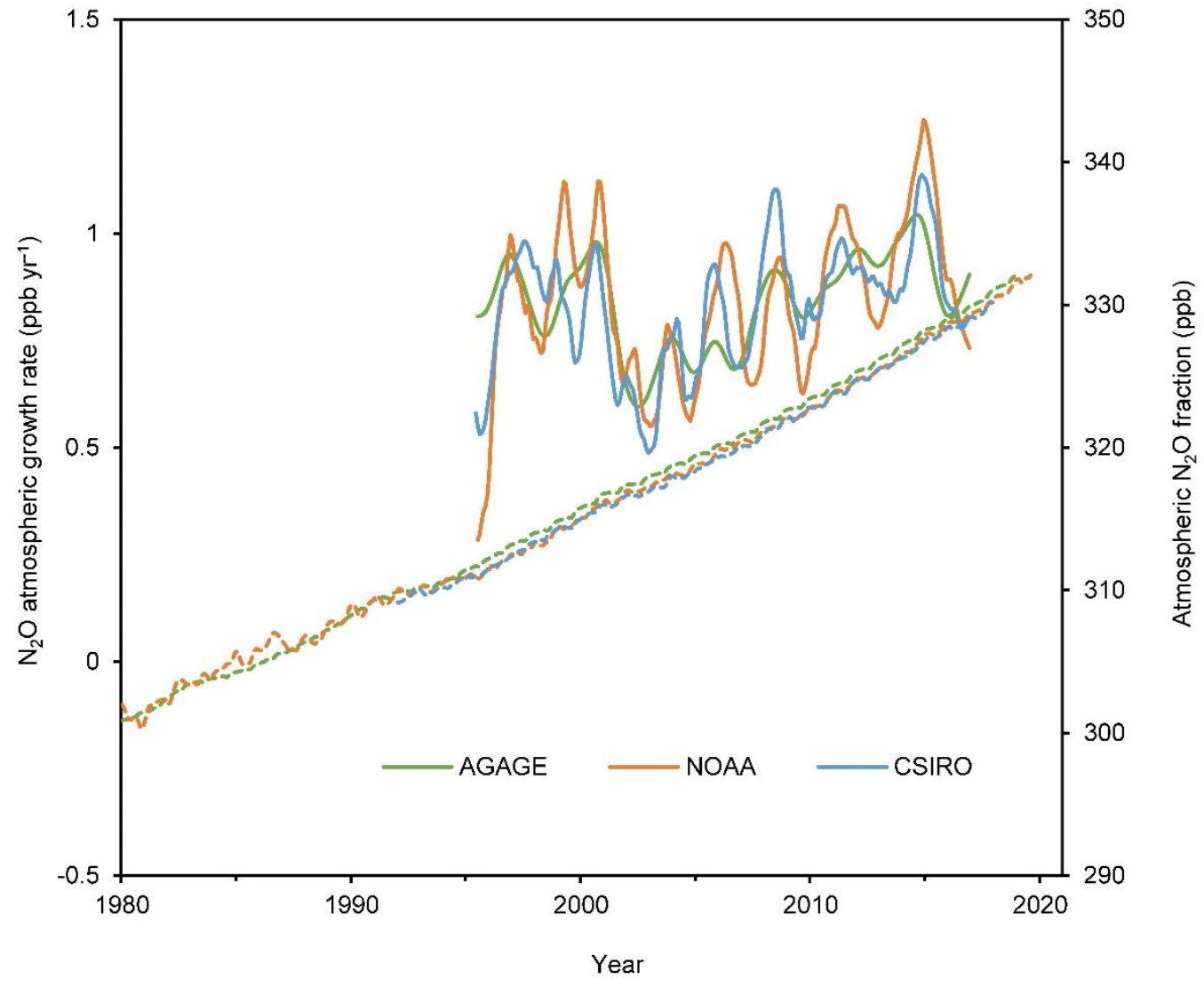

1058

1059 Extended Data Fig. 1 Global mean growth rates and atmospheric concentration of $\mathrm{N}_{2} \mathrm{O}$.

1060 Global mean growth rates (solid lines, during 1995-2017) and atmospheric $\mathrm{N}_{2} \mathrm{O}$ concentration 1061 (dashed lines, during 1980-2017) are from the $\mathrm{AGAGE}^{6}$ (green), $\mathrm{NOAA}^{5}$ (orange), and CSIRO 1062 (blue) networks. Global mean growth rates were calculated with annual time steps and are shown 1063 as 12-month moving averages. Growth rates are not calculated prior to 1995 due to insufficient 1064 data and higher uncertainties on the measurements. 


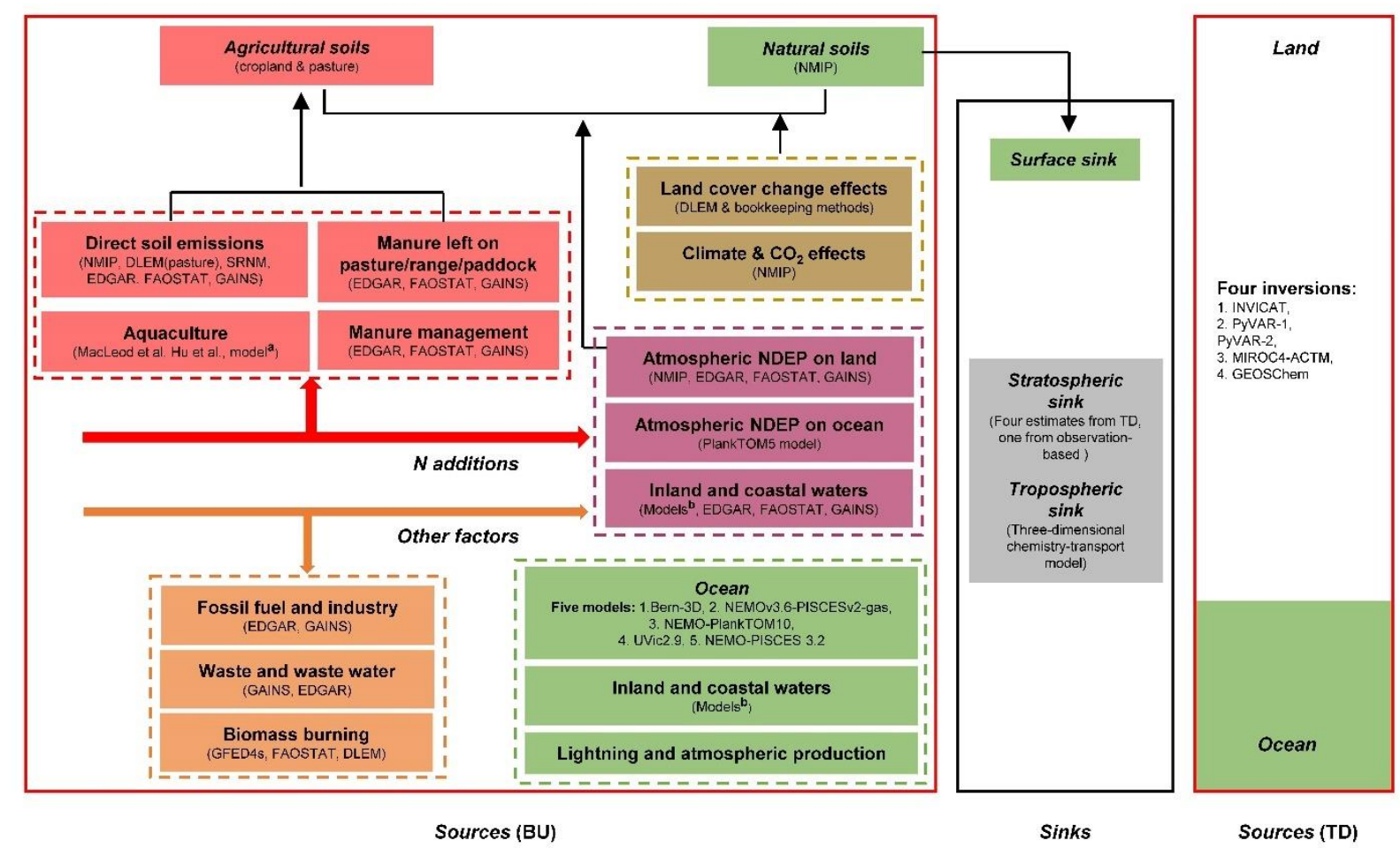

Extended Data Fig. 2 The methodology for data synthesis of global $\mathrm{N}_{2} \mathrm{O}$ budget. BU and TD represent bottom-up and top-down methods, respectively. The color codes are the same as that used in Table 1 and Figs. 1-3. We utilize both approaches, including $22 \mathrm{BU}$ and five TD estimates of $\mathrm{N}_{2} \mathrm{O}$ fluxes from land and oceans. For sources estimated by BU, we include six process-based terrestrial biosphere modeling studies ${ }^{16}$; five process-based ocean biogeochemical models ${ }^{100}$; one nutrient budget model ${ }^{30,60,61}$; five inland water modeling studies ${ }^{35,36,50,51,68}$; one statistical model SRNM based on spatial extrapolation of field measurements ${ }^{17}$; and four GHG inventories: EDGAR v4.3.2 ${ }^{101}$, FAOSTAT ${ }^{102}$, GAINS ${ }^{43}$, and GFED4s ${ }^{103}$. In addition, previous literatures regarding estimates of 'Surface sink' ${ }^{58,73}$, 'Lightning' 53,54 , 'Atmospheric production, ${ }^{\text {56,57,104, 'Aquaculture, }}{ }^{31,62}$, and model-based 'Tropospheric sink' ${ }^{81}$ and observed 'Stratospheric sink' ${ }^{1}$ are included in the current synthesis. ${ }^{a}$ MacLeod et al. ${ }^{31}$ and Hu et al. ${ }^{62}$ provide global aquaculture $\mathrm{N}_{2} \mathrm{O}$ emissions in 2013 and in 2009, respectively; and the nutrient budget model ${ }^{30,60,61}$ provides $\mathrm{N}$ flows in global freshwater and marine aquaculture over the period 1980-2016. 'Model-based estimates of $\mathrm{N}_{2} \mathrm{O}$ emissions from 'Inland and coastal waters' include rivers and reservoirs ${ }^{35,36}$, lakes ${ }^{51}$, estuaries ${ }^{35}$, coastal zones (i.e., seagrasses, mangroves, saltmarsh and intertidal saltmarsh $)^{68}$, and coastal upwelling ${ }^{50}$. 

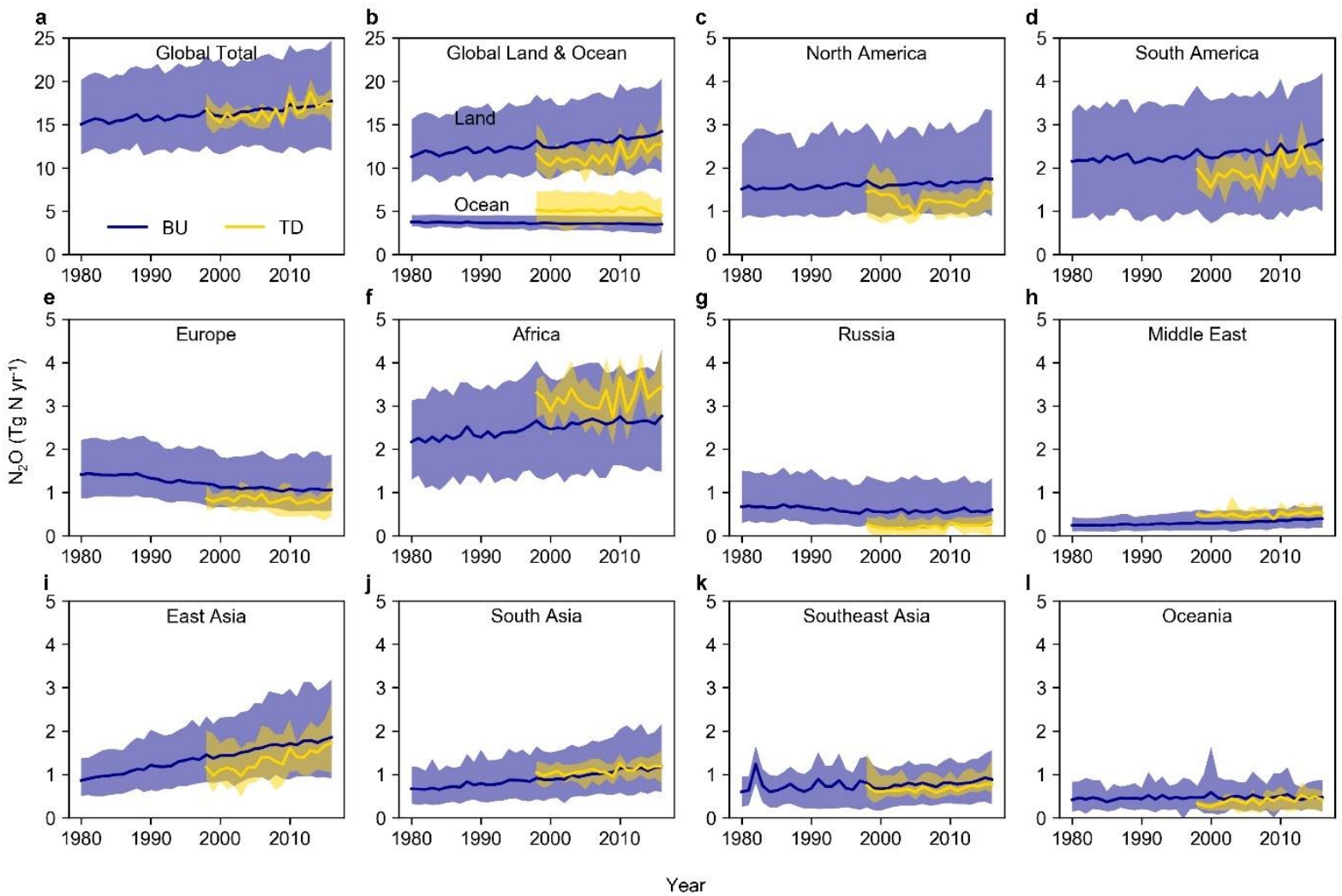

\section{Extended Data Fig. 3 Comparison of annual total $\mathrm{N}_{2} \mathrm{O}$ emissions at global and regional} scales estimated by $\mathrm{BU}$ and TD approaches. The blue lines represent the mean $\mathrm{N}_{2} \mathrm{O}$ emission from BU methods and the shaded areas show minimum and maximum estimates; The gold lines represent the mean $\mathrm{N}_{2} \mathrm{O}$ emission from TD methods and the shaded areas show minimum and maximum estimates. 

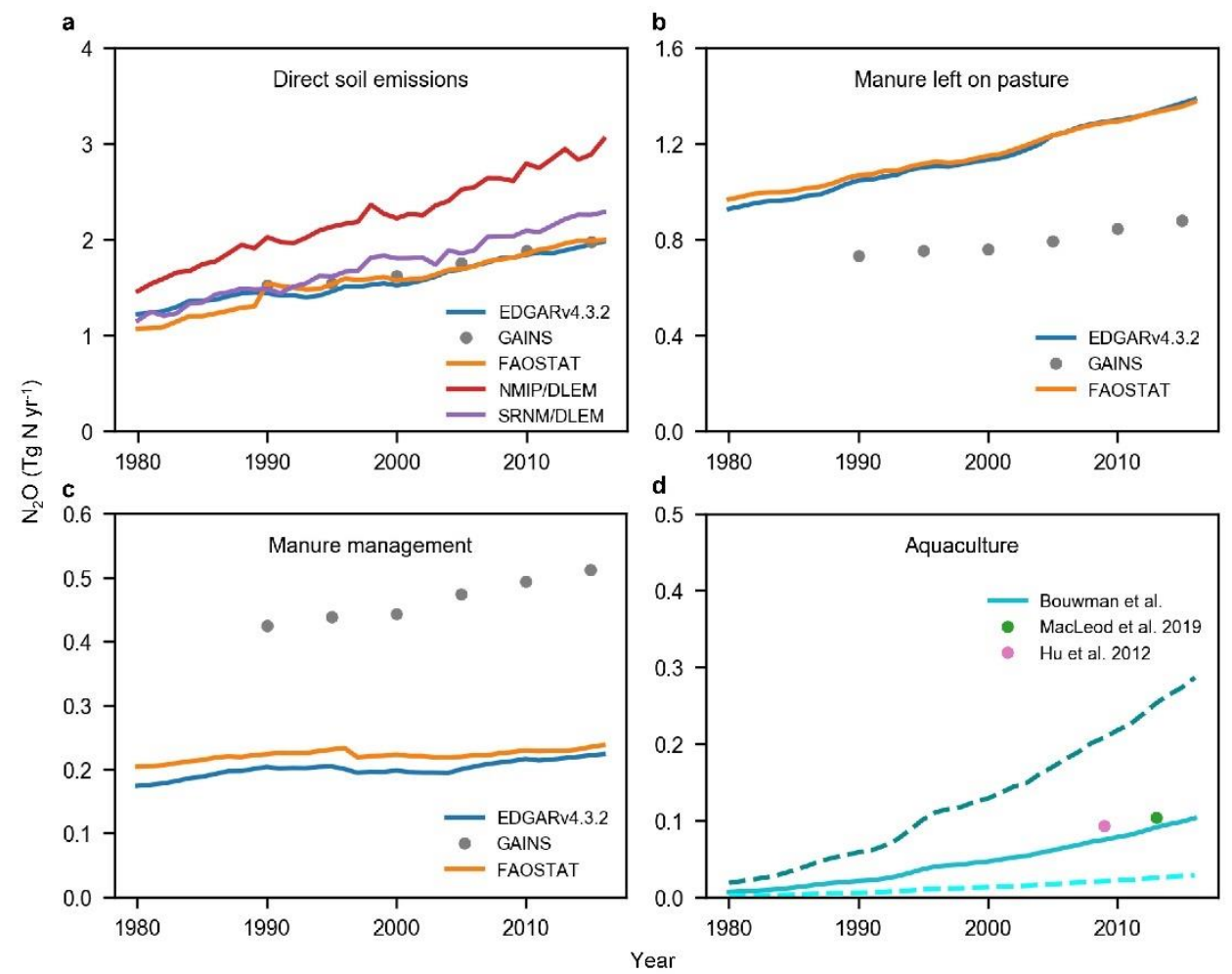

1092

1093

1094

1095

1096

1097

1098

1099

1100

1101

1102

1103

1104

1105

Extended Data Fig. 4 Global agricultural $\mathrm{N}_{2} \mathrm{O}$ emissions. a, Direct emission from agricultural soils associated with mineral fertilizer, manure and crop residue inputs, and cultivation of organic soils based on EDGAR v4.3.2, GAINS, FAOSTAT, NMIP/DLEM, and SRNM/DLEM estimates. NMIP/DLEM or SRNM/DLEM means the combination of $\mathrm{N}_{2} \mathrm{O}$ emission by NMIP or SRNM from croplands with $\mathrm{N}_{2} \mathrm{O}$ emission from intensively managed grassland (pasture) by DLEM. b, Direct emission from the global total area under permanent meadows and pasture, due to manure $\mathrm{N}$ deposition (left on pasture) based on EDGAR v4.3.2, FAOSTAT, and GAINS estimates. c, Emission from manure management based on FAOSTAT, GAINS, and EDGAR v4.3.2. d, Aquaculture $\mathrm{N}_{2} \mathrm{O}$ emission based on a nutrient budget model ${ }^{30}$, MacLeod et al. ${ }^{31}$, and $\mathrm{Hu}$ et al. ${ }^{62}$; the solid line represents the 'best estimate' that is the product of EF $(1.8 \%)$ and $\mathrm{N}$ waste from aquaculture provided by the nutrient budget model; the dashed lines represent the minimum and maximum values. 

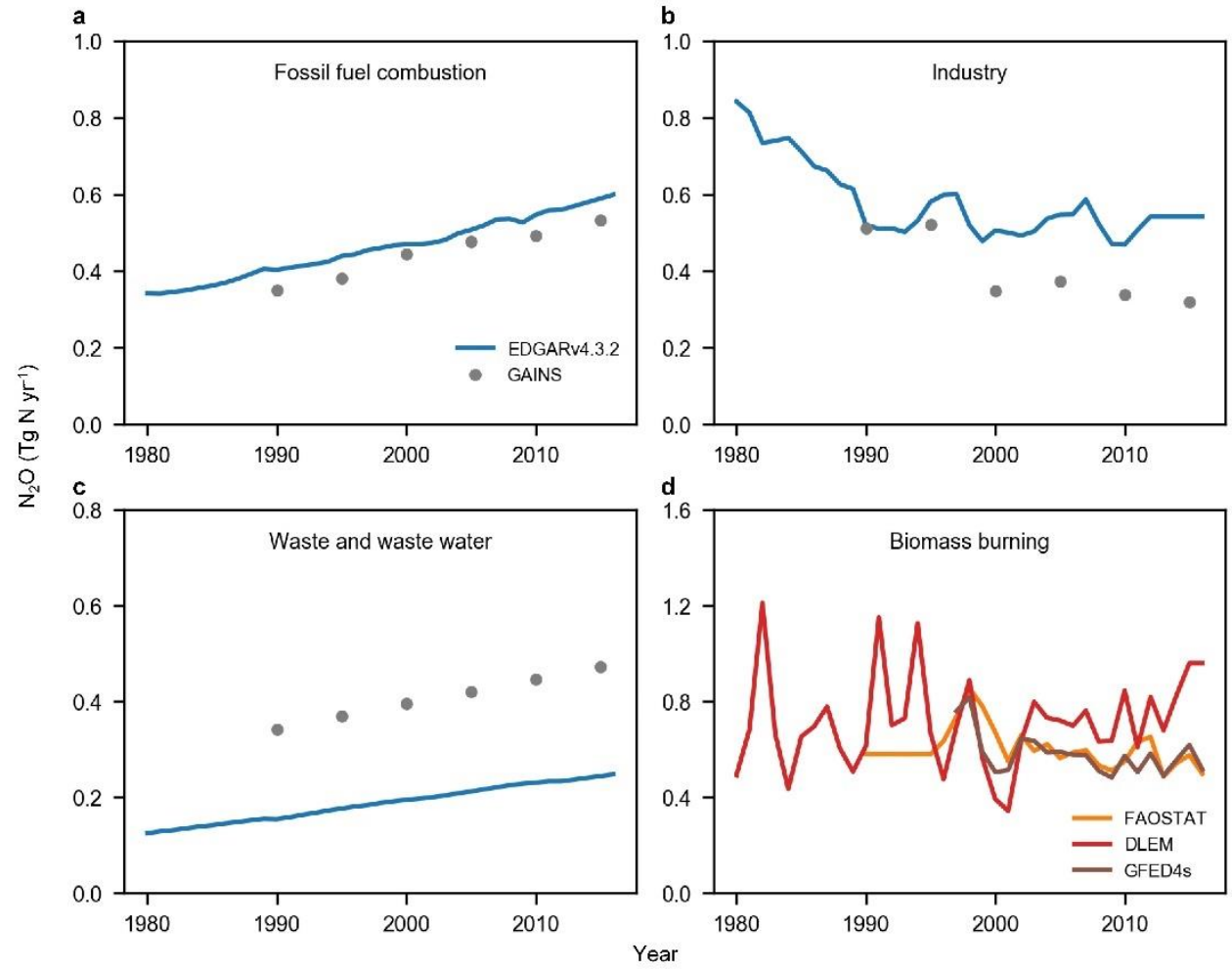

1106

Extended Data Fig. 5 Global $\mathrm{N}_{2} \mathrm{O}$ emission from other direct anthropogenic sources. a, Emission from fossil fuel combustion based on EDGAR v4.3.2 and GAINS estimates. b, Emission from industry based on EDGAR v4.3.2 and GAINS estimates. c, Emission from waste and waste water based on EDGAR v4.3.2 and GAINS estimates. d, Emission from biomass burning based on FAOSTAT, DLEM, and GFED4s estimates. 

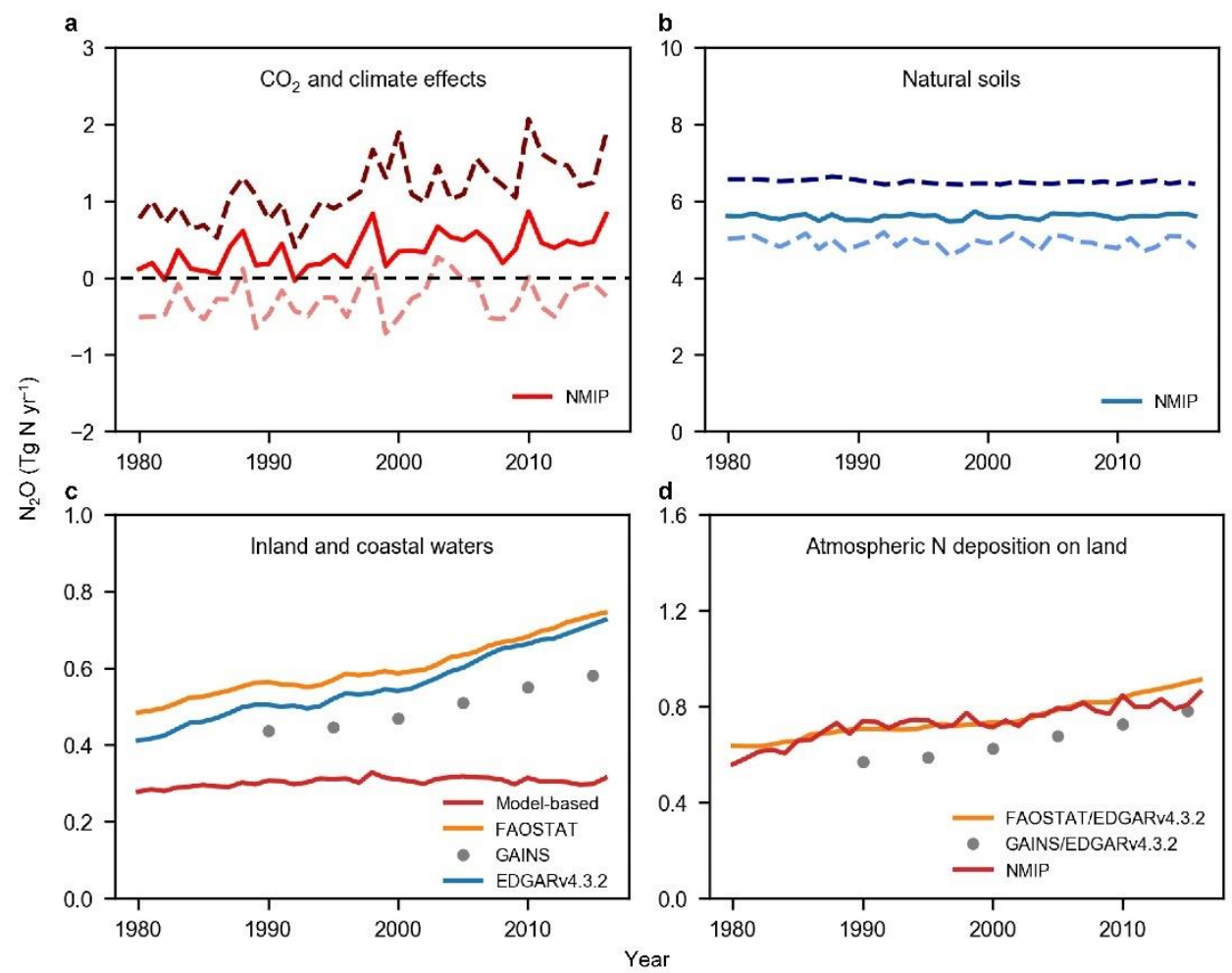

1113

1114

1115

1116

1117

1118

1119

1120

1121

1122

1123

1124

1125

1126

1127

1128

1129

1130

1131

1132

1133
Extended Data Fig. 6 Global $\mathrm{N}_{2} \mathrm{O}$ emissions from natural soils, inland and coastal waters and due to change in climate, atmospheric $\mathrm{CO}_{2}$ and $\mathrm{N}$ deposition. a, Changes in global soil $\mathrm{N}_{2} \mathrm{O}$ fluxes due to changing $\mathrm{CO}_{2}$ and climate. $\mathbf{b}$, Global natural soil $\mathrm{N}_{2} \mathrm{O}$ emissions without consideration of land use change (e.g., deforestation) and without consideration of indirect anthropogenic effects via global change (i.e., climate, elevated $\mathrm{CO}_{2}$, and atmospheric $\mathrm{N}$ deposition). The estimates are based on NMIP estimates during 1980-2016 including six process-based land biosphere models. Here, we also subtracted the difference between with and without consideration of secondary forests emissions that grow back after pasture or cropland abandonment from natural soil emissions based on NMIP estimates. The solid lines represent the ensemble and dashed lines show the minimum and maximum values. c, Global anthropogenic $\mathrm{N}_{2} \mathrm{O}$ emission from inland waters, estuaries, coastal zones based on models (model-based), FAOSTAT, GAINS, and EDGAR v4.3.2 estimates. d, Emission due to atmospheric N deposition (NDEP) on land based on NMIP, FAOSTAT/EDGAR v4.3.2, and GAINS/EDGAR v4.3.2. FAOSTAT/EDGAR v4.3.2 or GAINS/EDGAR v4.3.2 means the combination of agricultural source from FAOSTAT or GAINS with non-agricultural source from EDGAR v4.3.2. A processbased model DLEM ${ }^{36}$ and a mechanistic stochastic model ${ }^{35,51}$ were used to estimate $\mathrm{N}_{2} \mathrm{O}$ emission from inland waters and estuaries, while site-level emission rates of $\mathrm{N}_{2} \mathrm{O}$ were upscaled to estimate global $\mathrm{N}_{2} \mathrm{O}$ fluxes from the global seagrass area ${ }^{68}$. 


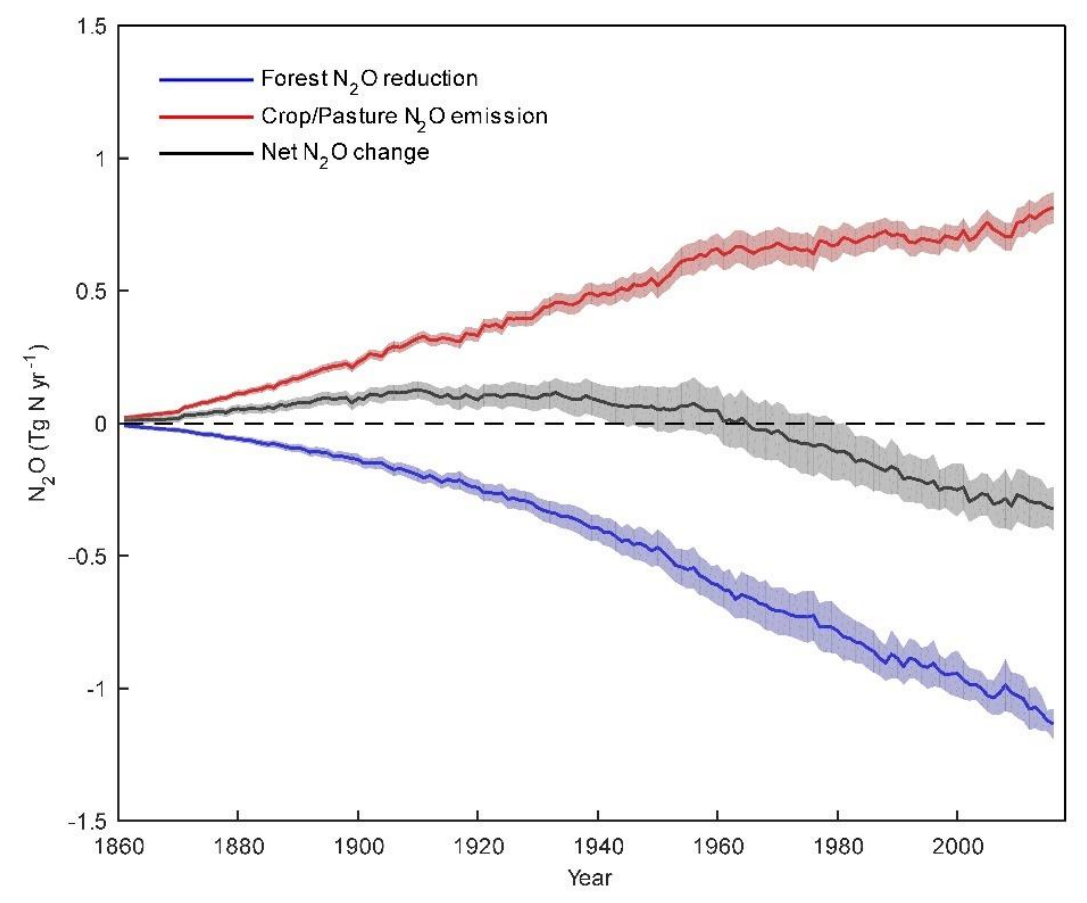

1135 Extended Data Fig. 7 Global $\mathbf{N}_{2} \mathrm{O}$ dynamics due to land cover changes. The blue line

1136 represents the mean forest $\mathrm{N}_{2} \mathrm{O}$ reduction caused by the long-term effect of reduced mature forest 1137 area (i.e., deforestation) and shaded areas show minimum and maximum estimates; the red line 1138 represents the mean $\mathrm{N}_{2} \mathrm{O}$ emission from post-deforestation pulse effect (i.e., crop/pasture $\mathrm{N}_{2} \mathrm{O}$ 1139 emissions from legacy $\mathrm{N}$ of previous forest soil, not accounting for new fertilizer $\mathrm{N}$ added to 1140 these crop/pasture lands) and shaded areas show minimum and maximum estimates; the gray line 1141 represents the mean net deforestation emission of $\mathrm{N}_{2} \mathrm{O}$ and shaded areas show minimum and 1142 maximum estimates.

1143

1144 


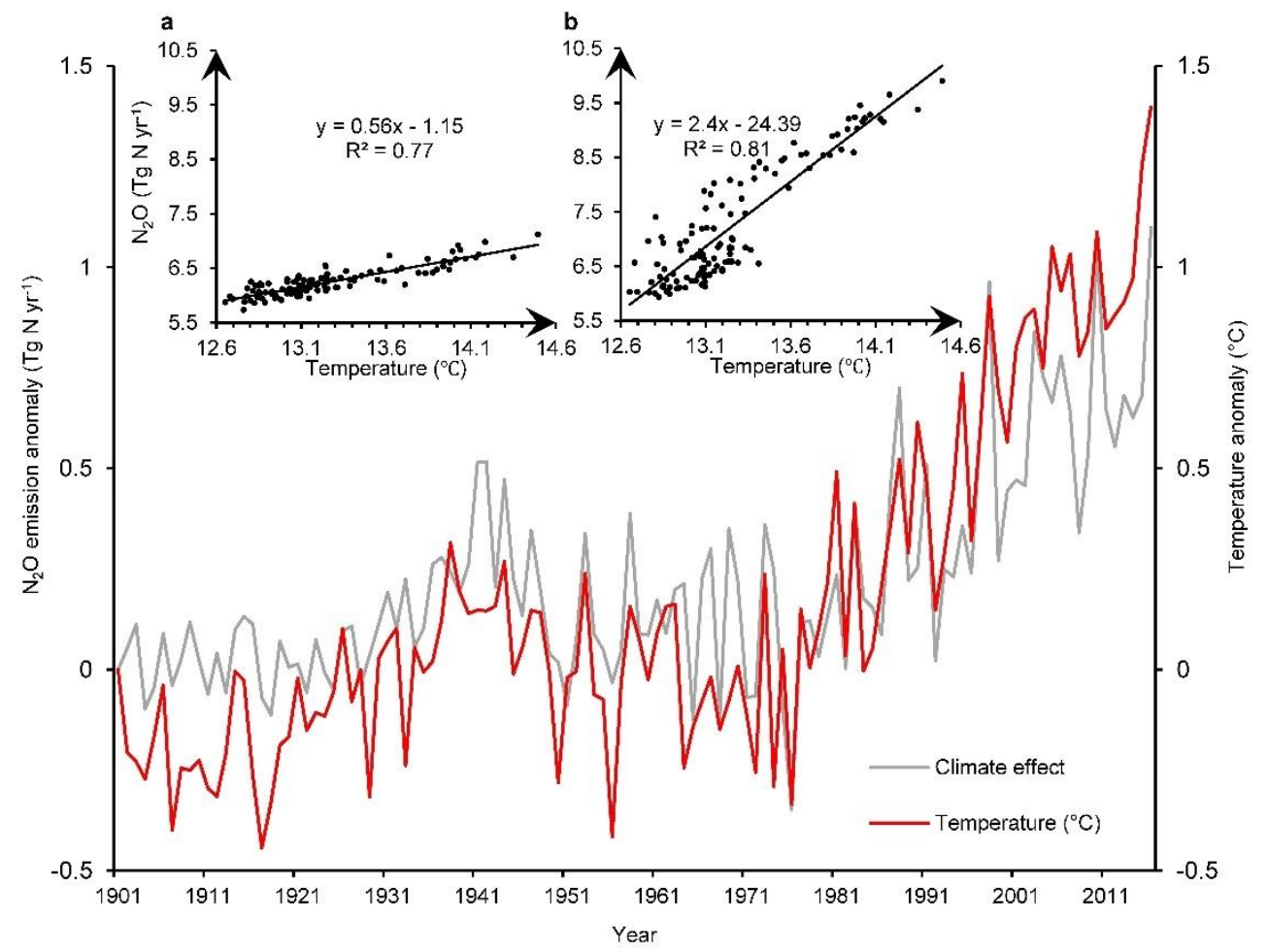

1145

1146

1147

1148

1149

1150

1151

1152

1153

1154

1155

1156

1157

1158
Extended Data Fig. 8 Global simulated $\mathrm{N}_{2} \mathrm{O}$ emission anomaly due to climate effect and global annual land surface temperature anomaly during 1901-2016. Global $\mathrm{N}_{2} \mathrm{O}$ emission anomalies are the ensemble of six process-based land biosphere models in NMIP. The temperature data were obtained from the CRU-NCEP v8 climate dataset (https://vesg.ipsl.upmc.fr). The above left figure a) shows the correlation between average global annual land surface temperature and simulated $\mathrm{N}_{2} \mathrm{O}$ emissions (i.e., the result of SE6 experiment in NMIP ${ }^{16}$ ) considering annual changes in climate but keeping all other factors (i.e., $\mathrm{N}$ fertilizer, manure, NDEP, elevated $\mathrm{CO}_{2}$, and land cover change) at the level of 1860 . The above right figure b) shows the correlation between average global annual land surface temperature and simulated $\mathrm{N}_{2} \mathrm{O}$ emissions (i.e., the result of SE1 experiment in $\mathrm{NMIP}^{16}$ ) considering annual changes in all factors during 1860-2016. 

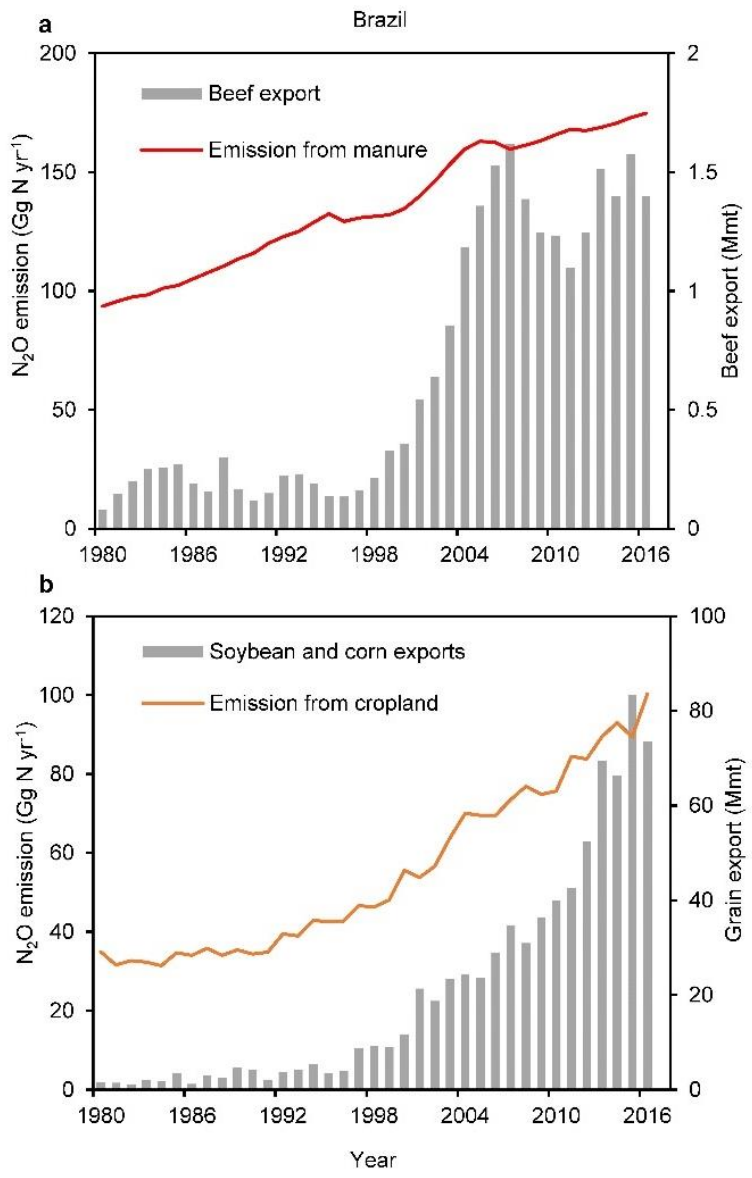

1160 Extended Data Fig. 9 Direct soil emissions and agricultural product trades in Brazil. a, Red

1161 line shows the ensemble direct $\mathrm{N}_{2} \mathrm{O}$ emissions from livestock manure based on EDGAR v4.3.2,

1162 GAINS, and FAOSTAT, the sum of 'manure left on pasture' and 'manure management'; The

1163 gray columns show the amount of beef export by Brazil. b, Orange line shows the ensemble

1164 direct $\mathrm{N}_{2} \mathrm{O}$ emissions from croplands due to $\mathrm{N}$ fertilization based on NMIP and SRNM; The gray

1165 columns show the amount of soybean and corn exports by Brazil. The data of beef and cereal

1166 product trades were adapted from the ABIEC (beef) and FAOSTAT (soybean and corn). Mmt $\mathrm{yr}^{-}$

$1167{ }^{1}$ represents millions of metric tons per year. 

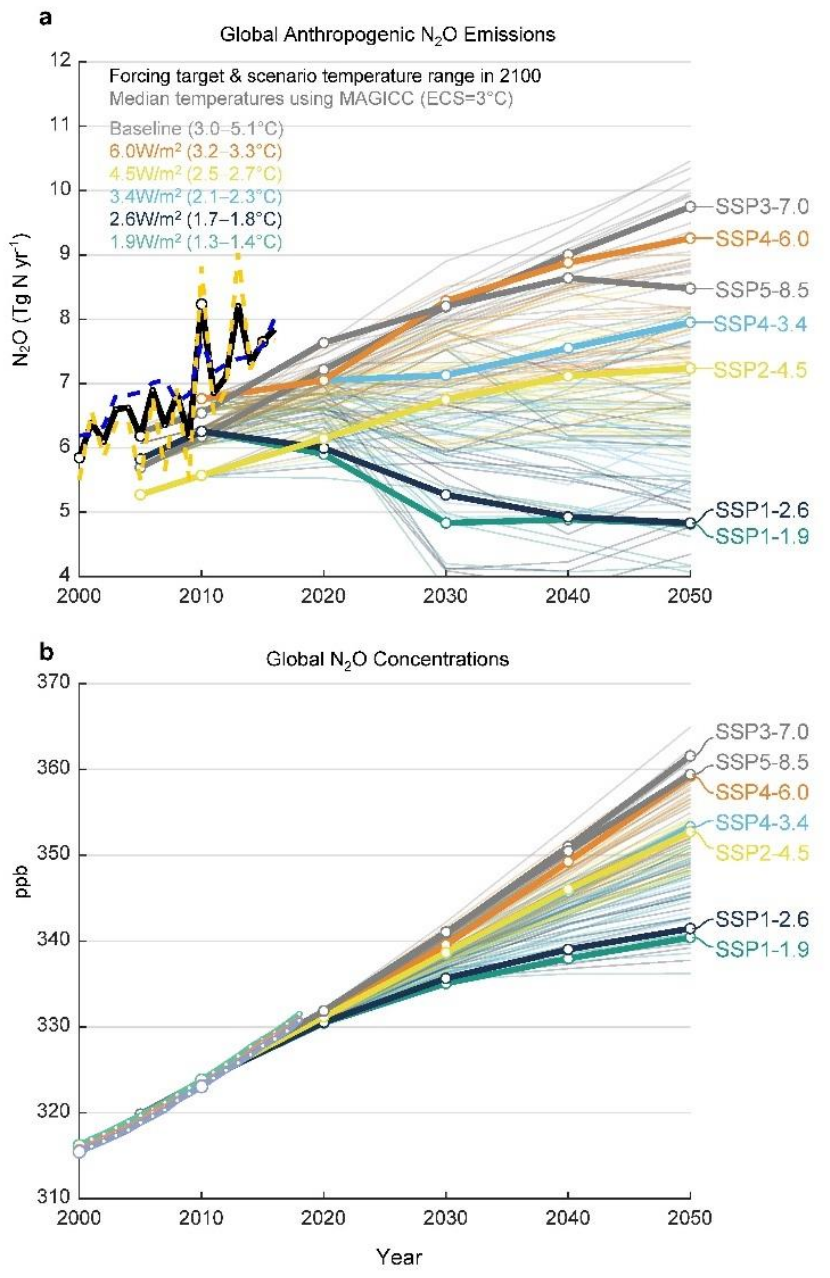

Extended Data Fig. 10 An extension of Fig. 4 to provide a comparison of anthropogenic $\mathrm{N}_{2} \mathrm{O}$ emissions (a) and atmospheric $\mathrm{N}_{2} \mathrm{O}$ concentrations (b) in the unharmonized SSPs ${ }^{105}$.

1173 The emission and concentration data are as in Fig. 4. The unharmonized emissions from the Integrated Assessment Models (IAMs) ${ }^{105}$ show a large variation due to different input data and model assumptions. Comparison with Fig. 4b, d illustrates the modifications to the IAM scenario data for use in CMIP6. All baseline scenarios (SSP3-7.0 and SSP5-8.5; without climate policy

1177 applied) are shown in gray regardless of the radiative forcing level they reach in 2100. 


\section{Supplementary Information}

\section{A comprehensive quantification of global nitrous oxide sources and sinks}

Hanqin Tian ${ }^{1}$, Rongting Xu${ }^{1}$, Josep G. Canadell ${ }^{2}$, Rona L. Thompson ${ }^{3}$, Wilfried Winiwarter ${ }^{4,5}$, Parvadha Suntharalingam $^{6}$, Eric A. Davidson ${ }^{7}$, Philippe Ciais ${ }^{8}$, Robert B. Jackson ${ }^{9,10,11}$, Greet Janssens-Maenhout ${ }^{12,13}$, Michael J. Prather ${ }^{14}$, Pierre Regnier ${ }^{15}$, Naiqing Pan ${ }^{1,16}$, Shufen Pan $^{1}$, Glen P. Peters ${ }^{17}$, Hao Shi ${ }^{1}$, Francesco N. Tubiello ${ }^{18}$, Sönke Zaehle ${ }^{19}$, Feng Zhou ${ }^{20}$, Almut Arneth $^{21}$, Gianna Battaglia ${ }^{22}$, Sarah Berthet ${ }^{23}$, Laurent Bopp ${ }^{24}$, Alexander F. Bouwman ${ }^{25,26,27}$, Erik T. Buitenhuis ${ }^{6,28}$, Jinfeng Chang ${ }^{8,29}$, Martyn P. Chipperfield ${ }^{30,31}$, Shree R. S. Dangal ${ }^{32}$, Edward Dlugokencky ${ }^{33}$, James W. Elkins ${ }^{33}$, Bradley D. Eyre ${ }^{34}$, Bojie Fu ${ }^{16,35}$, Bradley Hall ${ }^{33}$, Akihiko Ito ${ }^{36}$, Fortunat Joos ${ }^{22}$, Paul B. Krummel ${ }^{37}$, Angela Landolfi ${ }^{38,39}$, Goulven G. Laruelle ${ }^{15}$, Ronny Lauerwald ${ }^{8,15,40}$, Wei Li ${ }^{8,41}$, Sebastian Lienert ${ }^{22}$, Taylor Maavara ${ }^{42}$, Michael MacLeod ${ }^{43}$, Dylan B. Millet ${ }^{44}$, Stefan Olin ${ }^{45}$, Prabir K. Patra ${ }^{46,47}$, Ronald G. Prinn ${ }^{48}$, Peter A. Raymond ${ }^{42}$, Daniel J. Ruiz ${ }^{14}$, Guido R. van der Werf ${ }^{49}$, Nicolas Vuichard ${ }^{8}$, Junjie Wang ${ }^{27}$, Ray F. Weiss ${ }^{50}$, Kelley C. Wells ${ }^{44}$, Chris Wilson ${ }^{30,31}$, Jia Yang ${ }^{51} \&$ Yuanzhi Yao ${ }^{1}$

${ }^{1}$ International Center for Climate and Global Change Research, School of Forestry and Wildlife Sciences, Auburn University, Auburn, AL, USA

${ }^{2}$ Global Carbon Project, CSIRO Oceans and Atmosphere, Canberra, Australian Capital Territory, Australia

${ }^{3}$ Norsk Institutt for Luftforskning, NILU, Kjeller, Norway

${ }^{4}$ International Institute for Applied Systems Analysis, Laxenburg, Austria

${ }^{5}$ Institute of Environmental Engineering, University of Zielona Góra, Zielona Góra, Poland.

${ }^{6}$ School of Environmental Sciences, University of East Anglia, Norwich, UK

${ }^{7}$ Appalachian Laboratory, University of Maryland Center for Environmental Science, Frostburg, MD, USA

${ }^{8}$ Laboratoire des Sciences du Climat et de l'Environnement, LSCE, CEA CNRS, UVSQ UPSACLAY, Gif sur Yvette, France

${ }^{9}$ Department of Earth System Science, Stanford University, Stanford, CA, USA

${ }^{10}$ Woods Institute for the Environment, Stanford University, Stanford, CA, USA

${ }^{11}$ Precourt Institute for Energy, Stanford University, Stanford, CA, USA

${ }^{12}$ European Commission, Joint Research Centre (JRC), Ispra, Italy

${ }^{13}$ Ghent University, Faculty of Engineering and Architecture, Ghent, Belgium

${ }^{14}$ Department of Earth System Science, University of California Irvine, Irvine, CA, USA

${ }^{15}$ Department Geoscience, Environment \& Society, Université Libre de Bruxelles, Brussels, Belgium

${ }^{16}$ State Key Laboratory of Urban and Regional Ecology, Research Center for Eco-Environmental Sciences, Chinese Academy of Sciences, Beijing, China

${ }^{17}$ CICERO Center for International Climate Research, Oslo, Norway

${ }^{18}$ Statistics Division, Food and Agriculture Organization of the United Nations, Via Terme di Caracalla, Rome, Italy

${ }^{19}$ Max Planck Institute for Biogeochemistry, Jena, Germany 
${ }^{20}$ Sino-France Institute of Earth Systems Science, Laboratory for Earth Surface Processes, College of Urban and Environmental Sciences, Peking University, Beijing, China

${ }^{21}$ Karlsruhe Institute of Technology, Institute of Meteorology and Climate Research/Atmospheric Environmental Research, Garmisch-Partenkirchen, Germany

${ }^{22}$ Climate and Environmental Physics, Physics Institute and Oeschger Centre for Climate Change Research, University of Bern, Bern, Switzerland

${ }^{23}$ Centre National de Recherches Météorologiques (CNRM), Université de Toulouse, MétéoFrance, CNRS, Toulouse, France

${ }^{24}$ LMD-IPSL, Ecole Normale Supérieure / PSL Université, CNRS; Ecole Polytechnique, Sorbonne Université, Paris, France

${ }^{25}$ PBL Netherlands Environmental Assessment Agency, The Hague, The Netherlands

${ }^{26}$ Department of Earth Sciences - Geochemistry, Faculty of Geosciences, Utrecht University, Utrecht, The Netherlands

${ }^{27}$ Key Laboratory of Marine Chemistry Theory and Technology, Ministry of Education, Ocean University of China, Qingdao, China

${ }^{28}$ Tyndall Centre for Climate Change Research, School of Environmental Sciences, University of East Anglia, Norwich, UK

${ }^{29}$ College of Environmental and Resource Sciences, Zhejiang University, Hangzhou, China.

${ }^{30}$ National Centre for Earth Observation, University of Leeds, Leeds, UK

${ }^{31}$ Institute for Climate and Atmospheric Science, School of Earth and Environment, University of Leeds, Leeds, UK

${ }^{32}$ Woods Hole Research Center, Falmouth, MA, USA

${ }^{33}$ NOAA Global Monitoring Laboratory, Boulder, CO, USA

${ }^{34}$ Centre for Coastal Biogeochemistry, School of Environment Science and Engineering, Southern Cross University, Lismore, New South Wales, Australia

${ }^{35}$ Faculty of Geographical Science, Beijing Normal University, Beijing, China

${ }^{36}$ Center for Global Environmental Research, National Institute for Environmental Studies, Tsukuba, Japan

${ }^{37}$ Climate Science Centre, CSIRO Oceans and Atmosphere, Aspendale, Victoria, Australia

${ }^{38}$ GEOMAR Helmholtz Centre for Ocean Research Kiel, Kiel, Germany

${ }^{39}$ Istituto di Scienze Marine, Consiglio Nazionale delle Ricerche (CNR), Rome, Italy

${ }^{40}$ Université Paris-Saclay, INRAE, AgroParisTech, UMR ECOSYS, Thiverval-Grignon, France

${ }^{41}$ Ministry of Education Key Laboratory for Earth System modeling, Department of Earth System Science, Tsinghua University, Beijing, China

${ }^{42}$ Yale School of Forestry and Environmental Studies, New Haven, CT, USA

${ }^{43}$ Land Economy, Environment \& Society, Scotland's Rural College (SRUC), Edinburgh, UK

${ }^{44}$ Department of Soil, Water, and Climate, University of Minnesota, St Paul, MN, USA

${ }^{45}$ Department of Physical Geography and Ecosystem Science, Lund University, Lund, Sweden

${ }^{46}$ Research Institute for Global Change, JAMSTEC, Yokohama, Japan

${ }^{47}$ Center for Environmental Remote Sensing, Chiba University, Chiba, Japan

${ }^{48}$ Center for Global Change Science, Massachusetts Institute of Technology, Cambridge, MA, USA

${ }^{49}$ Faculty of Science, Vrije Universiteit, Amsterdam, Netherlands.

${ }^{50}$ Scripps Institution of Oceanography, University of California San Diego, La Jolla, USA

${ }^{51}$ Department of Forestry, Mississippi State University, Mississippi State, MS, USA 


\section{Supporting text}

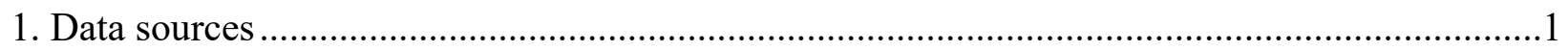

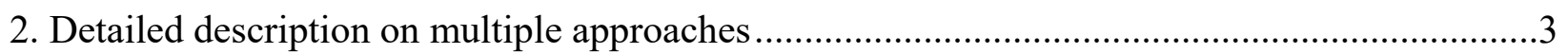

2.1 NMIP - Global $\mathrm{N}_{2} \mathrm{O}$ Model Inter-comparison Project.........................................................

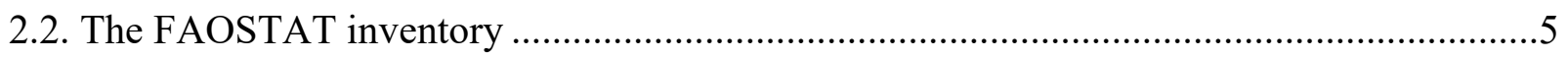

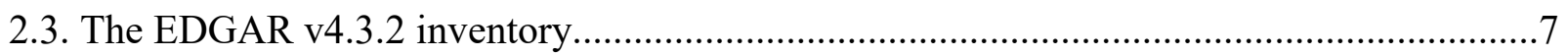

2.4. The GAINS inventory …………..........................................................................

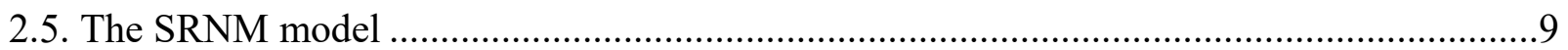

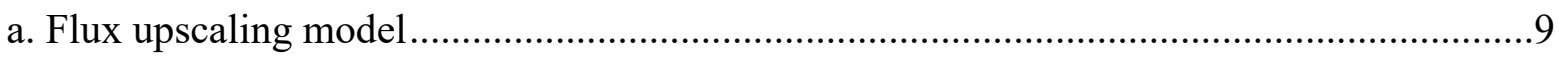

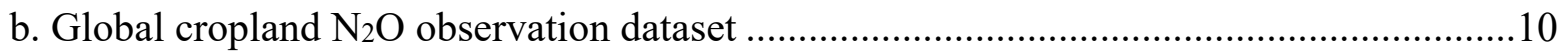

c. Gridded input datasets ................................................................................................11

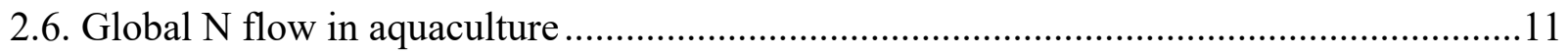

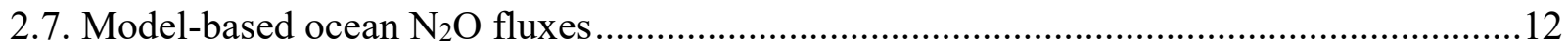

2.8. $\mathrm{Net}_{\mathrm{N}} \mathrm{O}$ emission from land cover change .................................................................13

a. Deforestation area and crop/pasture expansion ...........................................................13

c. Secondary tropical forest emissions. ..........................................................................14

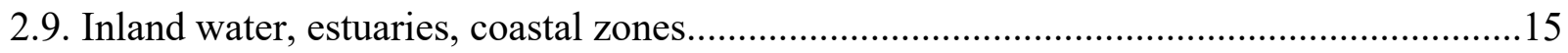

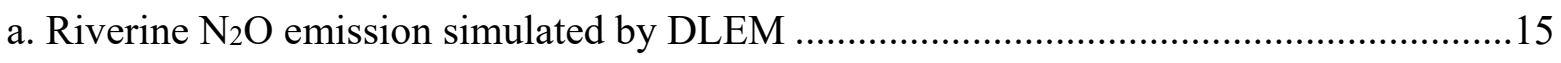

b. The DLEM estimate on $\mathrm{N}_{2} \mathrm{O}$ emission from global reservoirs ......................................16

c. Mechanistic Stochastic Modeling of $\mathrm{N}_{2} \mathrm{O}$ emissions from rivers, lakes, reservoirs and

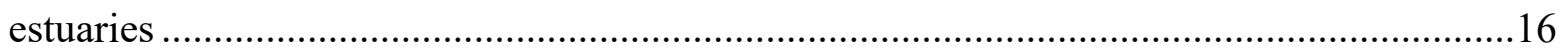

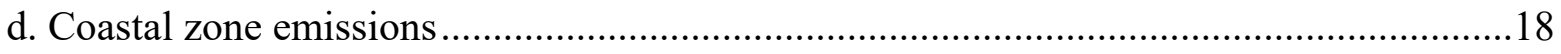

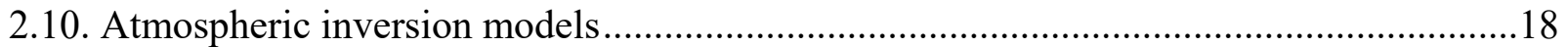

3. Atmospheric $\mathrm{N}_{2} \mathrm{O}$ observations and growth rates for three different atmospheric networks

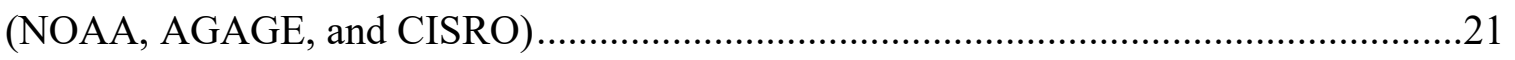

4. Comparison with the IPCC AR5

5. Per capita $\mathrm{N}_{2} \mathrm{O}$ emission at global and regional scales in the recent decade .............................24 


\section{Supporting tables}

Supplementary Table $1 \mathrm{~N}_{2} \mathrm{O}$ emissions from global agricultural soils based on multiple bottomup approaches including the additions of mineral $\mathrm{N}$ fertilizer, manure and crop residues, and cultivation of organic soils.

Supplementary Table $2 \mathrm{~N}_{2} \mathrm{O}$ emissions from global total area under permanent meadows and pasture, due to manure $\mathrm{N}$ deposition (left on pasture) based on EDGAR v4.3.2, FAOSTAT, and GAINS estimates.

Supplementary Table $3 \mathrm{~N}_{2} \mathrm{O}$ emissions due to global manure management based on multiple bottom-up approaches.

Supplementary Table 4 Aquaculture $\mathrm{N}_{2} \mathrm{O}$ emissions based on multiple sources.

Supplementary Table 5 Anthropogenic $\mathrm{N}_{2} \mathrm{O}$ emissions from the global inland waters based on process-based models.

Supplementary Table 6 Anthropogenic $\mathrm{N}_{2} \mathrm{O}$ emissions from the global inland waters based on multiple bottom-up approaches.

Supplementary Table 7 Natural $\mathrm{N}_{2} \mathrm{O}$ emissions from the global inland waters based on processbased models.

Supplementary Table 8 Nitrous oxide emissions due to atmospheric $\mathrm{N}$ deposition on land based on multiple bottom-up approaches................................................................................35

Supplementary Table 9 Global $\mathrm{N}_{2} \mathrm{O}$ emissions from waste and waste water based on EDGAR v4.3.2 and GAINS estimates.

Supplementary Table 10 Global $\mathrm{N}_{2} \mathrm{O}$ emissions from fossil fuel and industry based on multiple bottom-up approaches.

Supplementary Table 11 Global $\mathrm{N}_{2} \mathrm{O}$ emissions from biomass burning based on multiple bottomup approaches.

Supplementary Table 12 Global oceanic $\mathrm{N}_{2} \mathrm{O}$ emissions based on multiple models.

Supplementary Table 13 Global $\mathrm{N}_{2} \mathrm{O}$ emissions based on multiple top-down approaches............38

Supplementary Table 14 Comparison of terminologies used in this study and previous reports..39

Supplementary Table 15 Comparison of the global $\mathrm{N}_{2} \mathrm{O}$ budget in this study with the IPCC AR5.

Supplementary Table 16 Simulation experiments in the NMIP (Tian et al. ${ }^{1,17}$ )..........................41

Supplementary Table 17 Information of NMIP models using in this study .................................41

Supplementary Table 18 Summary of models in ocean $\mathrm{N}_{2} \mathrm{O}$ inter-comparison...........................42

Supplementary Table 19 Overview of the inversion frameworks that are included in the global $\mathrm{N}_{2} \mathrm{O}$ budget. 


\section{Supporting figures}

Supplementary Fig. 1 Spatial distribution of ten study regions across the globe......................43

Supplementary Fig. 2 Per capita $\mathrm{N}_{2} \mathrm{O}$ emission $\left(\mathrm{kg} \mathrm{N}_{\text {capita }}{ }^{-1} \mathrm{yr}^{-1}\right)$ during 2007-2016............44 


\section{Data sources}

Bottom-up methods include process-based models (NMIP ${ }^{1}$ including six process-based terrestrial biosphere models, DLEM-only ${ }^{2}$ for pastureland, five ocean models ${ }^{3-8}$, one mechanistic stochastic model ${ }^{9,10}$ ), four GHG emission databases [EDGAR v4.3.2 ${ }^{11}$, FAOSTAT $^{12}$, GAINS $^{13}$, GFED $^{1} \mathrm{~s}^{14}$ (only for biomass burning), and one statistical model (SRNM) only for cropland soils ${ }^{15}$. The topdown approach includes four independent atmospheric inversion frameworks ${ }^{16}$. The NMIP result provides nitrous oxide $\left(\mathrm{N}_{2} \mathrm{O}\right)$ emissions from natural and agricultural soils, defined as soils in agricultural land, during 1860-2016, with consideration of multiple environmental factors, such as climate, elevated atmospheric carbon dioxide $\left(\mathrm{CO}_{2}\right)$, land cover and land use change, atmospheric nitrogen $(\mathrm{N})$ deposition, mineral $\mathrm{N}$ fertilizer, and manure $\mathrm{N}$ in cropland ${ }^{17}$. Mineral $\mathrm{N}$ fertilizer and manure $\mathrm{N}$ are mainly applied to cropland, while $\mathrm{N}$ deposition can reach soils under all land uses. Natural soil emissions were estimated by NMIP based on the ensemble mean of six models (Supplementary Table 16): (1) the Dynamic Land Ecosystem Model (DLEM) ${ }^{18,19}$,

Land Processes and eXchanges model - Bern (LPX-Bern v1.4) ${ }^{20,21}$, (3) $\mathrm{O}-\mathrm{CN}^{22}$, (4) Organising Carbon and Hydrology In Dynamic Ecosystems (ORCHIDEE) ${ }^{23}$, (5) Organising Carbon and Hydrology In Dynamic Ecosystems-Carbon Nitrogen Phosphorus (ORCHIDEE-CNP) ${ }^{23}$, and (6) Vegetation Integrated SImulator for Trace gases (VISIT) ${ }^{24,25}$ (See more model information in Tian et al. ${ }^{1,17}$ ). Agricultural soil emissions were from manure and fertilizer $\mathrm{N}$ applications on cropland during 1860-2016 ${ }^{1}$ and intensively managed grassland (pastures) during 1900-2014 ${ }^{2}$. For 'Indirect emissions from anthropogenic $\mathrm{N}$ additions', we considered emissions from atmospheric $\mathrm{N}$ deposition and 'Inland and coastal waters' $\mathrm{N}$ leaching/runoff including five subsystems: rivers, lakes, estuaries, reservoirs, and coastal zones. Yao et al.$^{26}$ estimated $\mathrm{N}_{2} \mathrm{O}$ emissions from rivers using the process-based model (DLEM) during 1900-2016 and provided estimates from reservoirs as well, while emissions determined from the stochastic mechanistic model of Maavara et al. ${ }^{10}$ and Lauerwald et al. ${ }^{9}$ for the river-reservoir-estuary continuum, and lakes, respectively, were in 2000. Coastal zone emissions were obtained from data compilation reported in Camillini et al. ${ }^{27}$ and Murray et al. ${ }^{28}$. The DLEM model also provided an estimate of $\mathrm{N}_{2} \mathrm{O}$ emissions from biomass burning across various biomes (crop residue and savannas, peatland, tropical forest, temperate forest, and boreal forest) during 1860-2015. A nutrient budget model for shellfish and finfish ${ }^{29-31}$ was used to calculate the nutrient flows in aquaculture 
production systems. For computing the $\mathrm{N}_{2} \mathrm{O}$ emission we consider the amount of $\mathrm{N}$ released to the environment, i.e. the difference between $\mathrm{N}$ intake and $\mathrm{N}$ in the harvested fish, which includes all the nutrient excretion. Estimates of oceanic $\mathrm{N}_{2} \mathrm{O}$ fluxes are derived from an inter-comparison of five global ocean biogeochemistry models including Bern-3D ${ }^{3}$, NEMOv3.6-PISCESv2-gas ${ }^{4}$, NEMO-PlankTOM10 $0^{5}$ UVic2.96 ${ }^{6}$, and NEMO-PISCES $3.2^{7}$.

The EDGAR v4.3.2 applies the IPCC guidelines mostly at Tier-1, but integrates higher tier information based on available country reporting, mostly from Annex I countries. It provided data from 1970 to 2012 . We updated the data to 2016 based on the global and regional trends between 2000 and 2012 for each individual category. In EDGAR v4.3.2, 'Indirect emission from $\mathrm{N}$ deposition' only represents non-agricultural activities. 'Waste and waste water' includes 'Waste incineration' and 'Wastewater handling'. We merged 'Transportation', 'Energy', 'Industry', and 'Residential and other sectors' to represent the total emission from 'Fossil fuel and industry'. Since the EDGAR v4.3.2 database did not provide the emission of 'Biomass burning' from land use outside of agriculture, here we did not include its estimate of 'Agriculture waste burning' into the data synthesis. The FAOSTAT emissions database of the Food and Agriculture Organization of the United Nations (FAO) covers emissions of $\mathrm{N}_{2} \mathrm{O}$ from agriculture and land use by country and globally, from 1961 to 2017 for agriculture, and from $1990^{12}$ for relevant land use categories, i.e, cultivation of histosols, biomass burning, etc., applying only Tier-1 coefficients ${ }^{32}$. In addition to the IPCC agriculture burning categories 'Burning crop residues' and 'Burning savannah', FAOSTAT also estimates $\mathrm{N}_{2} \mathrm{O}$ emissions from deforestation fires, forest fires and peatland fires. Emissions from 'Fossil fuel and industry' are directly adapted from the EDGAR v4.3.2 emission inventory. The GAINS model ${ }^{13}$ provided $\mathrm{N}_{2} \mathrm{O}$ emissions data every five-years (i.e., 1990, 1995, 2000, 2005, 2010, 2015). We assumed the change between each five-year estimate was linear. To avoid abrupt jumps between 1989 and 1990 during data synthesis, we linearly extrapolated data to 1980 through using estimates in 1990 and 1995 in each sub-sector. 'Direct soil emissions' are from synthetic N fertilizer, animal manure, cultivation of histosols, and crop residues. 'Indirect emissions from anthropogenic $\mathrm{N}$ additions' are from ' $\mathrm{N}$ deposition on land' and 'Inland and coastal waters' (i.e., lakes, rivers, and shelf seas). The source of ' $\mathrm{N}$ deposition on land' is mainly from agricultural activities, but it deposited on all global ice-free areas (i.e., agricultural land, forest land, other land uses). The 'Energy' emission includes conversion, industry, transport, and domestic. The 'Industry' 
emission includes nitric acid plants, adipic acid plants, and caprolactam plants. We merged 'Energy' and 'Industry' to represent 'Fossil fuel and industry' emissions. They also considered $\mathrm{N}_{2} \mathrm{O}$ use, but we did not include this sector in the synthesis table. We merged 'Composting' and 'Wastewater' sectors into 'Waste and waste water' to make comparison with the EDGAR v4.3.2 database. In addition, the sector 'Grazing' was treated as 'Manure left on pasture' to make comparison. The GFED4s emission inventory ${ }^{14}$ provided $\mathrm{N}_{2} \mathrm{O}$ emissions from 'Biomass burning' including agricultural waste and other biomass burning (i.e., Savanna, grassland, and shrubland fires, boreal forest fires, temperate forest fires, deforestation and degradation, and peatland fires) during 1997-2016.

The spatially-referenced non-linear model SRNM was fitted through considering environmental factors and $\mathrm{N}$ management practices to generate gridded annual $\mathrm{EF}$ maps at $5^{\prime}$ spatial resolution, and then to calculate global/regional $\mathrm{N}_{2} \mathrm{O}$ emissions during 1901-2016 together with time-series $\mathrm{N}$ input datasets ${ }^{15}$. This database provides $\mathrm{N}_{2} \mathrm{O}$ emissions from global and regional cropland with the application of synthetic $\mathrm{N}$ fertilizer and manure $\mathrm{N}$ for the period 1980-2016.

For the top-down constraints on the global and regional $\mathrm{N}_{2} \mathrm{O}$ emissions for the period 1998-2016, we have used estimates from four independent atmospheric inversion frameworks (INVICAT, PyVAR, MIROC4-ACTM, and GEOSChem), all of which used the Bayesian inversion method. Here, two versions of PyVAR were run using different ocean priors (one high and one low) for determining the sensitivity to the ocean prior. These runs are denoted as PyVAR-1 and PyVAR-2, respectively. For the top-down global estimate, we used the original spatial resolution in each framework. For the top-down regional estimate, we interpolated the coarse resolution into $1^{\circ} \times 1^{\circ}$ to cover all land areas in the four frameworks (see details in section 2.10).

\section{Detailed description on multiple approaches}

\subsection{NMIP - Global $\mathrm{N}_{2} \mathrm{O}$ Model Inter-comparison Project}

Ten process-based Terrestrial Biosphere Models (TBMs) participate in NMIP. In general, $\mathrm{N}_{2} \mathrm{O}$ emissions from soil are regulated at two levels, which are the rates of nitrification and denitrification in the soil and soil physical factors regulating the ratio of $\mathrm{N}_{2} \mathrm{O}$ to other nitrous 
gases $^{33}$. For $\mathrm{N}$ input to land ecosystems, all ten models considered the atmospheric $\mathrm{N}$ deposition and biological fixation, nine models with crop $\mathrm{N}_{2} \mathrm{O}$ module included $\mathrm{N}$ fertilizer use, but only six models considered manure as $\mathrm{N}$ input. For vegetation processes, all models included dynamic algorithms in simulating $\mathrm{N}$ allocation to different living tissues and vegetation $\mathrm{N}$ turnover, and simulated plant N uptake using the "Demand and Supply-driven" approach. For soil N processes, all ten models simulated $\mathrm{N}$ leaching according to water runoff rate; however, models are different in representing nitrification and denitrification processes and the impacts of soil chemical and physical factors. The differences in simulating nitrification and denitrification processes are one of the major uncertainties in estimating $\mathrm{N}_{2} \mathrm{O}$ emissions. Algorithms associated with $\mathrm{N}_{2} \mathrm{O}$ emissions in each participating model are briefly described in Appendix A of Tian et al. ${ }^{17}$.

All participating models are driven by consistent input datasets (i.e., climate, atmospheric $\mathrm{CO}_{2}$ concentration, land cover change, atmospheric $\mathrm{N}$ deposition, mineral $\mathrm{N}$ fertilization, and manure $\mathrm{N}$ application) and implemented seven simulation experiments (SE0 - SE6; Supplementary Table 17) at the spatial resolution of $0.5^{\circ}$ globally covering the period of $1861-$ 2016 (ref. ${ }^{1}$ ). The SE1 includes all driving factors for models with manure addition, and the SE2 is the experiment including all the driving factors for models except manure N. In the SE0 simulation, driving forces were kept constant at the level in 1860 over the entire simulation period (1861-2016).

By comparing results from different model scenarios, it is possible to attribute the changed spatiotemporal variations of soil $\mathrm{N}_{2} \mathrm{O}$ emissions to the variations of six natural and anthropogenic factors, namely, climate (CLIM, including precipitation, humidity, temperature and photosynthetic active radiation changes), atmospheric $\mathrm{CO}_{2}$ concentration $\left(\mathrm{CO}_{2}\right)$, land cover change (LCC), atmospheric $\mathrm{N}$ deposition (NDEP), mineral $\mathrm{N}$ fertilizer use (NFER), and manure $\mathrm{N}$ use in cropland (MANN). In order to understand soil $\mathrm{N}_{2} \mathrm{O}$ emissions dynamics caused by crop cultivation, we further separated the global and regional $\mathrm{N}_{2} \mathrm{O}$ emissions into those derived from cropland soils and those from soils of other land ecosystems. All soils in other land ecosystems except cropland were treated as "natural soils" while model simulations were implemented in this study. Except for cropland, the current NMIP simulations do not include management 
practices (such as grazing and forest logging) for other managed ecosystems such as pasture, planted forests and urban.

In this study, we aimed to attribute the impact of single factor on cropland $\mathrm{N}_{2} \mathrm{O}$ emissions, thus participating models without providing SE2-SE6 and SE0 results in cropland were excluded. Here, we included estimates from six process-based models (Supplementary Table 16). Four models (DLEM, ORCHIDEE, ORCHIDEE-CNP, and VISIT) considered the effects of manure $\mathrm{N}$ application in cropland and ran all the seven simulation experiments (SE0-SE6), while the other two models (LPX-Bern and O-CN) did not include manure effects and ran six model experiments (all except SE1). We used four model results (i.e., DLEM, ORCHIDEE, ORCHIDEE-CNP, and VISIT) to calculate the manure N effect (SE1-SE2). Meanwhile, we used six model results (i.e., DLEM, LPX-Bern, O-CN, ORCHIDEE, ORCHIDEE-CNP, and VISIT) to calculate the effects of synthetic $\mathrm{N}$ fertilizer use (SE2-SE3) and atmospheric $\mathrm{N}$ deposition (SE3-SE4). The effect of $\mathrm{N}$ deposition in natural vegetation was calculated from the six models mentioned above.

\subsection{The FAOSTAT inventory}

The FAOSTAT emissions data are computed at Tier 1 following IPCC, 2006, Vol. 4. The overall equation is as follows:

Direct emissions are estimated at country level, using the formula:

$$
\text { Emission }=A * E F
$$

where emission represents $\mathrm{kg} \mathrm{N} \mathrm{yr}^{-1} ; A$ represents amount of $\mathrm{N}$ in the following items (annual synthetic $\mathrm{N}$ applications/manure applied to soils/manure left on pasture/manure treated in manure management systems/crop residue/biomass burned amount) in $\mathrm{kg} \mathrm{N} \mathrm{yr}^{-1} ; E F=$ Tier 1, default IPCC emission factors, expressed in $\mathrm{kg} \mathrm{N} / \mathrm{kg} \mathrm{N}$.

Indirect emissions are estimated at country level, using the formula:

$$
\text { Emission }=A_{v \& l} * E F
$$


where emission represents $\mathrm{kg} \mathrm{N} \mathrm{yr}^{-1} ; A v \& l$ represents the fraction of manure/synthetic $\mathrm{N}$ fertilizers that volatize as $\mathrm{NH}_{3}$ and $\mathrm{NO}_{x}$ and are lost through runoff and leaching in $\mathrm{kg} \mathrm{N} \mathrm{yr}^{-1} ; E F$ $=$ Tier 1, default IPCC emission factors, expressed in $\mathrm{kg} \mathrm{N} / \mathrm{kg} \mathrm{N}$.

Synthetic $\mathrm{N}$ fertilizers: $\mathrm{N}_{2} \mathrm{O}$ from synthetic fertilizers is produced by microbial processes of nitrification and denitrification taking place on the addition site (direct emissions), and after volatilization/redeposition and leaching processes (indirect emissions).

Manure management: The term manure includes both urine and dung (i.e., both liquid and solid material) produced by livestock. $\mathrm{N}_{2} \mathrm{O}$ is produced directly by nitrification and denitrification processes in the manure, and indirectly by $\mathrm{N}$ volatilization and redeposition processes.

Manure applied to soils: $\mathrm{N}_{2} \mathrm{O}$ is produced by microbial processes of nitrification and denitrification taking place on the application site (direct emissions), and after volatilization/redeposition and leaching processes (indirect emissions).

Manure left on pastures: $\mathrm{N}_{2} \mathrm{O}$ is produced by microbial processes of nitrification and denitrification taking place on the deposition site (direct emissions), and after volatilization/redeposition and leaching processes (indirect emissions).

Crop Residue: $\mathrm{N}_{2} \mathrm{O}$ emissions from crop residues consist of direct and indirect emissions from $\mathrm{N}$ in crop residues left on agricultural fields by farmers and from forages during pasture renewal (following the definitions in the IPCC guidelines ${ }^{34}$ ). Specifically, $\mathrm{N}_{2} \mathrm{O}$ is produced by microbial processes of nitrification and denitrification taking place on the deposition site (direct emissions), and leaching processes (indirect emissions).

Cultivation of organic soils: The FAOSTAT domain "Cultivation of organic soils" contains estimates of direct $\mathrm{N}_{2} \mathrm{O}$ emissions associated with the drainage of organic soils - histosols under cropland and grazed grassland.

Burning-savanna: $\mathrm{N}_{2} \mathrm{O}$ emissions from the burning of vegetation biomass in the land cover types: Savanna, Woody Savanna, Open Shrublands, Closed Shrublands, and Grasslands. Burning-crop residues: $\mathrm{N}_{2} \mathrm{O}$ produced by the combustion of a percentage of crop residues burnt on-site. Burning-biomass: $\mathrm{N}_{2} \mathrm{O}$ emissions from the burning of vegetation biomass in the land cover types: Humid tropical forest, other forest, and organic soils. 


\subsection{The EDGAR v4.3.2 inventory}

The new online version, EDGAR v4.3.2 incorporates a full differentiation of emission processes with technology-specific emission factors and additional end-of-pipe abatement measures6 and as such updates and refines the emission estimates. The emissions are modelled based on latest scientific knowledge, available global statistics, and methods recommended by IPCC (2006) ${ }^{34}$. Official data submitted by the Annex I countries to the United Nations Framework Convention on Climate Change (UNFCCC) and to the Kyoto Protocol are used to some extent, particularly regarding control measures implemented since 1990 that are not described by international statistics.

The $\mathrm{N}_{2} \mathrm{O}$ emission factor for direct soil emissions of $\mathrm{N}_{2} \mathrm{O}$ from the use of synthetic fertilizers and from manure used as fertilizers and from crop residues is taken from IPCC $(2006)^{34}$, that updated the default IPCC emission factor in the IPCC Good Practice Guidance (2000) with a $20 \%$ lower value. $\mathrm{N}_{2} \mathrm{O}$ emissions from the use of animal waste as fertilizer are estimated taking into account both the loss of $\mathrm{N}$ that occurs from manure management systems before manure is applied to soils and the additional $\mathrm{N}$ introduced by bedding material. $\mathrm{N}_{2} \mathrm{O}$ emissions from fertilizer use and $\mathrm{CO}_{2}$ from urea fertilization are estimated based on IFA and FAO statistics.

$\mathrm{N}_{2} \mathrm{O}$ emissions from manure management are based on distribution of manure management systems from Annex I countries reporting to the UNFCCC, Zhou et al. ${ }^{35}$ for China and IPCC $(2006)^{34}$ for the rest of the countries.

Different $\mathrm{N}_{2} \mathrm{O}$ emission factors are applied to tropical and non-tropical regions. $\mathrm{N}$ and dry matter content of agricultural residues are estimated from the cultivation area and yield for 24 crop types (two types of beans, barley, cassava, cereals, three types of peas, lentils, maize, millet, oats, two types of potatoes, pulses, roots and tubers, rice, rye, soybeans, sugar beet, sugar cane, sorghum, wheat and yams) from FAOSTAT (2014) and using emission factors of IPCC (2006) ${ }^{34}$.

Indirect $\mathrm{N}_{2} \mathrm{O}$ emissions from leaching and runoff of nitrate are estimated from $\mathrm{N}$ input to agricultural soils as described above. Leaching and runoff are assumed to occur in all agricultural areas except non-irrigated dryland regions, which are identified with maps of FAO Geonetwork (2011). The fraction of $\mathrm{N}$ lost through leaching and runoff is based on the study of Van Drecht et al. ${ }^{36}$. The updated emission factor for indirect $\mathrm{N}_{2} \mathrm{O}$ emissions from $\mathrm{N}$ leaching and run-off from 
the IPCC (2006) guidelines is selected, while noting that it is $70 \%$ lower than the mean value of the 1996 IPCC Guidelines and the IPCC Good Practice Guidance (IPCC, 1997, 2000).

Indirect $\mathrm{N}_{2} \mathrm{O}$ emissions from atmospheric deposition of $\mathrm{N}$ of $\mathrm{NO}_{\mathrm{x}}$ and $\mathrm{NH}_{3}$ emissions from non-agricultural sources, mainly fossil fuel combustion, are estimated using $\mathrm{N}$ in $\mathrm{NO}_{\mathrm{x}}$ and $\mathrm{NH}_{3}$ emissions from these sources as activity data, based on EDGAR v4.3.2 database for these gases. The same emission factor from IPCC $(2006)^{34}$ is used for indirect $\mathrm{N}_{2} \mathrm{O}$ from atmospheric deposition of $\mathrm{N}$ from $\mathrm{NH}_{3}$ and $\mathrm{NOx}$ emissions, as for agricultural emissions.

\subsection{The GAINS inventory}

The methodology adopted for the estimation of current and future greenhouse gas emissions and the available potential for emission controls follows the standard methodology used by the Greenhouse Gas - Air Pollution Interactions and Synergies (GAINS) model ${ }^{37}$. For a given year, emissions of each pollutant $p$ are calculated as the product of the activity levels, the "uncontrolled" emission factor in the absence of any emission control measures, the efficiency of emission control measures and the application rate of such measures:

$$
E_{i, p}=\sum_{j, a, t} E_{i, j, a, t, p}=\sum_{j, a, t} A_{i, j, a} e f_{i, j, a, p}\left(1-e f f_{t, p}\right) X_{i, j, a, t}
$$

where subscripts $i, j, a, t, p$ denote region, sector, activity, abatement technology, and pollutant, respectively; Ei,p represents emissions of the specific pollutant $p$ in region $i$; $A j$ represents activity in a given sector $j$; ef represents "uncontrolled" emission factor; eff represents reduction efficiency; $X$ represents actual implementation rate of the considered abatement.

Results (emissions from all anthropogenic sources) are available in 5-year intervals from 1990 to 2050 (in some regions up to 2070) for each GAINS region, typically comprising one country to express areas of common legislation also with respect of air pollution. Very large countries have been further split along administrative areas, while in cases of limited data availability also groups of countries have been combined into GAINS regions.

For $\mathrm{N}_{2} \mathrm{O}$, the fate of emissions abatement is often connected with action taken to control other pollutants. For example, it may occur that after control (e.g., of $\mathrm{NO}_{\mathrm{x}}$ emissions), $\mathrm{N}_{2} \mathrm{O}$ emissions become higher than in the unabated case. To reflect this effect, negative reduction efficiencies would need to be used for $\mathrm{N}_{2} \mathrm{O}$. As it is difficult to communicate such negative numbers, GAINS 
has resorted to present "controlled" emission factors instead, which describe the emission factor of a process after installation of abatement technology.

\subsection{The SRNM model}

a. Flux upscaling model

The SRNM model ${ }^{38}$ was applied to simulate direct cropland- $\mathrm{N}_{2} \mathrm{O}$ emissions. In SRNM, $\mathrm{N}_{2} \mathrm{O}$ emissions were simulated from $\mathrm{N}$ application rates using a quadratic relationship, with spatiallyvariable model parameters that depend on climate, soil properties, and management practices. The original version of SRNM was calibrated using field observations from China only ${ }^{39}$. In this study, we used the global $\mathrm{N}_{2} \mathrm{O}$ observation dataset to train it to create maps of gridded annual emission factors of $\mathrm{N}_{2} \mathrm{O}$ and the associated emissions at 5-minute resolution from 1901 to $2014^{15}$. The gridded EF and associated direct cropland- $\mathrm{N}_{2} \mathrm{O}$ emissions are simulated based on the following equation:

$$
E_{i j t}=\alpha_{i j} N_{i j t}^{2}+\beta_{i j} N_{i j t}+\varepsilon_{i j t}, \forall i
$$

where

$$
\begin{aligned}
& \alpha_{i j} \sim N\left(\sum_{k}\left(x_{k} \lambda_{i j k}\right), \sigma_{i j k}^{2}\right), \beta_{i j} \sim N\left(\sum_{k}\left(x_{k} \phi_{i j k}\right), \sigma_{i j k}^{\prime 2}\right) \\
& \lambda_{i j k} \sim N\left(\mu_{i j k}, \omega_{i j k}^{2}\right), \phi_{i j k} \sim N\left(\mu_{i j k}^{\prime}, \omega_{i j k}^{\prime 2}\right), \varepsilon_{i j t} \sim N\left(0, \tau^{2}\right)
\end{aligned}
$$

and $i$ denotes the sub-function of $\mathrm{N}_{2} \mathrm{O}$ emission $(i=1,2, \ldots, I)$ that applies for a sub-domain division $\Omega_{i}$ of six climate or soil factors, $j$ represents the type of crop $(j=1-2,1$ for upland crops and 2 for paddy rice), $k$ is the index of climate or soil factors $(k=1-6$, i.e., soil $\mathrm{pH}$, clay content, soil organic carbon, bulk density, the sum of cumulative precipitation and irrigation, mean daily air temperature). $\Omega_{i}$ denotes a set of the range of multiple $x_{k}$. $E_{i j t}$ denotes direct $\mathrm{N}_{2} \mathrm{O}$ emission flux ( $\mathrm{kg} \mathrm{N} \mathrm{ha}^{-1} \mathrm{yr}^{-1}$ ) estimated for crop type $j$ in year $t$ in the $i$ th sub-domain, $N_{i j t}$ is $\mathrm{N}$ application rate $\left(\mathrm{kg} \mathrm{N} \mathrm{ha}^{-1} \mathrm{yr}^{-1}\right)$, and $\alpha_{i j}$ and $\beta_{i j}$ are defined as summation of the product of $x_{k}$ and $\lambda_{i j k}$ over $k$. The random terms $\lambda$ and $\phi$ are assumed to be independent and normally distributed, representing 
the sensitivity of $\alpha$ and $\beta$ to $x_{k} . \varepsilon$ is the model error. $\mu$ and $\mu^{\prime}$ are the mean effect of $x_{k}$ for $\alpha$ and $\beta$, respectively. $\sigma, \sigma^{\prime}, \omega, \omega^{\prime}$, and $\tau$ are standard deviations. Optimal sub-domain division, associated parameters mean values and standard deviations were determined by using the Bayesian Recursive Regression Tree version 2 (BRRT v2) ${ }^{39-41}$, constrained by the extended global cropland- $\mathrm{N}_{2} \mathrm{O}$ observation dataset. The detailed methodological approach of the BRRT v2 is described in Zhou et al. ${ }^{41}$

b. Global cropland $\mathrm{N}_{2} \mathrm{O}$ observation dataset

We aggregated cropland $\mathrm{N}_{2} \mathrm{O}$ flux observation data from 180 globally distributed observation sites from online databases, on-going observation networks, and peer-reviewed publications. Chamber-based observations were only included in this dataset. These data repositories are as follows: the NitroEurope, CarbonEurope, GHG-Europe (EU-FP7), GRACEnet, TRAGnet, NANORP, and 14 meta-analysis datasets ${ }^{42-55}$. Four types of data were excluded from our analysis: (i) observations without a zero- $\mathrm{N}$ control for background $\mathrm{N}_{2} \mathrm{O}$ emission, (ii) observations from sites that used controlled-release fertilizers or nitrification inhibitors, (iii) observations not covering the entire crop growing season, (iv) observations made in laboratory or greenhouse. We then calculated cropland- $\mathrm{N}_{2} \mathrm{O}$ emissions as the difference between observed $\mathrm{N}_{2} \mathrm{O}$ emission (E) and background $\mathrm{N}_{2} \mathrm{O}$ emission ( $\left.\mathrm{E}_{0}\right)$. Values of EF were estimated for each nonzero $\mathrm{N}$ application rate $\left(N_{a}\right)$ as direct cropland $-\mathrm{N}_{2} \mathrm{O}$ emission divided by $N_{a}$ : EF $=(\mathrm{E}-$ $\left.\mathrm{E}_{0}\right) / N_{a}$. This yielded a global dataset of direct cropland- $\mathrm{N}_{2} \mathrm{O}$ emissions, N-rate-dependent $\mathrm{N}_{2} \mathrm{O}$ EFs and fertilization records from each site (i.e., 1,052 estimates for upland crops from 152 sites and 154 estimates for paddy rice from 28 sites), along with site-level information on climate, soils, crop type, and relevant experimental parameters. Total numbers of sites and total measurements in the dataset were more than doubled those for previous datasets of $\mathrm{N}_{2} \mathrm{O} E F$. The extended global $\mathrm{N}_{2} \mathrm{O}$ observation network covered most of fertilized croplands, representing a wide range of environmental conditions globally. For each site in our dataset, the variables included four broad categories: $\mathrm{N}_{2} \mathrm{O}$ emissions data, climate data (cumulative precipitation and mean daily air temperature), soil attributes (soil pH, clay content, SOC, BD), and managementrelated or experimental parameters ( $\mathrm{N}$ application rate, crop type). More details on global cropland $\mathrm{N}_{2} \mathrm{O}$ observation dataset can be found in Wang et al. ${ }^{15}$ 


\section{c. Gridded input datasets}

The updated SRNM model was driven by many input datasets, including climate, soil properties, $\mathrm{N}$ inputs (e.g., synthetic $\mathrm{N}$ fertilizer, livestock manure and crop residues applied to cropland), as well as the historical distribution of cropland. Cumulative precipitation and mean daily air temperature over the growing season were acquired from the CRU TS v3.23 climate dataset ${ }^{43}$ (0.5-degree resolution), where growing season in each grid cell was identified following Sacks et al. ${ }^{52}$ The patterns of SOC, clay content, BD, and soil $\mathrm{pH}$ were acquired from the HWSD v1.2 (ref. ${ }^{56}, 1-\mathrm{km}$ resolution). Both climate and soil properties were re-gridded at a resolution of $5^{\prime} \times$ 5' using a first-order conservative interpolation widely used in the CMIP5 model intercomparison $^{57}$. Annual cropland area at 5' spatial resolution from 1901 to 2014 was obtained from the History Database of the Global Environment (HYDE 3.2.1) ${ }^{58}$. N inputs of synthetic fertilizers were generated based on sub-national statistics (i.e., county-, municipal, provincial or state-levels) of $\mathrm{N}$-fertilizer consumption of 15,593 administrative units from 38 national statistical agencies and national statistics of the other 197 countries from FAOSTAT. N inputs of livestock manure and crop residues applied to cropland were provided by Zhang et al. ${ }^{59}$ and FAOSTAT, respectively. To compute crop-specific $\mathrm{N}$ application rates, we allocated $\mathrm{N}$ inputs for upland crops and paddy rice based on the breakdown (or proportion) of total fertilizer use by crop from $\operatorname{Rosas}^{60}$. Crop-specific $\mathrm{N}$ application rates $\left(N_{i j t}\right)$ were finally resampled into grid maps at $5^{\prime}$ spatial resolution following the dynamic cropland distributions of the HYDE 3.2.1. The assumption of a maximum combined synthetic + manure + crop residues $\mathrm{N}$ application rate was $1,000 \mathrm{~kg} \mathrm{~N} \mathrm{ha}^{-1}$, larger than the previous threshold ${ }^{61}$ that was only applied for the sum of synthetic fertilizers and manure.

\subsection{Global $\mathbf{N}$ flow in aquaculture}

We apply a nutrient budget model for shellfish and finfish ${ }^{62-64}$ to calculate the nutrient flows in aquaculture production systems. These flows comprise feed inputs, retention in the fish, and nutrient excretion. Individual species within crustaceans, seaweed, fish and molluscs are aggregated to the International Standard Statistical Classification of Aquatic Animals and Plants (ISSCAAP) groups ${ }^{65}$, for which production characteristics are specified. Feed and nutrient conversion rates are used for each ISSCAAP group to calculate the feed and nutrient intake from 
production data from $\mathrm{FAO}^{65}$. Feed types include home-made aquafeeds and commercial compound feeds with different feed conversion ratios that also vary in time due to efficiency improvement; in addition, the model accounts for algae in ponds, that are often fertilized with commercial fertilizers or animal manure, consumed by omnivore fish species like carp. A special case is the filter-feeding bivalves that filter seston from the water column, and excrete pseudofeces, feces and dissolved nutrients. Based on production data and tissue/shell nutrient contents the model computes the nutrient retention in the fish. Using apparent digestibility coefficients, the model calculates outflows in the form of feces (i.e. particulate nutrients) and dissolved nutrients. Finally, nutrient deposition in pond systems and recycling is calculated. For computing the $\mathrm{N}_{2} \mathrm{O}$ emission we consider the amount of $\mathrm{N}$ released to the environment, i.e. the difference between $\mathrm{N}$ intake and $\mathrm{N}$ in the harvested fish, which includes all the nutrient excretion. Since in pond cultures part of that $\mathrm{N}$ is managed, we made the amount of $\mathrm{N}$ recycling explicit, as well as ammonia emissions from ponds. This is to avoid double counting when computing $\mathrm{N}_{2} \mathrm{O}$ emissions from crop production.

\subsection{Model-based ocean $\mathrm{N}_{2} \mathrm{O}$ fluxes}

Oceanic $\mathrm{N}_{2} \mathrm{O}$ is produced by microbial activity during organic matter cycling in the subsurface ocean; its production mechanisms display significant sensitivity to ambient oxygen level. In the oxic ocean, $\mathrm{N}_{2} \mathrm{O}$ is produced as a byproduct during the oxidation of ammonia to nitrate, mediated by ammonia oxidizing bacteria and archaea. $\mathrm{N}_{2} \mathrm{O}$ is also produced and consumed in sub-oxic and anoxic waters through the action of marine denitrifiers during the multi-step reduction of nitrate to gaseous $\mathrm{N}$. The oceanic $\mathrm{N}_{2} \mathrm{O}$ distribution therefore displays significant heterogeneity with background levels of 10-20 nmol/1 in the well-oxygenated ocean basins, high concentrations (> $40 \mathrm{nmol} / \mathrm{l}$ ) in hypoxic waters, and $\mathrm{N}_{2} \mathrm{O}$ depletion in the core of ocean oxygen minimum zones (OMZs).

Oceanic $\mathrm{N}_{2} \mathrm{O}$ emissions are estimated to account for up to a third of the pre-industrial $\mathrm{N}_{2} \mathrm{O}$ fluxes to the atmosphere, however, the natural cycle of ocean $\mathrm{N}_{2} \mathrm{O}$ has been perturbed in recent decades by inputs of anthropogenically derived nutrient (via atmospheric deposition and riverine fluxes), and by the impacts of climate change (via impacts on biological productivity and ocean deoxygenation). 
Estimates of oceanic $\mathrm{N}_{2} \mathrm{O}$ fluxes for the Global $\mathrm{N}_{2} \mathrm{O}$ Budget synthesis are derived from an inter-comparison of five global ocean biogeochemistry models that include explicit representation of the oceanic $\mathrm{N}_{2} \mathrm{O}$ cycle (Supplementary Table 18). Ocean biogeochemistry models include process representation of ocean circulation, nutrient cycling and trace-gas generation. In particular, the $\mathrm{N}_{2} \mathrm{O}$ fluxes to the atmosphere are derived from $\mathrm{N}_{2} \mathrm{O}$ cycle parameterizations embedded in the ocean biogeochemistry models and combined with a parameterization of gas-exchange across the air-sea interface. The models participating in this inter-comparison are taken from the recent studies of Battaglia and Joos ${ }^{3}$, Berthet et al. ${ }^{4}$, Buitenhuis et al. ${ }^{5}$, Landolfi et al. ${ }^{6}$, and Martinez-Rey et al. ${ }^{7}$.

The models differ in aspects of physical configuration (e.g., spatial resolution), meteorological forcing applied at the ocean surface, and in their parameterizations of ocean biogeochemistry; specific details on individual models are provided in the publications listed in Supplementary Table 18 . Towards the $\mathrm{N}_{2} \mathrm{O}$ budget synthesis, all modelling groups reported annual mean estimates of ocean-atmosphere $\mathrm{N}_{2} \mathrm{O}$ fluxes for the period 1980-2016 (or for as many years as possible in that period). Fluxes were reported at the following spatial scales: (a) global; (b) Southern latitudes $\left(90^{\circ}-30^{\circ} \mathrm{S}\right)$; (c) Tropics $\left(30^{\circ} \mathrm{S}-30^{\circ} \mathrm{N}\right)$; and (d) Northern latitudes $\left(30^{\circ}-90^{\circ} \mathrm{N}\right)$. In addition, four modelling groups reported annually averaged ocean $\mathrm{N}_{2} \mathrm{O}$ fluxes at higher spatial resolution; i.e., gridded to a $1^{\circ} \times 1^{\circ}$ resolution.

\subsection{Net $\mathrm{N}_{2} \mathrm{O}$ emission from land cover change}

a. Deforestation area and crop/pasture expansion

Two sets of deforestation area were used to represent land cover changes during 1860-2016. The LUH2 v2h (land use harmonization, http://luh.umd.edu) land use forcing data were used to derive the deforestation area and its partition between crops and pastures from 1860-2016. LUH2 categorizes forest lands into forested primary land and potentially forested secondary land, while croplands are divided into C3 annual crops, C3 perennial crops, C4 annual crops, C4 perennial crops, and C3 N-fixing crops. In the empirical computation, all sub-classes within each land use type were treated the same. Thus only the annual transition area from forests to croplands or managed pasture was needed. 
In the process-based estimates, the model requires input of the plant functional types (PFTs) of the forests (e.g., tropical broadleaf evergreen forest and tropical broadleaf deciduous forest), and the species of croplands (e.g., wheat and rice). Thus, a potential vegetation map and the accompanied composition ratio map of each natural PFT acquired from the Synergetic Land Cover Product (SYNMAP) were jointly used with LUH2 v2h to generate the historical spatial distribution of PFTs.

b. Methods

Here we ran the DLEM model with varying climate and $\mathrm{CO}_{2}$ but hold other factors constant to estimate forest baseline emissions and unfertilized crop/pasture emissions from 1860-2016. The climate data were acquired from CRU-NCEP v7 (https://vesg.ipsl.upmc.fr), which is a fusion of the CRU and NCEP/NCAR reanalysis products at a spatial resolution of $0.5^{\circ} \times 0.5^{\circ}$ and a daily time-step. The atmospheric $\mathrm{CO}_{2}$ data were obtained from NOAA GLOBLVIEW-CO2 dataset (https://www.esrl.noaa.gov), which are derived from atmospheric and ice core measurements. In the tropical area, both estimates from the DLEM model and the bookkeeping method were adopted, whereas in extra-tropical area, we only adopted the DLEM outputs.

\section{c. Secondary tropical forest emissions}

There are not many published studies on $\mathrm{N}_{2} \mathrm{O}$ emissions from secondary tropical forests that grow back after crop or pasture abandonment. A recent meta-analysis by Sullivan et al. ${ }^{66}$ lumps together all forms of $\mathrm{N}$ "gas loss" including $\mathrm{NO}$ and $\mathrm{N}_{2} \mathrm{O}$, so it does not address $\mathrm{N}_{2} \mathrm{O}$ specifically. It also reviews the data for secondary forests across the tropics and shows that eight $\mathrm{N}$ cycling parameters, including $\mathrm{N}$ gas loss and some other parameters that overlap with those measured by Davidson et al. ${ }^{67}$ and Keller and Reiners ${ }^{68}$, recover only gradually during secondary tropical forest succession. Their meta-analysis of the $\mathrm{N}$ gas loss parameter showed a significant positive slope, indicating gradually increasing gas loss rates with age after initiation of secondary forest regrowth ${ }^{66}$. Keller and Reiners ${ }^{68}$ showed a gradual recovery of soil nitrate and soil emissions of $\mathrm{N}_{2} \mathrm{O}$ and nitric oxide (NO) during 20 years of secondary forest succession. As shown, $\mathrm{N}_{2} \mathrm{O}$ emissions did not return to the level of the primary forest after about 20 years of secondary forest succession. Davidson et al. ${ }^{67}$ found that it takes $40-70$ years of secondary forest succession for $\mathrm{N}_{2} \mathrm{O}$ emissions to approach levels of the primary forest. This is also consistent with other trends of related $\mathrm{N}$ cycling parameters, such as the nitrate:ammonium ratio, soil 
nitrate, litter mass:N, litterfall N:P, and foliar ${ }^{15} \mathrm{~N}$. In this study, through using the sites of field observation from Davidson et al. ${ }^{67}$ and Keller and Reiners ${ }^{68}$, we estimated $\mathrm{N}_{2} \mathrm{O}$ emission from secondary tropical forests based on the algorithm: $y=0.0084 x+0.2401\left(\mathrm{R}^{2}=0.44\right)$. ). $x$ (unit: year) indicates secondary forest age and $y$ (unitless; $0-1$ ) indicates the ratio of secondary forest $\mathrm{N}_{2} \mathrm{O}$ emission over that of a reference mature forest. The difference between primary forests and secondary forests were subtracted from natural soil emissions simulated by six land-surface models in NMIP.

\subsection{Inland water, estuaries, coastal zones}

a. Riverine $\mathrm{N}_{2} \mathrm{O}$ emission simulated by DLEM

Here we developed a riverine $\mathrm{N}_{2} \mathrm{O}$ module within a scale adaptive water transport model and coupled with the DLEM model ${ }^{15}$. The land surface module of DLEM-simulated $\mathrm{N}$ species $\left(\mathrm{NO}_{3}{ }^{-}, \mathrm{NH}_{4}{ }^{+}, \mathrm{DON}\right.$ and $\left.\mathrm{PON}\right)$ leaching from soils when $\mathrm{N}$ inputs were into the water transport model. The river routine module within the DLEM is a fully distributed water transport model, which explicitly calculated the flow routine cell-to-cell based on hydraulics methods. The water quality module built into the water transport module can simulate the carbon lateral transportation, biogeochemical reactions (e.g., decomposition of organic matter, nitrification, denitrification), $\mathrm{CO}_{2}$ degassing and physical deposition of particle organic matter and has been successfully applied in the Gulf of Mexico and the U.S. east coast ${ }^{69-75}$. Specifically, by introducing sub-grid routine processes technology into the model, the scale adaptive water transport module can effectively address the physical and biogeochemical processes of the small streams within a grid cell, which has been overly simplified in earth system models. We validated global $\mathrm{N}$ fluxes based on GEMS-GLORI world river discharge database. The newly developed riverine $\mathrm{N}_{2} \mathrm{O}$ module receives dissolved $\mathrm{N}_{2} \mathrm{O}$ from land and groundwater, atmosphere wet deposition, and calculate the dynamics of dissolved $\mathrm{N}_{2} \mathrm{O}$ concentration and fluxes in both small streams and large rivers. Here, we validated the annual mean riverine $\mathrm{N}_{2} \mathrm{O}$ concentration, ground water $\mathrm{N}_{2} \mathrm{O}$ concentration, and riverine $\mathrm{N}_{2} \mathrm{O}$ emissions globally based on literature survey. DLEM simulated results all agree well with the observations. 


\section{b. The DLEM estimate on $\mathrm{N}_{2} \mathrm{O}$ emission from global reservoirs}

We assumed the reservoirs were linked to rivers, and thus these aquatic systems shared the similar $\mathrm{N}_{2} \mathrm{O}$ emission rates in the large-scale studies. We therefore estimate the reservoir surfacearea form the Global Reservoirs and Dams (GRanD) database. In riverine $\mathrm{N}_{2} \mathrm{O}$ fluxes estimations, we have two $\mathrm{N}_{2} \mathrm{O}$ fluxes rates: one is the emission from the large river channel, and the other one is the emission from small rivers within the grid cell. We obtained the upstream area of each dam from the GRanD database and overlaid with the area raster of the $0.5^{\circ}$ cell. If the upstream area of a dam is less than the area of its belonging $0.5^{\circ}$ grid cell, we considered the dam was located at the small streams within the grid cell and the fluxes of that dam equal to the small river $\mathrm{N}_{2} \mathrm{O}$ fluxes of that grid. On the contrary, if the upstream area was larger than the area of the grid cell, the dam is located at the large river channel, thus the fluxes of that dam equal to the riverine $\mathrm{N}_{2} \mathrm{O}$ fluxes of the main channel in that grid cell. Align with uncertainty analysis in the riverine $\mathrm{N}_{2} \mathrm{O}$ estimations, we overlaid the surface area of dams with riverine $\mathrm{N}_{2} \mathrm{O}$ emission rate estimates from the nine-uncertainty experiments to get the reservoir $\mathrm{N}_{2} \mathrm{O}$ emissions. We calculated the average as the final reported value.

c. Mechanistic Stochastic Modeling of $\mathrm{N}_{2} \mathrm{O}$ emissions from rivers, lakes, reservoirs and estuaries In our calculations, we used a process-oriented model recently developed to estimate $\mathrm{N}_{2} \mathrm{O}$ emissions from inland waters, including rivers, reservoirs and estuaries ${ }^{10}$. To estimate $\mathrm{N}_{2} \mathrm{O}$ emissions from lakes ${ }^{9}$, we applied the same approach to a global lake dataset ${ }^{76}$. Based on a spatially explicit representation of water bodies and point and non-point sources of $\mathrm{N}$ and phosphorus (P), this model quantifies the global scale spatial patterns in inland water $\mathrm{N}_{2} \mathrm{O}$ emissions in a consistent manner at $0.5^{\circ}$ resolution. The methodology is based on the application of a stochastic Monte Carlo-based model to estimate average annual rates of primary production, ammonification, nitrification, denitrification, $\mathrm{N}$ fixation and burial of $\mathrm{N}$ in sediments as well as $\mathrm{N}_{2} \mathrm{O}$ production and emission generated by nitrification and denitrification. Because of the scarcity of observations, the Monte Carlo approach is a necessary step to generate predictive equations for the $\mathrm{N}$ budget and $\mathrm{N}_{2} \mathrm{O}$ emission of each inland water body based on inputs of total $\mathrm{N}(\mathrm{TN})$ and total P (TP) from the watershed and water residence times in a given river segment, lake, reservoir or estuary ${ }^{9,10}$. In situ $\mathrm{N}$ cycling processes for each specific water body worldwide cannot be predicted due to the lack of parameter constraints or data at this fine granularity. 
Instead, the model is fed with hypothetical but realistic combinations of physical and biogeochemical parameters through the use of probability density functions (PDFs) approximating the global statistical distribution of those parameters as derived from literature values and databases. A Monte Carlo analysis of the model is then performed, in which parameters are stochastically selected from the pre-assigned PDFs. After several thousand iterations spanning the entire parameter space of physical and biogeochemical characteristics, a database of hypothetical worldwide $\mathrm{N}$ dynamics, including $\mathrm{N}_{2} \mathrm{O}$ production and emissions, is generated for river, lake, reservoir, and estuarine systems. Then, global relationships relating $\mathrm{N}$ processes and $\mathrm{N}_{2} \mathrm{O}$ emissions to TN and TP loads and water residence time are fitted from the database and applied for the global upscaling.

To calculate the cascading loads of TN and TP delivered to each water body along the riverreservoir-estuary continuum, we spatially routed all reservoirs from the GRanD database ${ }^{77}$, with river networks from Hydrosheds $15 \mathrm{~s}^{78}$ and, at latitudes above $50^{\circ} \mathrm{N}$, Hydro1K (USGS, 2000), which were in turn connected to estuaries as represented in the "Worldwide Typology of Nearshore Coastal Systems" of Dürr et al. ${ }^{79}$. In addition, the global data base HydroLAKES ${ }^{76}$ was used to topologically connect 1.4 million lakes with a minimum surface area of $0.1 \mathrm{~km}^{2}$ within the river network. Note that besides natural lakes, HydroLAKES includes updated information on 6,796 reservoirs from the GRanD data base, which was used in the study of Maavara et al. ${ }^{10}$. In order to estimate the TN and TP loads to each water body, we then relied on a spatially explicit representation of TN and TP mobilization from the watershed into the river network (see Maavara et al. for details ${ }^{80,81}$ ).

For the estimation of $\mathrm{N}_{2} \mathrm{O}$ emission, we applied two distinct model configurations, respectively named DS1 and DS2 in Maavara et al. ${ }^{10}$. DS1 estimates $\mathrm{N}_{2} \mathrm{O}$ emissions from denitrification and nitrification based on an $\mathrm{EF}$ of $0.9 \%$, which is in the mean of published values ${ }^{82}$, and the assumption that $\mathrm{N}_{2} \mathrm{O}$ production equals $\mathrm{N}_{2} \mathrm{O}$ emissions ${ }^{10}$. For DS2, the reduction of $\mathrm{N}_{2} \mathrm{O}$ to $\mathrm{N}_{2}$ during denitrification if $\mathrm{N}_{2} \mathrm{O}$ is not evading sufficiently rapidly from the water body is taken into account. The fluxes in the model represent lumped sediment-water column rates and were resolved at the annual timescale. The use of water residence time as independent variable in both the mechanistic model and the upscaling process introduces an important kinetic refinement to existing global $\mathrm{N}_{2} \mathrm{O}$ emission estimates. Rather than applying an average $\mathrm{EF}$ (directly scaling $\mathrm{N}_{2} \mathrm{O}$ emissions to $\mathrm{N}$ inputs) to all water bodies, the use of water 
residence time explicitly adjusts for the extent of $\mathrm{N}_{2} \mathrm{O}$ production and emission that is kinetically possible within the timeframe available in a given water body. Simulated $\mathrm{N}_{2} \mathrm{O}$ emission rates were evaluated against measurement-based upscaling methods applied to reservoirs ${ }^{83}$ and rivers ${ }^{84}$ as well as against observation-driven regional estimates of lake $\mathrm{N}_{2} \mathrm{O}$ emissions based on literature data 9 .

\section{d. Coastal zone emissions}

The average of net $\mathrm{N}_{2} \mathrm{O}$ fluxes from three seagrass species ${ }^{27}$ (seagrasses, mangroves, saltmarsh and intertidal) was scaled to the global seagrass area ${ }^{28}$. The mangrove data from Murray et al. ${ }^{28}$ was updated with water-air and sediment-air $\mathrm{N}_{2} \mathrm{O}$ fluxes from Maher et al. ${ }^{85}$ and Murray et al. ${ }^{86}$. The average sediment-air $\mathrm{N}_{2} \mathrm{O}$ flux and the average water-air $\mathrm{N}_{2} \mathrm{O}$ flux were each applied for 12 hours a day (see Rosentreter et al. ${ }^{87}$ ), and scaled to the global mangrove area ${ }^{28}$. Murray et al. ${ }^{28}$ saltmarsh data was updated with sediment-air $\mathrm{N}_{2} \mathrm{O}$ fluxes from Yang et al. ${ }^{88}$, Chmura et al. ${ }^{89}$, Welti et al. ${ }^{90}$ and Roughan et al. ${ }^{91}$ and scaled to the global saltmarsh area ${ }^{28}$. Murray et al. ${ }^{28}$ intertidal data was updated with sediment-air $\mathrm{N}_{2} \mathrm{O}$ fluxes from Moseman-Valtierra et al. ${ }^{92}$ and Sun et al. ${ }^{93}$ and scaled to the global intertidal area ${ }^{94}$.

\subsection{Atmospheric inversion models}

Emissions were estimated using four independent atmospheric inversion frameworks (see Supplementary Table 19). The frameworks all used the Bayesian inversion method, which finds the optimal emissions, that is, those, which when coupled to a model of atmospheric transport, provide the best agreement to observed $\mathrm{N}_{2} \mathrm{O}$ mixing ratios while being guided by the prior estimates and their uncertainty. In other words, the optimal emissions are those that minimize the cost function:

$$
J(\mathbf{x})=\frac{1}{2}\left(\mathbf{x}-\mathbf{x}_{\mathbf{b}}\right)^{\mathrm{T}} \mathbf{B}^{-1}\left(\mathbf{x}-\mathbf{x}_{\mathbf{b}}\right)+\frac{1}{2}(\mathbf{y}-H(\mathbf{x}))^{\mathrm{T}} \mathbf{R}^{-1}(\mathbf{y}-H(\mathbf{x}))
$$

where $\mathbf{x}$ and $\mathbf{x}_{\mathbf{b}}$ are, respectively, vectors of the optimal and prior emissions, $\mathbf{B}$ is the prior error covariance matrix, $\mathbf{y}$ is a vector of observed $\mathrm{N}_{2} \mathrm{O}$ mixing ratios, $\mathbf{R}$ is the observation error covariance matrix, and $H(\mathbf{x})$ is the model of atmospheric transport (for details on the inversion 
method $\mathrm{se}^{95}$ ). The optimal emissions, $\mathbf{x}$, were found by solving the first order derivative of equation (5a):

$J^{\prime}(\mathbf{x})=\mathbf{B}^{-1}\left(\mathbf{x}-\mathbf{x}_{\mathbf{b}}\right)+\left(H^{\prime}(\mathbf{x})\right)^{\mathrm{T}} \mathbf{R}^{-1}(\mathbf{y}-H(\mathbf{x}))=0$

where $\left(H^{\prime}(\mathbf{x})\right)^{\mathrm{T}}$ is the adjoint model of transport. In frameworks INVICAT, PyVAR and GEOSChem, equation (5b) was solved using the variational approach ${ }^{96-98}$, which uses a descent algorithm and computations involving the forward and adjoint models. In framework MIROC4ACTM, equation (5b) was solved directly by computing a transport operator, $\mathbf{H}$ from integrations of the forward model, such that $\mathbf{H x}$ is equivalent to $H(\mathbf{x})$, and taking the transpose of $\mathbf{H}^{99}$.

Each of the inversion frameworks used a different model of atmospheric transport with different horizontal and vertical resolutions (see Supplementary Table 19). The transport models TOMCAT and LMDz5, used in INVICAT and PyVAR respectively, were driven by ECMWF ERA-Interim wind fields, MIROC4-ACTM, was driven by JRA-55 wind fields, and GEOSChem was driven by MERRA-2 wind fields. While INVICAT, PyVAR, and GEOSChem optimized the emissions at the spatial resolution of the transport model, MIROC4-ACTM optimized the error in the emissions aggregated into 84 land and ocean regions. All frameworks optimized the emissions with monthly temporal resolution. The transport models included an online calculation of the loss of $\mathrm{N}_{2} \mathrm{O}$ in the stratosphere due to photolysis and oxidation by $\mathrm{O}\left({ }^{1} \mathrm{D}\right)$ resulting in mean atmospheric lifetimes of between 118 and 129 years, broadly consistent with recent independent estimates of the lifetime of $116 \pm 9$ years (ref. ${ }^{100}$ ).

All inversions used $\mathrm{N}_{2} \mathrm{O}$ measurements of discrete air samples from the National Oceanic and Atmospheric Administration Carbon Cycle Cooperative Global Air Sampling Network (NOAA). In addition, discrete measurements from the Commonwealth Scientific and Industrial Research Organisation network (CSIRO) as well as in-situ measurements from the Advanced Global Atmospheric Gases Experiment network (AGAGE), the NOAA CATS network, and from individual sites operated by University of Edinburgh (UE), National Institute for Environmental Studies (NIES) and the Finnish Meteorological Institute (FMI) were included in INVICAT, PyVAR and GEOSchem. Measurements from networks other than NOAA were corrected to the NOAA calibration scale, NOAA-2006A, using the results of the WMO Round Robin inter- 
comparison experiment (https://www.esrl.noaa.gov/gmd/ccgg/wmorr/), where available. For AGAGE and CSIRO, which did not participate in the WMO Round Robins, the data at sites where NOAA discrete samples are also collected were used to calculate a linear regression with NOAA data, which was applied to adjust the data to the NOAA-2006A scale. For the remaining CSIRO sites where there were no NOAA discrete samples, the mean regression coefficient and offset from all other CSIRO sites were used. The inversions used the discrete sample measurements without averaging, and hourly or daily means of the in-situ measurements, depending on the particular inversion framework.

Each framework applied its own method for calculating the observation space uncertainty, the square of which gives the diagonal elements of the observation error covariance matrix $\mathbf{R}$. The observation space uncertainty accounts for measurement and model representation errors and is equal to the quadratic sum of these terms. Typical values for the observation space uncertainty were between 0.3 and $0.5 \mathrm{ppb}$ for all inversion frameworks.

Prior emissions were based on estimates from terrestrial biosphere and ocean biogeochemistry models as well as from inventories. INVICAT, PyVAR and GEOSChem used the same prior estimates for emissions from natural and agricultural soils from the model OCN v1.122 and for biomass burning emissions from GFEDv4.1s. For non-soil anthropogenic emissions (namely those from energy, industry and waste sectors), INVICAT and GEOSChem used EDGAR v4.2FT2010 and PyVAR used EDGAR v4.3.2. MIROC4-ACTM used the VISIT model ${ }^{24,25}$ for emissions from natural soils and EDGAR 4.2 for all anthropogenic emissions, including agricultural burning, but did not explicitly include a prior estimate for wildfire emissions.

Three different prior estimates for ocean emissions were used: 1) from the ocean biogeochemistry model, NEMO-PlankTOM5 ${ }^{101}$, with a global total of $\left.6.6 \mathrm{Tg} \mathrm{N} \mathrm{yr}^{-1}, 2\right)$ from the updated version of this model, NEMO-PlankTOM10 ${ }^{5}$ with a global total of $3.7 \mathrm{Tg} \mathrm{N}^{-1}$, and 3) from the MIT ocean general circulation model, as described by Manizza et al. ${ }^{102}$ with a global

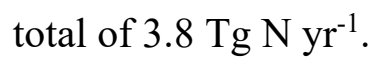

Prior uncertainties were estimated in all the inversion frameworks for each grid cell (INVICAT, PyVAR and GEOSChem) or for each region (MIROC4-ACTM) and square of the uncertainties formed the diagonal elements of the prior error covariance matrix B. INVICAT, PyVAR and GEOSChem estimated the uncertainty as proportional to the prior value in each grid 
cell, but MIROC4-ACTM set the uncertainty uniformly for the land regions at $1 \mathrm{Tg} \mathrm{N} \mathrm{yr}^{-1}$ and

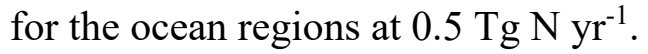

\section{Atmospheric $\mathrm{N}_{2} \mathrm{O}$ observations and growth rates for three different atmospheric networks (NOAA, AGAGE, and CISRO)}

The monthly atmospheric $\mathrm{N}_{2} \mathrm{O}$ abundances and their growth rates are derived from three different atmospheric observational networks (AGAGE, CISRO and NOAA) (Extended Data Fig. 1).

For atmospheric $\mathrm{N}_{2} \mathrm{O}$ observations from the NOAA network ${ }^{103}$, we used global mean mixing ratios from the GMD combined dataset during 1980-2017 based on measurements from five different measurement programs [HATS old flask instrument, HATS current flask instrument (OTTO), CCGG group Cooperative Global Air Sampling Network (https://www.esrl.noaa.gov/gmd/ccgg/flask.php), HATS in situ (RITS program), and HATS in situ (CATS program)]. CCGG provides uncertainties with each measurement (see site files: ftp://aftp.cmdl.noaa.gov/data/greenhouse gases/n2o/flask/surface/). Global means are derived from flask and in situ measurements obtained by gas chromatography with electron capture detection, from 4-12 sites (fewer sites in the earlier years), weighted by representative area. Monthly mean observations from different NOAA measurement programs are statistically combined to create a long-term NOAA/ESRL GMD dataset. Uncertainties (1 sigma) associated with monthly estimates of global mean $\mathrm{N}_{2} \mathrm{O}$, are $\sim 1 \mathrm{ppb}$ from 1977-1987, $0.6 \mathrm{ppb}$ from 1988-1994, 0.3-0.4 ppb from 1995-2000, and 0.1 ppb from 2001-2017. NOAA data are generally more consistent after 1995, with standard deviations on the monthly mean mixing ratios at individual sites of $\sim 0.5 \mathrm{ppb}$ from 1995-1998, and 0.1-0.4 ppb after 1998. A detailed description of these measurement programs and the method to combine them are available via https:/www.esrl.noaa.gov/gmd/hats/combined/N2O.html.

The Advanced Global Atmospheric Gases Experiment (AGAGE) global network (and its predecessors ALE and GAGE) ${ }^{104}$ has made continuous high frequency gas chromatographic measurements of $\mathrm{N}_{2} \mathrm{O}$ at five globally distributed sites since 1978. AGAGE includes two types of instruments [i.e., a gas chromatograph with multiple detectors (GC-MD) and a gas 
chromatograph with preconcentration and mass spectrometric analysis (Medusa GC-MS)]. The measurement precision for $\mathrm{N}_{2} \mathrm{O}$ improved from about $0.35 \%$ in ALE to $0.13 \%$ in $\mathrm{GAGE}^{105}$ and $0.05 \%$ in $\mathrm{AGAGE}^{104}$. We used the global mean of $\mathrm{N}_{2} \mathrm{O}$ measurements from the GC-MD during 1980-2017. Further information on AGAGE stations, instruments, calibration, uncertainties and access to data is available at the AGAGE website: http://agage.mit.edu.

The CSIRO flask network ${ }^{106}$ consists of nine sampling sites distributed globally and has been in operation since 1992. Flask samples are collected approximately every two weeks and shipped back to CSIRO GASLAB for analysis. Samples were analyzed by gas chromatography with electron capture detection (GC-ECD). One Shimadzu gas chromatograph, labelled "Shimadzu-1" (S1) was used over the entire length of the record and the measurement precision for $\mathrm{N}_{2} \mathrm{O}$ from this instrument is about $0.1 \%$. $\mathrm{N}_{2} \mathrm{O}$ data from the CSIRO global flask network are reported on the NOAA-2006A N $2 \mathrm{O}$ scale and are archived at the World Data Centre for Greenhouse Gases (WDCGG: https://gaw.kishou.go.jp/). Nine sites from the CSIRO network were used to calculate the annual global $\mathrm{N}_{2} \mathrm{O}$ mole fractions. Smooth curve fits to the $\mathrm{N}_{2} \mathrm{O}$ data from each of these sites were calculated using the technique outlined in Thoning et al. ${ }^{107}$, using a short-term cut-off of 80 days. The smooth curve fit data were then placed on an evenly spaced latitude ( 5 degree) versus time (weekly) grid using the Kriging interpolation technique. Finally, the gridded data were used to calculate the global annual average mole fractions weighted by latitude.

We plotted the atmospheric globally averaged $\mathrm{N}_{2} \mathrm{O}$ abundances and the associated growth rates for the three global atmospheric networks NOAA, AGAGE, and CSIRO during 1980-2017 (see Extended Data Fig. 1). We see remarkably consistent global mean $\mathrm{N}_{2} \mathrm{O}$ estimated from the three different networks, increasing from 301.0 $\pm 0.1 \mathrm{ppb}$ in 1980 to $329.9 \pm 0.4 \mathrm{ppb}$ in 2017. Growth rates of $\mathrm{N}_{2} \mathrm{O}$ are also remarkably consistent among the three measurement networks. After a period in the late 1990s in which the growth rate averaged about $0.8 \mathrm{ppb} \mathrm{yr}^{-1}$, the global growth rate fell to $\sim 0.6 \mathrm{ppb} \mathrm{yr}^{-1}$ and then gradually increased to nearly $1 \mathrm{ppb} \mathrm{yr}^{-1}$ by $2013-2017$. Interannual variability in the $\mathrm{N}_{2} \mathrm{O}$ growth rate was higher prior to 1995 (not shown) than after 1995, which may be an artifact of less precise measurements due to changes in instrumental precision and measurement frequency over the study period. Additional discussion on uncertainties associated with measurement errors and emission errors in inversions can be found in Chen and Prinn ${ }^{108}$ and Thompson et $\mathrm{al}^{16}$. 


\section{Comparison with the IPCC AR5}

Our methodology significantly differs from past approaches summarized in the IPCC AR5. Most of the estimates used in the AR5 (e.g., natural sources) directly inherited or adopted with minor revisions data from studies conducted mainly in the 1990s. Some estimates used in the IPCC AR5 (e.g., atmospheric deposition on land) were from a review by Syakila and Kroeze ${ }^{109}$, which depended on empirical methods and simple assumptions.

Compared to the findings reported in the IPCC AR5, our budget includes several new sources (e.g., aquaculture, deforestation/post-deforestation, the effects of environmental factors, natural sources of inland and coastal waters) and one additional (tropospheric) sink for $\mathrm{N}_{2} \mathrm{O}$ (Table 6). We report natural sources of $\mathrm{N}_{2} \mathrm{O}$ emissions from inland and coastal waters with a value of $0.3 \mathrm{Tg} \mathrm{N} \mathrm{yr}^{-1}$. The total source of $\mathrm{N}_{2} \mathrm{O}$ in our study is $0.9 \mathrm{Tg} \mathrm{N} \mathrm{yr}^{-1}$ smaller than that in the IPCC AR5, while our estimate of anthropogenic $\mathrm{N}_{2} \mathrm{O}$ emissions is $0.4 \mathrm{Tg} \mathrm{N} \mathrm{yr}^{-1}$ larger in the recent decade (Supplementary Table 15). Our larger estimate of anthropogenic emissions is associated with environmental effects ( 0.2 , with a range of -0.6 to $1.1 \mathrm{Tg} \mathrm{N} \mathrm{yr}^{-1}$, based on NMIP simulations), and a $0.4 \mathrm{Tg} \mathrm{N} \mathrm{yr}^{-1}$ larger estimate of atmospheric $\mathrm{N}$ deposition emissions (based on modeling results and inventories, Table 1). In contrast, our estimate of direct emissions from agriculture [(3.8 (2.5-5.8) $\mathrm{Tg} \mathrm{N} \mathrm{yr}^{-1}$, plus aquaculture, a minor contribution] is $0.3 \mathrm{Tg} \mathrm{N} \mathrm{yr}^{-1}$ smaller than reported in the IPCC AR5.

Natural sources in our study are $1.3 \mathrm{Tg} \mathrm{N} \mathrm{yr}^{-1}$ smaller than those reported by the IPCC AR5 for 2007-2016 and the range is significantly reduced. The mean NMIP estimate of global natural soil emission [5.6 (4.9-6.6) $\mathrm{Tg} \mathrm{N} \mathrm{yr}^{-1}$ ] is $1.0 \mathrm{Tg} \mathrm{N} \mathrm{yr}^{-1}$ smaller compared to those in the IPCC AR5 estimate [6.6 (3.3-9.0) $\mathrm{Tg} \mathrm{N} \mathrm{yr}^{-1}$ ]. The reduction in uncertainty in NMIP estimates may result from calibration of terrestrial biosphere models in NMIP against in situ observations across the globe ${ }^{1}$, while the AR5 estimate, essentially inherited from the AR4 synthesis, was based on results from a single simple model by Bouwman et al. ${ }^{110}$. 
In this study, global oceanic $\mathrm{N}_{2} \mathrm{O}$ emission is derived from an ensemble of global ocean biogeochemistry models. Our estimate [3.4 (2.5-4.3) $\left.\mathrm{Tg} \mathrm{N} \mathrm{yr}^{-1}\right]$ is $0.4 \mathrm{Tg} \mathrm{N} \mathrm{yr}^{-1}$ smaller and the uncertainty range is significantly smaller than reported in the IPCC AR5 $\left(1.8-9.4 \mathrm{Tg} \mathrm{N} \mathrm{yr}^{-1}\right)$. The larger AR5 range was determined using an analysis of Atlantic Ocean surface measurements (Rhee et al. ${ }^{111}$; the Atlantic is not a region of significant $\mathrm{N}_{2} \mathrm{O}$ emission) as the lower bound, and the upper bound was the maximal value of $\mathrm{N}_{2} \mathrm{O}$ production from a global empirically based analysis ${ }^{112}$. The parameterizations governing marine productivity and $\mathrm{N}_{2} \mathrm{O}$ yield in our five ocean models have been constrained by a variety of datasets characterizing marine biogeochemical process rates, and the model simulations of ocean $\mathrm{N}_{2} \mathrm{O}$ have been evaluated against global biogeochemical databases (e.g., see Battaglia and Joos ${ }^{3}$ and Buitenhuis et al. ${ }^{5}$ for more detail). The smaller range of ocean $\mathrm{N}_{2} \mathrm{O}$ emission reported in this study includes advances in modeling such factors as quantification of global marine export production, improved constraints on $\mathrm{N}_{2} \mathrm{O}$ yield parameters (particularly in the well-oxygenated ocean), and more comprehensive evaluation of modeled biogeochemical distributions.

The estimated $\mathrm{N}_{2} \mathrm{O}$ production through atmospheric chemistry is $0.2 \mathrm{Tg} \mathrm{N} \mathrm{yr}^{-1}$ smaller than reported in the IPCC AR5. The observed stratospheric sink of $\mathrm{N}_{2} \mathrm{O}$ in this study is $0.9 \mathrm{Tg} \mathrm{N} \mathrm{yr}^{-1}$ smaller than in the IPCC AR5, wherein stratospheric $\mathrm{N}_{2} \mathrm{O}$ destruction was tuned to be consistent with the difference between the total source and the observed atmospheric $\mathrm{N}_{2} \mathrm{O}$ growth rate. In our study, stratospheric sinks were obtained from atmospheric chemistry transport models and the recent post-AR5 study by Prather et al. ${ }^{16,100,113}$ who calculated $\mathrm{N}_{2} \mathrm{O}$ stratospheric loss (\& lifetime) based on satellite observations combined with simple photolysis models using observed atmospheric temperature, $\mathrm{O}_{2}$, and $\mathrm{O}_{3}$. Our uncertainties in the atmospheric loss of $\mathrm{N}_{2} \mathrm{O}( \pm 1.1 \mathrm{Tg}$ $\left.\mathrm{N} \mathrm{yr}^{-1}\right)$ are slightly larger than those of the AR5 $\left( \pm 0.9 \mathrm{Tg} \mathrm{N} \mathrm{yr}^{-1}\right)$. In our study, annual change in atmospheric abundance is calculated from the combined NOAA and AGAGE record of surface $\mathrm{N}_{2} \mathrm{O}$ and uncertainty $\left( \pm 0.5 \mathrm{Tg} \mathrm{N} \mathrm{yr}^{-1}\right)$ is taken from the IPCC AR5 (ref. ${ }^{114}$ ).

\section{Per capita $\mathrm{N}_{2} \mathrm{O}$ emission at global and regional scales in the recent decade}

Per capita $\mathrm{N}_{2} \mathrm{O}$ emission is calculated using global and regional emissions divided by the numbers of global and regional population ${ }^{115}$ (see Supplementary Fig. 2). Global per capita emissions from top-down and bottom-up approaches were on average $\sim 2 \mathrm{~kg} \mathrm{~N}$ capita $^{-1} \mathrm{yr}^{-1}$ in the 
recent decade. Bottom-up estimates show that per capita natural fluxes including natural soils and inland and coastal waters were the largest source, followed by agriculture and other direct anthropogenic sources. South America and Oceania have $\sim 2$ times and $\sim 6$ times higher per capita emissions than the global average, respectively. Africa and Russia also have higher per capita $\mathrm{N}_{2} \mathrm{O}$ emissions than the global value contributed primarily by natural fluxes and to a minor extent by other direct anthropogenic sources (Africa: Biomass burning; Russia: Fossil fuel and industry and Biomass burning). In addition, North America and Europe show higher than global per capita emissions from agriculture and other direct anthropogenic sources (primary from Fossil fuel and industry). Middle East, East Asia, South Asia, and Southeast Asia show lower than global per capita emissions from all sources. 


\section{References:}

1 Tian, H. Q. et al. Global soil nitrous oxide emissions since the preindustrial era estimated by an ensemble of terrestrial biosphere models: Magnitude, attribution, and uncertainty. Global Change Biology 25, 640-659 (2019).

2 Dangal, S. R. et al. Global nitrous oxide emissions from pasturelands and rangelands: Magnitude, spatio-temporal patterns and attribution. Global Biogeochemical Cycles 33, 200-222 (2019).

3 Battaglia, G. \& Joos, F. Marine $\mathrm{N}_{2} \mathrm{O}$ Emissions From Nitrification and Denitrification Constrained by Modern Observations and Projected in Multimillennial Global Warming Simulations. Global Biogeochemical Cycles 32, 92-121 (2018).

4 Berthet, S. et al. Evaluation of an Online Grid-Coarsening Algorithm in a Global Eddy-Admitting Ocean Biogeochemical Model. Journal of Advances in Modeling Earth Systems 11, 1759-1783 (2019).

5 Buitenhuis, E. T., Suntharalingam, P. \& Le Quéré, C. Constraints on global oceanic emissions of $\mathrm{N}_{2} \mathrm{O}$ from observations and models. Biogeosciences 15, 2161-2175 (2018).

6 Landolfi, A., Somes, C. J., Koeve, W., Zamora, L. M. \& Oschlies, A. Oceanic nitrogen cycling and $\mathrm{N}_{2} \mathrm{O}$ flux perturbations in the Anthropocene. Global Biogeochemical Cycles 31, 1236-1255 (2017).

7 Martinez-Rey, J., Bopp, L., Gehlen, M., Tagliabue, A. \& Gruber, N. Projections of oceanic $\mathrm{N}_{2} \mathrm{O}$ emissions in the 21st century using the IPSL Earth system model. Biogeosciences 12, 4133-4148 (2015).

8 Suntharalingam, P. et al. Estimates of Oceanic Nitrous-oxide Emissions from Global Biogeochemistry Models. American Geophysical Union, Fall Meeting 2018 (2018).

9 Lauerwald, R. et al. Natural lakes are a minor global source of $\mathrm{N}_{2} \mathrm{O}$ to the atmosphere. Global Biogeochemical Cycles 33, 1564-1581 (2019).

10 Maavara, T. et al. Nitrous oxide emissions from inland waters: Are IPCC estimates too high? Global Change Biology 25, 473-488 (2019).

11 Janssens-Maenhout, G. et al. EDGAR v4.3.2 Global Atlas of the three major greenhouse gas emissions for the period 1970-2012. Earth System Science Data 11, 959-1002 (2019).

12 Tubiello, F. et al. Estimating greenhouse gas emissions in agriculture: a manual to address data requirements for developing countries. FAO, Rome (2015).

13 Winiwarter, W., Höglund-Isaksson, L., Klimont, Z., Schöpp, W. \& Amann, M. Technical opportunities to reduce global anthropogenic emissions of nitrous oxide. Environmental research letters 13, 014011 (2018).

14 Van Der Werf, G. R. et al. Global fire emissions estimates during 1997-2016. Earth System Science Data 9, 697-720 (2017).

15 Wang, Q. et al. Data-driven estimates of global nitrous oxide emissions from croplands. National Science Review 00, 1-12 (2019).

16 Thompson, R. L. et al. Acceleration of global $\mathrm{N}_{2} \mathrm{O}$ emissions seen from two decades of atmospheric inversion. Natural Climate Change 9, 993-998 (2019).

17 Tian, H. Q. et al. The Global $\mathrm{N}_{2} \mathrm{O}$ Model Intercomparison Project. Bulletin of the American Meteorological Society 99, 1231-1252 (2018).

18 Tian, H. et al. Global methane and nitrous oxide emissions from terrestrial ecosystems due to multiple environmental changes. Ecosystem Health and Sustainability 1, 1-20 (2015).

$19 \mathrm{Xu}$, R. et al. Preindustrial nitrous oxide emissions from the land biosphere estimated by using a global biogeochemistry model. Climate of the Past 13, 977 (2017).

20 Stocker, B. D. et al. Multiple greenhouse-gas feedbacks from the land biosphere under future climate change scenarios. Nature Climate Change 3, 666, doi:10.1038/nclimate1864 (2013).

21 XU-RI \& PRENTICE, I. C. Terrestrial nitrogen cycle simulation with a dynamic global vegetation model. Global Change Biology 14, 1745-1764 (2008). 

nitrogen offset by nitrous oxide emissions. Nature Geoscience 4, 601-605 (2011).

23 Goll, D. S. et al. A representation of the phosphorus cycle for ORCHIDEE (revision 4520). Geosci. Model Dev. 10, 3745-3770 (2017).

24 Inatomi, M., Ito, A., Ishijima, K. \& Murayama, S. Greenhouse Gas Budget of a Cool-Temperate Deciduous Broad-Leaved Forest in Japan Estimated Using a Process-Based Model. Ecosystems 13, 472-483 (2010).

25 Ito, A., Nishina, K., Ishijima, K., Hashimoto, S. \& Inatomi, M. Emissions of nitrous oxide $\left(\mathrm{N}_{2} \mathrm{O}\right)$ from soil surfaces and their historical changes in East Asia: a model-based assessment. Progress in Earth and Planetary Science 5, 55, doi:10.1186/s40645-018-0215-4 (2018).

26 Yao, Y. et al. Increased global nitrous oxide emissions from streams and rivers in the Anthropocene. Natural Climate Change 10, 138-142 (2020).

27 Camillini, N., Rossentreter, J., Erler, D., Glud, R. N. \& Eyre, B. Blue carbon burial in seagrass meadows is partially offset by $\mathrm{CH}_{4}$ and $\mathrm{N}_{2} \mathrm{O}$ fluxes. Science Advance (Submitted).

28 Murray, R. H., Erler, D. V. \& Eyre, B. D. Nitrous oxide fluxes in estuarine environments: response to global change. Global Change Biology 21, 3219-3245 (2015).

29 Beusen, A. H., Bouwman, A. F., Van Beek, L. P., Mogollón, J. M. \& Middelburg, J. J. Global riverine $\mathrm{N}$ and $\mathrm{P}$ transport to ocean increased during the 20th century despite increased retention along the aquatic continuum. Biogeosciences 13, 2441-2451 (2016).

30 Bouwman, A. F. et al. Hindcasts and future projections of global inland and coastal nitrogen and phosphorus loads due to finfish aquaculture. Reviews in Fisheries Science 21, 112-156 (2013).

31 Bouwman, A. F. et al. Global hindcasts and future projections of coastal nitrogen and phosphorus loads due to shellfish and seaweed aquaculture. Reviews in Fisheries Science 19, 331-357 (2011).

32 Tubiello, F. N. et al. The FAOSTAT database of greenhouse gas emissions from agriculture. 8, 015009 (2013).

33 Davidson, E. A., Erickson, H. E., Verchot, L. V., Keller, M. \& Veldkamp, E. Testing a Conceptual Model of Soil Emissions of Nitrous and Nitric Oxides: Using two functions based on soil nitrogen availability and soil water content, the hole-in-the-pipe model characterizes a large fraction of the observed variation of nitric oxide and nitrous oxide emissions from soils.

BioScience 50, 667-680 (2000).

34 IPCC. 2006 IPCC Guidelines for National Greenhouse Gas Inventories., (Japan on behalf of the IPCC, Hayama, Japan, 2006).

35 Zhou, J., Jiang, M. \& Chen, G. Estimation of methane and nitrous oxide emission from livestock and poultry in China during 1949-2003. Energy Policy 35, 3759-3767 (2007).

36 Van Drecht, G., Bouwman, A. F., Knoop, J. M., Beusen, A. H. W. \& Meinardi, C. R. Global modeling of the fate of nitrogen from point and nonpoint sources in soils, groundwater, and surface water. Global Biogeochemical Cycles 17, 1115, doi:10.1029/2003gb002060 (2003).

37 Amann, M. et al. Cost-effective control of air quality and greenhouse gases in Europe: Modeling and policy applications. Environmental Modelling \& Software 26, 1489-1501 (2011).

38 Zhang, X. et al. Managing nitrogen for sustainable development. Nature 528, 51, doi:doi:10.1038/nature15743 (2015).

39 Gao, S. et al. Quantifying nitrogen leaching response to fertilizer additions in China's cropland. Environmental pollution 211, 241-251 (2016).

40 Hou, X. et al. Detection and attribution of nitrogen runoff trend in China's croplands. Environmental pollution 234, 270-278 (2018).

41 Zhou, F. et al. New model for capturing the variations of fertilizer-induced emission factors of N2O. Global Biogeochemical Cycles 29, 885-897 (2015).

42 Decock, C. Mitigating nitrous oxide emissions from corn cropping systems in the midwestern US: potential and data gaps. Environmental science \& technology 48, 4247-4256 (2014). 

climatic observations-the CRU TS3. 10 Dataset. International journal of climatology 34, 623642 (2014).

44 Helgason, B. et al. Toward improved coefficients for predicting direct $\mathrm{N}_{2} \mathrm{O}$ emissions from soil in Canadian agroecosystems. Nutrient Cycling in Agroecosystems 72, 87-99 (2005).

45 Hénault, C. et al. Predicting in situ soil $\mathrm{N}_{2} \mathrm{O}$ emission using NOE algorithm and soil database. Global Change Biology 11, 115-127 (2005).

46 Hickman, J. E., Scholes, R. J., Rosenstock, T. S., Garcia-Pando, C. P. \& Nyamangara, J. Assessing non- $\mathrm{CO}_{2}$ climate-forcing emissions and mitigation in sub-Saharan Africa. Current Opinion in Environmental Sustainability 9, 65-72 (2014).

47 Kim, D.-G., Giltrap, D. \& Hernandez-Ramirez, G. Background nitrous oxide emissions in agricultural and natural lands: a meta-analysis. Plant and soil 373, 17-30 (2013).

48 Kim, D.-G., Hernandez-Ramirez, G. \& Giltrap, D. Linear and nonlinear dependency of direct nitrous oxide emissions on fertilizer nitrogen input: A meta-analysis. Agriculture, Ecosystems \& Environment 168, 53-65 (2013).

49 Lehuger, S. et al. Predicting and mitigating the net greenhouse gas emissions of crop rotations in Western Europe. Agricultural and forest meteorology 151, 1654-1671 (2011).

50 Leppelt, T. et al. Nitrous oxide emission budgets and land-use-driven hotspots for organic soils in Europe. Biogeosciences (2014).

51 Rochette, P. \& Janzen, H. H. Towards a revised coefficient for estimating $\mathrm{N}_{2} \mathrm{O}$ emissions from legumes. Nutrient Cycling in Agroecosystems 73, 171-179 (2005).

52 Sacks, W. J., Deryng, D., Foley, J. A. \& Ramankutty, N. Crop planting dates: an analysis of global patterns. Global Ecol Biogeogr 19, 607-620 (2010).

53 Shcherbak, I., Millar, N. \& Robertson, G. P. Global metaanalysis of the nonlinear response of soil nitrous oxide $\left(\mathrm{N}_{2} \mathrm{O}\right)$ emissions to fertilizer nitrogen. Proceedings of the National Academy of Sciences 111, 9199-9204 (2014).

54 Stehfest, E. \& Bouwman, L. $\mathrm{N}_{2} \mathrm{O}$ and $\mathrm{NO}$ emission from agricultural fields and soils under natural vegetation: summarizing available measurement data and modeling of global annual emissions. Nutrient Cycling in Agroecosystems 74, 207-228 (2006).

55 Walter, K. et al. Direct nitrous oxide emissions from oilseed rape cropping-a meta-analysis. $G C B$ Bioenergy 7, 1260-1271 (2015).

56 Berdanier, A. B. \& Conant, R. T. Regionally differentiated estimates of cropland $\mathrm{N}_{2} \mathrm{O}$ emissions reduce uncertainty in global calculations. Global change biology 18, 928-935 (2012).

57 Yang, H. et al. Regional patterns of future runoff changes from Earth system models constrained by observation. Geophysical Research Letters 44, 5540-5549 (2017).

58 Goldewijk, K. K., Beusen, A., Doelman, J. \& Stehfest, E. Anthropogenic land use estimates for the Holocene-HYDE 3.2. Earth System Science Data 9, 927-953 (2017).

59 Zhang, B. et al. Global manure nitrogen production and application in cropland during 18602014: a 5 arcmin gridded global dataset for Earth system modeling. Earth System Science Data 9, 667-678 (2017).

60 Rosas, F. Fertilizer use by crop at the country level (1990-2010). CARD Working Papers 555 (2012).

61 Carlson, K. M. et al. Greenhouse gas emissions intensity of global croplands. Nature Climate Change 7, 63 (2017).

62 Bouwman, L. et al. Mariculture: significant and expanding cause of coastal nutrient enrichment. Environmental Research Letters 8, 044026, doi:044010.041088/041748049326/044028/044024/044026 (2013).

63 Bouwman, A. F. et al. Hindcasts and future projections of global inland and coastal nitrogen and phosphorus loads due to finfish aquaculture. Reviews in Fisheries Science 21, 112-156 (2013).

64 Bouwman, A. F. et al. Global hindcasts and future projections of coastal nitrogen and phosphorus loads due to shellfish and seaweed aquaculture. Reviews in Fisheries Science 19, 331-357 (2011). 
FAO. FishStatJ - Software for Fishery and Aquaculture Statistical Time Series. http://www.fao.org/fishery/statistics/software/fishstatj/en. (Fisheries and Aquaculture Information and Statistics Service, Food and Agriculture Organization of the United Nations, retrieved 22 May 2019, Rome, 2019).

66 Sullivan, B. W. et al. Biogeochemical recuperation of lowland tropical forest during succession. Ecology 100, e02641, doi:10.1002/ecy.2641 (2019).

67 Davidson, E. A. et al. Recuperation of nitrogen cycling in Amazonian forests following agricultural abandonment. Nature 447, 995 (2007).

68 Keller, M. \& Reiners, W. A. Soil-atmosphere exchange of nitrous oxide, nitric oxide, and methane under secondary succession of pasture to forest in the Atlantic lowlands of Costa Rica. Global Biogeochemical Cycles 8, 399-409 (1994).

69 Liu, M. et al. Long-term trends in evapotranspiration and runoff over the drainage basins of the Gulf of Mexico during 1901-2008. Water Resources Research 49, 1988-2012 (2013).

70 Ren, W. et al. Century-long increasing trend and variability of dissolved organic carbon export from the Mississippi River basin driven by natural and anthropogenic forcing. Global Biogeochemical Cycles 30, 1288-1299 (2016).

71 Ren, W. et al. Large increase in dissolved inorganic carbon flux from the Mississippi River to Gulf of Mexico due to climatic and anthropogenic changes over the 21st century. Journal of Geophysical Research: Biogeosciences 120, 724-736 (2015).

72 Tao, B. et al. Increasing Mississippi river discharge throughout the 21st century influenced by changes in climate, land use, and atmospheric $\mathrm{CO}_{2}$. Geophysical Research Letters 41, 4978-4986 (2014).

73 Tian, H. et al. Climate extremes dominating seasonal and interannual variations in carbon export from the Mississippi River Basin. Global Biogeochemical Cycles 29, 1333-1347 (2015).

74 Tian, H. et al. Anthropogenic and climatic influences on carbon fluxes from eastern North America to the Atlantic Ocean: A process-based modeling study. Journal of Geophysical Research: Biogeosciences 120, 757-772 (2015).

75 Yang, Q. et al. Increased nitrogen export from eastern North America to the Atlantic Ocean due to climatic and anthropogenic changes during 1901-2008. Journal of Geophysical Research: Biogeosciences 120, 1046-1068 (2015).

76 Messager, M. L., Lehner, B., Grill, G., Nedeva, I. \& Schmitt, O. Estimating the volume and age of water stored in global lakes using a geo-statistical approach. Nature Communications 7, 13603 (2016).

77 Lehner, B. et al. High-resolution mapping of the world's reservoirs and dams for sustainable river-flow management. Frontiers in Ecology and the Environment 9, 494-502 (2011).

78 Lehner, B., Verdin, K. \& Jarvis, A. New global hydrography derived from spaceborne elevation data. Eos, Transactions, American Geophysical Union 89, 93-94 (2008).

79 Dürr, H. H. et al. Worldwide Typology of Nearshore Coastal Systems: Defining the Estuarine Filter of River Inputs to the Oceans. Estuaries and Coasts 34, 441-458 (2011).

80 Bouwman, A., Beusen, A. H. \& Billen, G. J. G. B. C. Human alteration of the global nitrogen and phosphorus soil balances for the period 1970-2050. Global Biogeochemical Cycles 23, GB0A04, doi:10.1029/2009GB003576 (2009).

81 Van Drecht, G., Bouwman, A., Harrison, J. \& Knoop, J. Global nitrogen and phosphate in urban wastewater for the period 1970 to 2050. Global Biogeochemical Cycles 23, GB0A03 (2009).

82 Beaulieu, J. J. et al. Nitrous oxide emission from denitrification in stream and river networks. Proceedings of the National Academy of Sciences 108, 214-219 (2011).

83 Deemer, B. R. et al. Greenhouse gas emissions from reservoir water surfaces: a new global synthesis. 66, 949-964 (2016).

84 Hu, M., Chen, D. \& Dahlgren, R. A. Modeling nitrous oxide $\left(\mathrm{N}_{2} \mathrm{O}\right)$ emission from rivers: A global assessment. Global Change Biology 22, 3566-3582 (2016). 

waters are a sink of nitrous oxide. Scientific reports 6, 25701 (2016).

86 Murray, R., Erler, D., Rosentreter, J., Maher, D. \& Eyre, B. A seasonal source and sink of nitrous oxide in mangroves: Insights from concentration, isotope, and isotopomer measurements. Geochimica et Cosmochimica Acta 238, 169-192 (2018).

87 Rosentreter, J. A., Maher, D. T., Erler, D. V., Murray, R. H. \& Eyre, B. D. Methane emissions partially offset "blue carbon" burial in mangroves. Science advances 4, eaao4985 (2018).

88 Yang, W. H. \& Silver, W. L. Gross nitrous oxide production drives net nitrous oxide fluxes across a salt marsh landscape. Global Change Biology 22, 2228-2237 (2016).

89 Chmura, G. L., Kellman, L., Van Ardenne, L. \& Guntenspergen, G. R. Greenhouse gas fluxes from salt marshes exposed to chronic nutrient enrichment. PloS one 11, e0149937 (2016).

90 Welti, N., Hayes, M. \& Lockington, D. Seasonal nitrous oxide and methane emissions across a subtropical estuarine salinity gradient. Biogeochemistry 132, 55-69 (2017).

91 Roughan, B. L., Kellman, L., Smith, E. \& Chmura, G. L. Nitrous oxide emissions could reduce the blue carbon value of marshes on eutrophic estuaries. Environmental Research Letters 13, 044034 (2018).

92 Moseman-Valtierra, S. et al. Substantial nitrous oxide emissions from intertidal sediments and groundwater in anthropogenically-impacted West Falmouth Harbor, Massachusetts. Chemosphere 119, 1281-1288 (2015).

93 Sun, W., Sun, Z., Mou, X., Sun, W. \& Hu, X. Nitrous oxide emissions from intertidal zone of the Yellow River estuary in autumn and winter during 2011-2012. Estuaries and coasts 40, 145-159 (2017).

94 Murray, N. J. et al. The global distribution and trajectory of tidal flats. Nature 565, 222 (2019).

95 Tarantola, A. Inverse problem theory and methods for model parameter estimation. Vol. 89 (Society for Industrial and Applied Mathematics 2005).

96 Thompson, R. L. et al. Nitrous oxide emissions 1999 to 2009 from a global atmospheric inversion. Atmospheric Chemistry and Physics 14, 1801-1817 (2014).

97 Wells, K. C. et al. Simulation of atmospheric $\mathrm{N}_{2} \mathrm{O}$ with GEOS-Chem and its adjoint: evaluation of observational constraints. Geoscience Model Development 8, 3179-3198 (2015).

98 Wilson, C., Chipperfield, M., Gloor, M. \& Chevallier, F. Development of a variational flux inversion system (INVICAT v1.0) using the TOMCAT chemical transport model. Geoscientific Model Development 7, 2485-2500 (2014).

99 Patra, P. K. et al. Improved Chemical Tracer Simulation by MIROC4. 0-based Atmospheric Chemistry-Transport Model (MIROC4-ACTM). Sola 14, 91-96 (2018).

100 Prather, M. J. et al. Measuring and modeling the lifetime of nitrous oxide including its variability. Journal of Geophysical Research: Atmospheres 120, 5693-5705 (2015).

101 Suntharalingam, P. et al. Quantifying the impact of anthropogenic nitrogen deposition on oceanic nitrous oxide. Geophysical Research Letters 39, L07605, doi:10.1029/2011GL050778 (2012).

102 Manizza, M., Keeling, R. F. \& Nevison, C. D. On the processes controlling the seasonal cycles of the air-sea fluxes of $\mathrm{O}_{2}$ and $\mathrm{N}_{2} \mathrm{O}$ : A modelling study. Tellus $B$ : Chemical and Physical Meteorology 64, 18429, doi:10.3402/tellusb.v64i0.18429 (2012).

103 Hall, B., Dutton, G. \& Elkins, J. The NOAA nitrous oxide standard scale for atmospheric observations. Journal of Geophysical Research: Atmospheres 112, D09305, doi:10.1029/2006JD007954 (2007).

104 Prinn, R. G. et al. History of chemically and radiatively important atmospheric gases from the Advanced Global Atmospheric Gases Experiment (AGAGE). Earth System Science Data 10, 985-1018 (2018).

105 Prinn, R. et al. Atmospheric emissions and trends of nitrous oxide deduced from 10 years of ALE-GAGE data. Journal of Geophysical Research: Atmospheres 95, 18369-18385 (1990).

106 Francey, R. J. et al. The CSIRO (Australia) measurement of greenhouse gases in the global atmosphere. 97-111 (World Meteorological Organization, Tokyo, Japan, 2003). 
107 Thoning, K. W., Tans, P. P. \& Komhyr, W. D. Atmospheric carbon dioxide at Mauna Loa Observatory: 2. Analysis of the NOAA GMCC data, 1974-1985. Journal of Geophysical Research: Atmospheres 94, 8549-8565 (1989).

108 Chen, Y. H. \& Prinn, R. G. Estimation of atmospheric methane emissions between 1996 and 2001 using a three-dimensional global chemical transport model. Journal of Geophysical Research: Atmospheres 111, 307, doi:10.1029/2005JD006058 (2006).

109 Syakila, A. \& Kroeze, C. The global nitrous oxide budget revisited. Greenhouse Gas Measurement and Management 1, 17-26 (2011).

110 Bouwman, A., Fung, I., Matthews, E. \& John, J. Global analysis of the potential for $\mathrm{N}_{2} \mathrm{O}$ production in natural soils. Global Biogeochemical Cycles 7, 557-597 (1993).

111 Rhee, T. S., Kettle, A. J. \& Andreae, M. O. Methane and nitrous oxide emissions from the ocean: A reassessment using basin-wide observations in the Atlantic. Journal of Geophysical Research: Atmospheres 114, doi:10.1029/2008jd011662 (2009).

112 Bianchi, D., Dunne, J. P., Sarmiento, J. L. \& Galbraith, E. D. Data-based estimates of suboxia, denitrification, and $\mathrm{N}_{2} \mathrm{O}$ production in the ocean and their sensitivities to dissolved $\mathrm{O}_{2}$. Global Biogeochemical Cycles 26, doi:10.1029/2011gb004209 (2012).

113 Prather, M. J. \& Hsu, J. Coupling of Nitrous Oxide and Methane by Global Atmospheric Chemistry. Science 330, 952-954 (2010).

114 Ciais, P. et al. in Climate Change 2013: The Physical Science Basis. Contribution of Working Group I to the Fifth Assessment Report of the Intergovernmental Panel on Climate Change 465-570 (Cambridge University Press, 2014).

115 FAOSTAT. Food and Agriculture Organization of the United Nations Statistics-Population, 2020).

116 Hu, Z., Lee, J. W., Chandran, K., Kim, S. \& Khanal, S. K. Nitrous oxide $\left(\mathrm{N}_{2} \mathrm{O}\right)$ emission from aquaculture: a review. Environmental science technology 46, 6470-6480 (2012).

117 MacLeod, M., Hasan, M. R., Robb, D. H. F. \& Mamun-Ur-Rashid, M. Quantifying and mitigating greenhouse gas emissions from global aquaculture. FAO, Rome, (2019). 
Supplementary Table $1 \mathrm{~N}_{2} \mathrm{O}$ emissions from global agricultural soils based on multiple bottom-up approaches including the additions of mineral $\mathrm{N}$ fertilizer, manure and crop residues, and cultivation of organic soils. Unit: $\mathrm{Tg}$ $\mathrm{N} \mathrm{yr}{ }^{-1}$

\begin{tabular}{llcccc}
\hline & Data sources & $1980 \mathrm{~s}$ & $1990 \mathrm{~s}$ & $2000 \mathrm{~s}$ & $2007-2016$ \\
\hline \multirow{2}{*}{$\begin{array}{l}\text { Process-based } \\
\text { models }\end{array}$} & NMIP/DLEM Mean & 1.7 & 2.1 & 2.4 & 2.8 \\
Statistical model & NMIP/DLEM Min & 0.9 & 1.1 & 1.3 & 1.4 \\
plus DLEM & NMIP/DLEM Max & 2.6 & 3.1 & 3.4 & 3.8 \\
\cline { 2 - 6 } & \multirow{2}{*}{ SRNM/DLEM } & 1.3 & 1.6 & 1.9 & 2.1 \\
\cline { 2 - 6 } Inventories & EDGAR v4.3.2 & 1.3 & 1.5 & 1.7 & 1.9 \\
& GAINS & 1.5 & 1.6 & 1.7 & 1.9 \\
\hline Mean & FAOSTAT & 1.2 & 1.5 & 1.7 & 1.9 \\
Min & & 1.5 & 1.8 & 2.0 & 2.3 \\
Max & & 0.9 & 1.1 & 1.3 & 1.4 \\
\hline
\end{tabular}

Supplementary Table $2 \mathrm{~N}_{2} \mathrm{O}$ emissions from global total area under permanent meadows and pasture, due to manure $\mathrm{N}$ deposition (left on pasture) based on EDGAR v4.3.2, FAOSTAT, and GAINS estimates. Unit: $\mathrm{Tg} \mathrm{N} \mathrm{yr}^{-1}$

\begin{tabular}{lcccc}
\hline Data sources & $1980 \mathrm{~s}$ & $1990 \mathrm{~s}$ & $2000 \mathrm{~s}$ & $2007-2016$ \\
\hline EDGAR v4.3.2 & 1.0 & 1.1 & 1.2 & 1.3 \\
GAINS & 0.7 & 0.7 & 0.8 & 0.9 \\
FAOSTAT & 1.0 & 1.1 & 1.2 & 1.3 \\
\hline Mean & 0.9 & 1.0 & 1.1 & 1.2 \\
Min & 0.7 & 0.7 & 0.8 & 0.9 \\
Max & 1.0 & 1.1 & 1.2 & 1.3 \\
\hline
\end{tabular}


Supplementary Table $3 \mathrm{~N}_{2} \mathrm{O}$ emissions due to global manure management based on multiple bottom-up approaches. Unit: ${\mathrm{Tg} \mathrm{N} \mathrm{yr}^{-1}}^{-1}$

\begin{tabular}{lcccc}
\hline Data sources & $1980 \mathrm{~s}$ & $1990 \mathrm{~s}$ & $2000 \mathrm{~s}$ & $2007-2016$ \\
\hline EDGAR v4.3.2 & 0.2 & 0.2 & 0.2 & 0.2 \\
GAINS & 0.4 & 0.4 & 0.5 & 0.5 \\
FAOSTAT & 0.2 & 0.2 & 0.2 & 0.2 \\
\hline Mean & 0.3 & 0.3 & 0.3 & 0.3 \\
Min & 0.2 & 0.2 & 0.2 & 0.2 \\
Max & 0.4 & 0.4 & 0.5 & 0.5 \\
\hline
\end{tabular}

Supplementary Table 4 Aquaculture $\mathrm{N}_{2} \mathrm{O}$ emissions based on multiple sources. Unit: $\mathrm{Tg} \mathrm{N} \mathrm{yr}^{-1}$

\begin{tabular}{lccccc}
\hline Data sources & $\begin{array}{c}\text { Emission } \\
\text { factor (\%) }\end{array}$ & $1980 \mathrm{~s}$ & $1990 \mathrm{~s}$ & $2000 \mathrm{~s}$ & $\begin{array}{c}2007- \\
2016^{*}\end{array}$ \\
\hline Hu et al. ${ }^{\mathbf{1 1 6}}$ & 1.8 & N/A & N/A & N/A & 0.1 \\
MacLeod et al.117 & 1.8 & N/A & N/A & N/A & 0.1 \\
Bouwman et al. & 1.8 & 0.01 & 0.03 & 0.1 & 0.1 \\
Bouwman et al._Min & 0.5 & 0.00 & 0.01 & 0.02 & 0.02 \\
Bouwman et al._Max & 5.0 & 0.03 & 0.1 & 0.2 & 0.2 \\
\hline
\end{tabular}

* Estimates in Hu et al. ${ }^{116}$ and Macleod et al. ${ }^{117}$ were in 2009 and 2013, respectively. N/A represents data are not available. 
Supplementary Table 5 Anthropogenic $\mathrm{N}_{2} \mathrm{O}$ emissions from the global inland waters based on process-based models. Unit: ${\mathrm{Tg} \mathrm{N} \mathrm{yr}^{-1}}^{-1}$

\begin{tabular}{lcccc}
\hline Data sources/sectors & $1980 \mathrm{~s}$ & $1990 \mathrm{~s}$ & $2000 \mathrm{~s}$ & $2007-2016$ \\
\hline River_DLEM & 0.2 & 0.2 & 0.2 & 0.2 \\
River_Maavara & 0.03 & 0.03 & 0.03 & 0.03 \\
\cline { 2 - 5 } River_Mean & 0.1 & 0.1 & 0.1 & 0.1 \\
\hline Resevoirs_DLEM & 0.05 & 0.05 & 0.05 & 0.05 \\
Resevoirs_Maavara & 0.03 & 0.03 & 0.03 & 0.03 \\
\cline { 2 - 5 } Resevoirs_Mean & 0.04 & 0.04 & 0.04 & 0.04 \\
\hline Estuaries_Maavara & 0.1 & 0.1 & 0.1 & 0.1 \\
Lake_Lauerwald & 0.02 & 0.02 & 0.02 & 0.02 \\
Blue carbon_Murray & 0.1 & 0.1 & 0.1 & 0.1 \\
\hline Total_Mean & 0.3 & 0.3 & 0.3 & 0.3 \\
Total_Min & 0.2 & 0.2 & 0.2 & 0.2 \\
Total_Max & 0.4 & 0.4 & 0.4 & 0.4 \\
\hline
\end{tabular}

Supplementary Table 6 Anthropogenic $\mathrm{N}_{2} \mathrm{O}$ emissions from the global inland waters based on multiple bottom-up approaches. Unit: $\mathrm{Tg} \mathrm{N} \mathrm{yr}^{-1}$

\begin{tabular}{lcccc}
\hline Data sources & $1980 \mathrm{~s}$ & $1990 \mathrm{~s}$ & $2000 \mathrm{~s}$ & $2007-2016$ \\
\hline FAOSTAT & 0.4 & 0.4 & 0.5 & 0.6 \\
GAINS & 0.4 & 0.4 & 0.5 & 0.6 \\
EDGAR v4.3.2 & 0.5 & 0.5 & 0.6 & 0.7 \\
Model-based & 0.3 & 0.3 & 0.3 & 0.3 \\
\hline Mean & 0.4 & 0.4 & 0.4 & 0.5 \\
Min & 0.2 & 0.2 & 0.2 & 0.2 \\
Max & 0.5 & 0.5 & 0.6 & 0.7 \\
\hline
\end{tabular}


Supplementary Table 7 Natural $\mathrm{N}_{2} \mathrm{O}$ emissions from the global inland waters based on process-based models. Unit: $\mathrm{Tg} \mathrm{N}_{\mathrm{yr}}{ }^{-1}$

\begin{tabular}{lcccc}
\hline Data sources/sectors & $1980 \mathrm{~s}$ & $1990 \mathrm{~s}$ & $2000 \mathrm{~s}$ & $2007-2016$ \\
\hline River_DLEM & 0.1 & 0.1 & 0.1 & 0.1 \\
River_Maavara & 0.02 & 0.02 & 0.02 & 0.02 \\
\cline { 2 - 5 } River_Mean & 0.04 & 0.04 & 0.04 & 0.04 \\
\hline Resevoirs_DLEM & 0.04 & 0.04 & 0.04 & 0.04 \\
Resevoirs_Maavara & 0.03 & 0.03 & 0.03 & 0.03 \\
\cline { 2 - 5 } Resevoirs_Mean & 0.03 & 0.03 & 0.03 & 0.03 \\
\hline Estuaries_Maavara & 0.05 & 0.05 & 0.05 & 0.05 \\
Lake_Lauerwald & 0.02 & 0.02 & 0.02 & 0.02 \\
Blue carbon_Murray & 0.2 & 0.2 & 0.2 & 0.2 \\
\hline Total_Mean & 0.3 & 0.3 & 0.3 & 0.3 \\
Total_Min & 0.3 & 0.3 & 0.3 & 0.3 \\
Total_Max & 0.4 & 0.4 & 0.4 & 0.4 \\
\hline
\end{tabular}

Supplementary Table 8 Nitrous oxide emissions due to atmospheric $\mathbf{N}$ deposition on land based on multiple bottom-up approaches. Unit: $\mathrm{Tg} \mathrm{N} \mathrm{yr}^{-1}$

\begin{tabular}{lcccc}
\hline Data sources & $1980 \mathrm{~s}$ & $1990 \mathrm{~s}$ & $2000 \mathrm{~s}$ & $2007-2016$ \\
\hline EDGAR v4.3.2 & 0.3 & 0.3 & 0.3 & 0.4 \\
FAOSTAT & 0.3 & 0.3 & 0.3 & 0.4 \\
GAINS & 0.3 & 0.3 & 0.3 & 0.4 \\
\cline { 2 - 5 } FAOSTAT/EDGAR v4.3.2 & 0.6 & 0.6 & 0.7 & 0.8 \\
GAINS/EDGAR v4.3.2 & 0.6 & 0.6 & 0.7 & 0.7 \\
\hline NMIP_Mean & 0.6 & 0.7 & 0.8 & 0.8 \\
NMIP_Min & 0.3 & 0.4 & 0.4 & 0.4 \\
NMIP_Max & 1.2 & 1.4 & 1.3 & 1.4 \\
\hline Mean & 0.6 & 0.7 & 0.7 & 0.8 \\
Min & 0.3 & 0.4 & 0.4 & 0.4 \\
Max & 1.2 & 1.4 & 1.3 & 1.4 \\
\hline
\end{tabular}


Supplementary Table 9 Global $\mathrm{N}_{2} \mathrm{O}$ emissions from waste and waste water based on EDGAR v4.3.2 and GAINS estimates. Unit: ${\mathrm{Tg} \mathrm{N} \mathrm{yr}^{-1}}^{-1}$

\begin{tabular}{lcccc}
\hline Data sources & $1980 \mathrm{~s}$ & $1990 \mathrm{~s}$ & $2000 \mathrm{~s}$ & $2007-2016$ \\
\hline EDGAR v4.3.2 & 0.1 & 0.2 & 0.2 & 0.2 \\
GAINS & 0.3 & 0.4 & 0.4 & 0.5 \\
\hline Mean & 0.2 & 0.3 & 0.3 & 0.3 \\
Min & 0.1 & 0.2 & 0.2 & 0.2 \\
Max & 0.3 & 0.4 & 0.4 & 0.5 \\
\hline
\end{tabular}

Supplementary Table 10 Global $\mathrm{N}_{2} \mathrm{O}$ emissions from fossil fuel and industry based on multiple bottom-up approaches. Unit: ${\mathrm{Tg} \mathrm{N} \mathrm{yr}^{-1}}^{-1}$

\begin{tabular}{|c|c|c|c|c|c|}
\hline $\begin{array}{l}\text { Data } \\
\text { sources }\end{array}$ & Sectors & $1980 \mathrm{~s}$ & $1990 \mathrm{~s}$ & $2000 \mathrm{~s}$ & $2007-2016$ \\
\hline \multirow{4}{*}{$\begin{array}{l}\text { EDGAR } \\
\mathrm{v} 4.3 .2\end{array}$} & Energy & 0.1 & 0.1 & 0.1 & 0.2 \\
\hline & Transportation & 0.2 & 0.2 & 0.2 & 0.2 \\
\hline & Others_residential & 0.1 & 0.2 & 0.2 & 0.2 \\
\hline & Industry & 0.7 & 0.5 & 0.5 & 0.5 \\
\hline \multirow{5}{*}{ GAINS } & Energy & 0.3 & 0.4 & 0.5 & 0.5 \\
\hline & Industry & 0.5 & 0.5 & 0.4 & 0.3 \\
\hline & Mean & 0.9 & 0.9 & 0.9 & 1.0 \\
\hline & Min & 0.8 & 0.9 & 0.8 & 0.8 \\
\hline & Max & 1.1 & 1.0 & 1.0 & 1.1 \\
\hline
\end{tabular}


Supplementary Table 11 Global $\mathrm{N}_{2} \mathrm{O}$ emissions from biomass burning based on multiple bottom-up approaches. Unit: $\mathrm{Tg} \mathrm{N} \mathrm{yr}^{-1}$

\begin{tabular}{llcccc}
\hline Fire categories & Data sources & $1980 \mathrm{~s}$ & $1990 \mathrm{~s}$ & $2000 \mathrm{~s}$ & $2007-2016$ \\
\hline \multirow{3}{*}{$\begin{array}{l}\text { Crop residues and } \\
\text { savannas }\end{array}$} & GFED4s & & 0.4 & 0.4 & 0.4 \\
& FAOSTAT & & 0.4 & 0.4 & 0.3 \\
& DLEM & 0.3 & 0.3 & 0.3 & 0.4 \\
\cline { 2 - 6 } Tropical forests and & Mean & 0.3 & 0.4 & 0.4 & 0.4 \\
Deforestation* & GFED4s & & 0.1 & 0.1 & 0.1 \\
& FAOSTAT & & 0.1 & 0.1 & 0.1 \\
\cline { 2 - 6 } & DLEM & 0.2 & 0.2 & 0.2 & 0.2 \\
\hline \multirow{3}{*}{ Peatland } & GFED4s & 0.2 & 0.1 & 0.1 & 0.1 \\
& FAOSTAT & & 0.04 & 0.01 & 0.01 \\
& DLEM & 0.04 & 0.1 & 0.1 & 0.1 \\
\cline { 2 - 6 } Boreal and & Mean & 0.04 & 0.06 & 0.02 & 0.02 \\
temperate forests & GFED4s & & 0.1 & 0.04 & 0.04 \\
& FAOSTAT & & 0.1 & 0.1 & 0.1 \\
\hline Total_Mean & DLEM & 0.1 & 0.1 & 0.1 & 0.1 \\
Total_Min & Mean & 0.1 & 0.1 & 0.1 & 0.1 \\
Total_Max & & 0.7 & 0.7 & 0.6 & 0.6 \\
\hline
\end{tabular}

* DLEM estimates represent burning of tropical forests that are caused by natural and deforestation fires.

Supplementary Table 12 Global oceanic $\mathbf{N}_{2} \mathrm{O}$ emissions based on multiple models. Unit: $\mathrm{Tg} \mathrm{N} \mathrm{yr}^{-1}$

\begin{tabular}{lcccc}
\hline Model & $1980 \mathrm{~s}$ & $1990 \mathrm{~s}$ & $2000 \mathrm{~s}$ & $2007-2016$ \\
\hline Bern-3D & 4.4 & 4.4 & 4.3 & 4.3 \\
NEMOv3.6-PISCESv2-gas & 3.3 & 3.2 & 3.3 & 3.4 \\
NEMO-PlankTOM10 & 3.0 & 2.8 & 2.7 & 2.5 \\
UVic2.9 & 3.3 & 3.2 & 3.2 & 3.1 \\
NEMO-PISCES 3.2 & 4.0 & 3.9 & 3.9 & 3.8 \\
\hline Mean & 3.6 & 3.5 & 3.5 & 3.4 \\
Min & 3.0 & 2.8 & 2.7 & 2.5 \\
Max & 4.4 & 4.4 & 4.3 & 4.3 \\
\hline
\end{tabular}


Supplementary Table 13 Global $\mathbf{N}_{2} \mathrm{O}$ emissions based on multiple top-down approaches. Unit: $\mathrm{Tg} \mathrm{N}_{\mathrm{Nr}}{ }^{-1}$

\begin{tabular}{|c|c|c|c|}
\hline Name & Category & $2000 \mathrm{~s}$ & $2007-2016$ \\
\hline \multirow{3}{*}{ INVICAT } & Land & 9.7 & 10.6 \\
\hline & Ocean & 7.2 & 7.1 \\
\hline & Total & 16.9 & 17.7 \\
\hline \multirow{3}{*}{ PyVAR-1 } & Land & 9.4 & 10.6 \\
\hline & Ocean & 6.4 & 6.4 \\
\hline & Total & 15.8 & 17.0 \\
\hline \multirow{3}{*}{ PyVAR-2 } & Land & 11.8 & 12.7 \\
\hline & Ocean & 4.0 & 4.3 \\
\hline & Total & 15.8 & 17.0 \\
\hline \multirow{3}{*}{$\begin{array}{l}\text { MIROC4- } \\
\text { ACTM }\end{array}$} & Land & 12.5 & 13.8 \\
\hline & Ocean & 3.1 & 3.4 \\
\hline & Total & 15.7 & 17.1 \\
\hline \multirow{3}{*}{ GEOSChem } & Land & 10.6 & 11.3 \\
\hline & Ocean & 4.5 & 4.6 \\
\hline & Total & 15.1 & 15.9 \\
\hline \multirow{3}{*}{ Mean } & Land & 10.8 & 11.8 \\
\hline & Ocean & 5.1 & 5.1 \\
\hline & Total & 15.9 & 16.9 \\
\hline \multirow{3}{*}{ Min } & Land & 9.4 & 10.6 \\
\hline & Ocean & 3.1 & 3.4 \\
\hline & Total & 15.1 & 15.9 \\
\hline \multirow{3}{*}{ Max } & Land & 12.5 & 13.8 \\
\hline & Ocean & 7.2 & 7.1 \\
\hline & Total & 16.9 & 17.7 \\
\hline
\end{tabular}


Supplementary Table 14 Comparison of terminologies used in this study and previous reports.

\begin{tabular}{|c|c|c|c|c|}
\hline \multicolumn{2}{|c|}{ GCP Terminology (in this study) } & IPCC AR5 (IPCC, 2013) & $\begin{array}{l}\text { National GHG inventories (used by UNFCCC } \\
\text { according to IPCC, } 2006 \text { and IPCC, 2019) }\end{array}$ & $\begin{array}{l}\text { UNFCCC / } \\
\text { IPCC } 2006 \\
\text { Source sector }\end{array}$ \\
\hline \multicolumn{5}{|c|}{ Anthropogenic sources } \\
\hline \multirow{4}{*}{$\begin{array}{l}\text { Direct emissions } \\
\text { of } \mathrm{N} \text { additions in } \\
\text { the agricultural } \\
\text { sector } \\
\text { (Agriculture) }\end{array}$} & $\begin{array}{l}\text { Direct soil emissions (mineral } \mathrm{N} \text { and manure } \\
\text { fertilization, cultivation of organic soils, and } \\
\text { crop residue returns) }\end{array}$ & \multirow{3}{*}{ Agriculture } & $\begin{array}{l}\text { Direct } \mathrm{N}_{2} \mathrm{O} \text { emissions from managed soils (except } \\
\text { due to grazing animals) }\end{array}$ & $\begin{array}{l}\text { 3Da without } \\
3 \mathrm{Da} 3\end{array}$ \\
\hline & Manure left on pasture & & Urine and dung deposited by grazing animals & $3 \mathrm{Da} 3$ \\
\hline & Manure management & & Manure management & $3 \mathrm{~B}$ \\
\hline & Aquaculture & -- & --- & --- \\
\hline \multirow{3}{*}{$\begin{array}{l}\text { Other direct } \\
\text { anthropogenic } \\
\text { sources }\end{array}$} & Fossil fuel and industry & $\begin{array}{l}\text { Fossil fuel combustion } \\
\text { and industrial processes }\end{array}$ & Energy and industrial processes & 1,2 \\
\hline & Waste and waste water & Human excreta & Waste & 5 \\
\hline & $\begin{array}{l}\text { Biomass burning (from crop residue, } \\
\text { grassland, shrubland and savannas; peat fires, } \\
\text { tropical forests, boreal forests, and temperate } \\
\text { forests) }\end{array}$ & $\begin{array}{l}\text { Biomass and biofuel } \\
\text { burning }\end{array}$ & $\begin{array}{l}\text { Prescribed burning of savannas, field burning of } \\
\text { agricultural residues }\end{array}$ & $3 \mathrm{E}, 3 \mathrm{~F}$ \\
\hline \multirow{3}{*}{$\begin{array}{l}\text { Indirect emissions } \\
\text { from } \\
\text { anthropogenic N } \\
\text { additions }\end{array}$} & $\begin{array}{l}\text { Inland and coastal waters (rivers, lakes, } \\
\text { reservoirs, estuaries, and coastal zones) }\end{array}$ & $\begin{array}{l}\text { Rivers, estuaries, coastal } \\
\text { zones }\end{array}$ & Indirect emissions due to leaching and runoff & $3 \mathrm{Db} 2$ \\
\hline & Atmospheric N deposition on land & $\begin{array}{l}\text { Atmospheric deposition } \\
\text { on land }\end{array}$ & \multirow{2}{*}{$\begin{array}{l}\text { Indirect emissions due to atmospheric deposition } \\
\text { (of agricultural as well as other anthropogenic } \\
\text { compounds emitted) }\end{array}$} & part of $3 \mathrm{Db} 1$ \\
\hline & Atmospheric $\mathrm{N}$ deposition on ocean & $\begin{array}{l}\text { Atmospheric deposition } \\
\text { on ocean }\end{array}$ & & part of $3 \mathrm{Db} 1$ \\
\hline \multirow{4}{*}{$\begin{array}{l}\text { Perturbed fluxes } \\
\text { from } \\
\text { climate } / \mathrm{CO}_{2} / \text { land } \\
\text { cover change }\end{array}$} & $\mathrm{CO}_{2}$ effect & --- & --- & --- \\
\hline & Climate effect & --- & --- & --- \\
\hline & Post-deforestation pulse effect & --- & -- & --- \\
\hline & Long-term effect of reduced mature forest area & --- & -- & --- \\
\hline \multicolumn{5}{|c|}{ Natural sources and sinks } \\
\hline \multicolumn{2}{|c|}{ Natural soils baseline } & $\begin{array}{l}\text { Soils under natural } \\
\text { vegetation }\end{array}$ & --- & --- \\
\hline \multicolumn{2}{|l|}{ Ocean baseline } & Oceans & -- & --- \\
\hline \multicolumn{2}{|c|}{ Natural (rivers, lakes, reservoirs, estuaries, and coastal upwelling) } & --- & --- & --- \\
\hline \multirow{2}{*}{\multicolumn{2}{|c|}{ Lightning and atmospheric production }} & Lightning & --- & -- \\
\hline & & Atmospheric chemistry & -- & --- \\
\hline \multicolumn{2}{|c|}{ Soil/wetland surface sink } & Surface sink & --- & --- \\
\hline
\end{tabular}


Supplementary Table 15 Comparison of the global $\mathrm{N}_{2} \mathrm{O}$ budget in this study with the IPCC AR5.

\begin{tabular}{|c|c|c|}
\hline & $\begin{array}{l}\text { This study } \\
\text { (2007-2016) }\end{array}$ & $\begin{array}{l}\text { IPCC AR5 } \\
(2006 / 2011)\end{array}$ \\
\hline \multicolumn{3}{|l|}{ Bottom-up budget } \\
\hline \multicolumn{3}{|l|}{ Anthropogenic Sources } \\
\hline Fossil fuel combustion and industry & $1.0(0.8-1.1)$ & $0.7(0.2-1.8)$ \\
\hline Agriculture (incl. Aquaculture) & $3.8(2.5-5.8)$ & $4.1(1.7-4.8)$ \\
\hline Biomass and biofuel burning & $0.6(0.5-0.8)$ & $0.7(0.2-1.0)$ \\
\hline Wastewater & $0.3(0.2-0.5)$ & $0.2(0.1-0.3)$ \\
\hline Rivers, estuaries, and coastal zones & $0.5(0.2-0.7)$ & $0.6(0.1-2.9)$ \\
\hline Atmospheric $\mathrm{N}$ deposition on ocean & $0.1(0.1-0.2)$ & $0.2(0.1-0.4)$ \\
\hline Atmospheric $\mathrm{N}$ deposition on land & $0.8(0.4-1.4)$ & $0.4(0.3-0.9)$ \\
\hline Other indirect effects from $\mathrm{CO}_{2}$, climate and land-use change & $0.2(-0.6-1.1)$ & \\
\hline Total Anthropogenic & $7.3(4.2-11.4)$ & $6.9(2.7-12.1)$ \\
\hline \multicolumn{3}{|l|}{ Natural Sources and Sinks } \\
\hline Rivers, estuaries, and coastal zones & $0.3(0.3-0.4)$ & \\
\hline Oceans & $3.4(2.5-4.3)$ & $3.8(1.8-9.4)$ \\
\hline Soils under natural vegetation & $5.6(4.9-6.5)$ & $6.6(3.3-9.0)$ \\
\hline Atmospheric chemistry & $0.4(0.2-1.2)$ & $0.6(0.3-1.2)$ \\
\hline Surface sink & $-0.01(0--0.3)$ & $-0.01(0--1)$ \\
\hline Total natural & $9.7(8.0-12.0)$ & $11.0(5.4-18.6)$ \\
\hline Total bottom-up source & $17.0(12.2-23.5)$ & $17.9(8.1-30.7)$ \\
\hline Observed growth rate & $4.3(3.8-4.8)$ & $3.6(3.5-3.8)$ \\
\hline Tropospheric sink & $0.1(0.1-0.2)$ & \\
\hline Stratospheric sink* & $13.4(12.3-14.4)$ & $14.3(4.3-28.7)$ \\
\hline \multicolumn{3}{|l|}{ Atmospheric inversion } \\
\hline Atmospheric loss & $12.4(11.7-13.3)$ & $11.9(11.0-12.8)$ \\
\hline Total source & $16.9(15.9-17.7)$ & $15.8(14.8-16.8)$ \\
\hline
\end{tabular}

Note: * Calculated from satellite observations combined with simple photolysis models in our study. 
Supplementary Table 16 Simulation experiments in the NMIP (Tian et al. ${ }^{1,17}$ )

\begin{tabular}{lllllll}
\hline & CLIM & CO $_{2}$ & LCC & NDEP & NFER & MANN \\
\hline SE0 & $1901-1920 *$ & 1860 & 1860 & 1860 & 1860 & 1860 \\
SE1 & $1901-2016$ & $1860-2016$ & $1860-2016$ & $1860-2016$ & $1860-2016$ & $1860-2016$ \\
SE2 & $1901-2016$ & $1860-2016$ & $1860-2016$ & $1860-2016$ & $1860-2016$ & 1860 \\
SE3 & $1901-2016$ & $1860-2016$ & $1860-2016$ & $1860-2016$ & 1860 & 1860 \\
SE4 & $1901-2016$ & $1860-2016$ & $1860-2016$ & 1860 & 1860 & 1860 \\
SE5 & $1901-2016$ & $1860-2016$ & 1860 & 1860 & 1860 & 1860 \\
SE6 & $1901-2016$ & 1860 & 1860 & 1860 & 1860 & 1860 \\
\hline
\end{tabular}

Note: CLIM: climate condition; $\mathrm{CO}_{2}$ : atmospheric $\mathrm{CO}_{2}$ concentration; $L C C$ : land cover change; NDEP: atmospheric N deposition; NFER: mineral $N$ fertilizer use; and MANN: manure N use in cropland. SE0: baseline and control run with repeated climate forcing from 1901-1920; SE1: CLIM+CO $+L C L U+N D E P+N F E R+M A N N$; SE2:

$C L I M+C_{2}+L C L U+N D E P+N F E R ; S E 3: C L I M+C_{2}+L C L U+N D E P ; S E 4: C L I M+C_{2}+L C L U ; S E 5: C L I M+C O_{2}$; SE6: CLIM. "1901-1920*” denotes that variable is constant at the level of 20-year average; "1860" denotes that variable is constant at the level of 1860; and "1860-2016" denotes that variable changes with time over the study period.

\section{Supplementary Table 17 Information of NMIP models using in this study}

\begin{tabular}{|c|c|c|c|}
\hline Model & Contact & Affiliation & Publication \\
\hline DLEM & Hanqin Tian & Auburn University & Tian et al. ${ }^{18}, \mathrm{Xu}$ et al. ${ }^{19}$ \\
\hline LPX-Bern & $\begin{array}{l}\text { Sebastian Lienert/ } \\
\text { Fortunat Joos }\end{array}$ & University of Bern, Switzerland & $\begin{array}{l}\text { Stocker et al. }{ }^{20}, \text { Xu-Ri \& } \\
\text { Prentice }\end{array}$ \\
\hline $\mathrm{O}-\mathrm{CN}$ & Sönke Zaehle & $\begin{array}{l}\text { Max Planck Institute for } \\
\text { Biogeochemistry }\end{array}$ & Zaehle et al. ${ }^{22}$ \\
\hline ORCHIDEE & Nicolas Vuichard & IPSL - LSCE, France & \\
\hline $\begin{array}{l}\text { ORCHIDEE- } \\
\text { CNP }\end{array}$ & $\begin{array}{l}\text { Jinfeng Chang/ } \\
\text { Daniel Goll }\end{array}$ & IPSL - LSCE, France & Goll et al. ${ }^{23}$ \\
\hline VISIT & Akihiko Ito & $\begin{array}{l}\text { National Institute for Environmental } \\
\text { Studies, Japan }\end{array}$ & $\begin{array}{l}\text { Inatomi et al. }{ }^{24} \text {, Ito et } \\
\text { al. }^{25}\end{array}$ \\
\hline
\end{tabular}


Supplementary Table 18 Summary of models in ocean $\mathrm{N}_{2} \mathrm{O}$ inter-comparison

\begin{tabular}{llll}
\hline Group & Model & $\begin{array}{l}\text { Native resolution } \\
(\text { Lon } \times \text { Lat } \times \text { Depth })\end{array}$ & Publication \\
\hline U. Bern & Bern-3D & $9^{\circ} \times 4.5^{\circ} \times 32$ levels & Battaglia and Joos $^{3}$ \\
CNRM & $\begin{array}{l}\text { NEMOv3.6- } \\
\text { PISCESv2-gas }\end{array}$ & $1^{\circ} \times 1^{\circ} \times 75$ levels & Berthet et al. $^{4}$ \\
UEA & NEMO-PlankTOM10 & $2^{\circ} \times\left(0.5^{\circ}-2^{\circ}\right) \times 30$ levels & Buitenhuis et al. $^{5}$ \\
GEOMAR & UVic2.9 & $3.6^{\circ} \times 1.8^{\circ} \times 19$ levels & Landolfi et al. $^{6}$ \\
IPSL & NEMO-PISCES 3.2 & $2^{\circ} \times\left(0.5^{\circ}-2^{\circ}\right) \times 30$ levels & Martinez-Rey et al. $^{7}$ \\
\hline
\end{tabular}

Supplementary Table 19 Overview of the inversion frameworks that are included in the global $\mathrm{N}_{2} \mathrm{O}$ budget.

\begin{tabular}{|c|c|c|c|c|c|c|}
\hline Name & ACTM & Method & $\begin{array}{l}\text { Resolution } \\
\text { of state } \\
\text { vector }\end{array}$ & $\begin{array}{l}\text { ACTM } \\
\text { horizontal } \\
\text { resolution }\end{array}$ & $\begin{array}{l}\text { ACTM } \\
\text { vertical } \\
\text { levels }\end{array}$ & Ocean prior \\
\hline INVICAT & TOMCAT & 4D-Var & $\begin{array}{l}5.625^{\circ} \times 5.62 \\
5^{\circ}\end{array}$ & $\begin{array}{c}5.625^{\circ} \times 5.62 \\
5^{\circ}\end{array}$ & 60 & 1 (high) \\
\hline PyVAR-1 & LMDz5 & \multirow{2}{*}{ 4D-Var } & \multirow{2}{*}{$3.75^{\circ} \times 1.875$} & \multirow{2}{*}{$\begin{array}{c}3.75^{\circ} \times 1.875 \\
\circ\end{array}$} & \multirow{2}{*}{39} & 1 (high) \\
\hline PyVAR-2 & LMDz5 & & & & & 2 (low) \\
\hline $\begin{array}{l}\text { MIROC4- } \\
\text { ACTM }\end{array}$ & $\begin{array}{l}\text { MIROC4- } \\
\text { ACTM }\end{array}$ & $\begin{array}{l}\text { Bayesian } \\
\text { analytical }\end{array}$ & 84 regions & $2.8^{\circ} \times 2.8^{\circ}$ & 67 & 3 (low) \\
\hline GEOSChem & GEOSChem & 4D-Var & $5^{\circ} \times 4^{\circ}$ & $5^{\circ} \times 4^{\circ}$ & 47 & 2 (low) \\
\hline
\end{tabular}




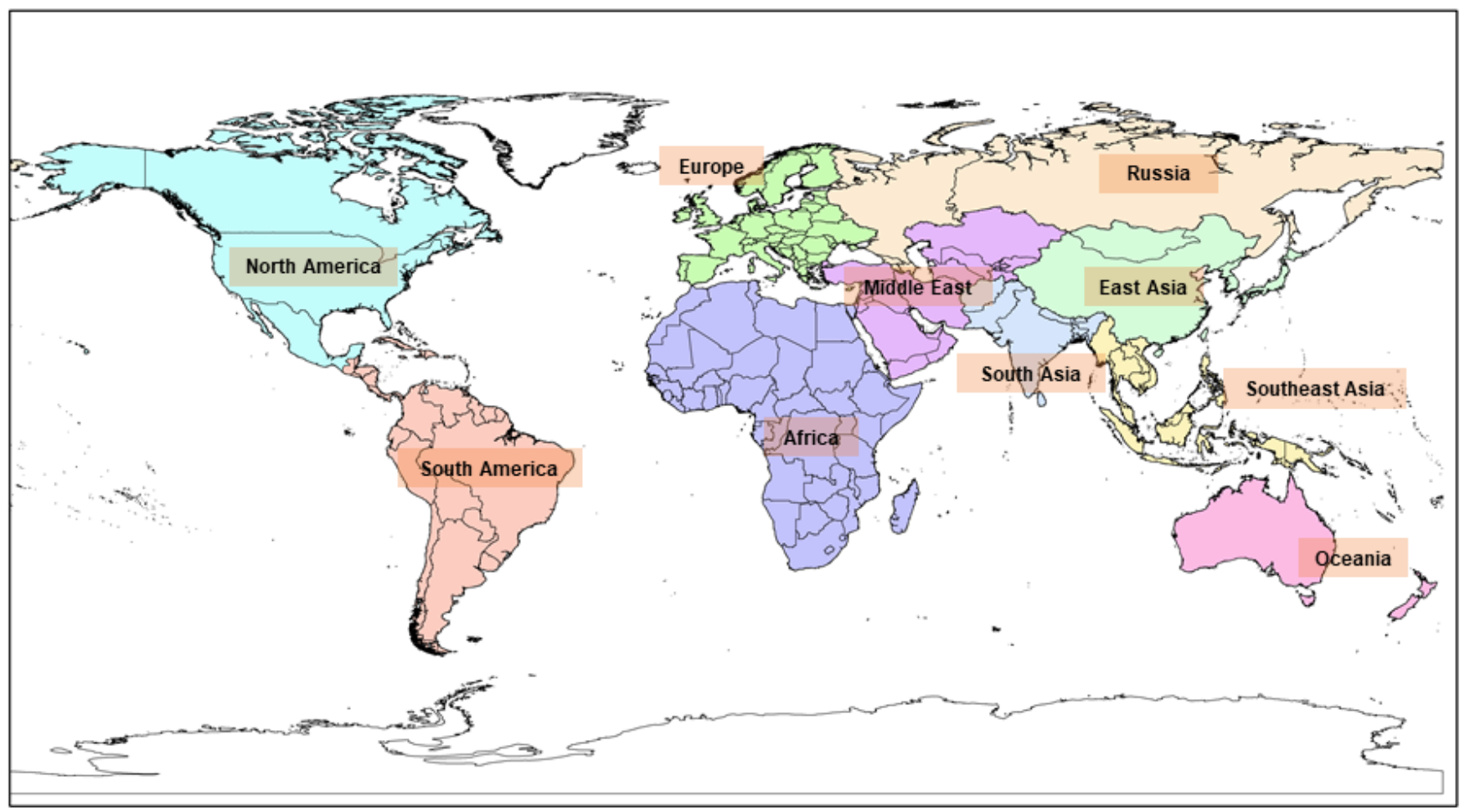

Supplementary Fig. 1 Spatial distribution of ten study regions across the globe. 

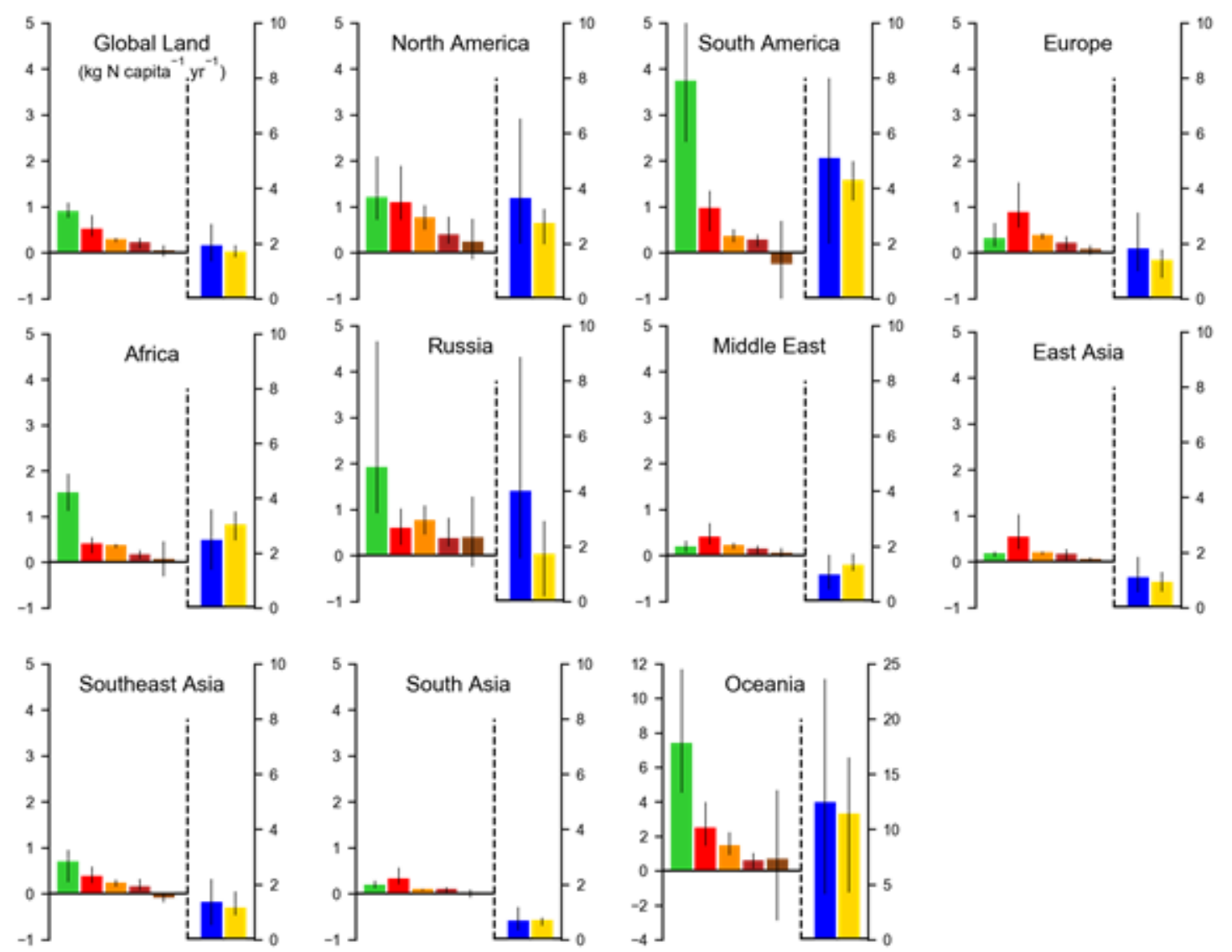

Natural fluxes without ocean

Agriculture

Other direct anthropogenic sources
Indirect emissions from anthropogenic $\mathrm{N}$ additions
Perturbed fluxes from climate/ $\mathrm{CO}_{2}$ /land cover change

Supplementary Fig. 2 Per capita $\mathrm{N}_{2} \mathrm{O}$ emission $\left(\mathrm{kg} \mathrm{N}_{\text {capita }} \mathrm{yr}^{-1}\right)$ during 2007-2016. Annual population was obtained from FAOSTAT ${ }^{115}$ (http://www.fao.org/faostat/en/\#data/OA). 